UNIVERSIDADE DE SÃO PAULO

ESCOLA DE ENFERMAGEM DE RIBEIRÃO PRETO

ÚLCERA POR PRESSÃO E FATORES DE RISCO EM PACIENTES HOSPITALIZADOS

COM FRATURA DE QUADRIL E FÊMUR

ANDRÉA MATHES FAUSTINO

RIBEIRÃO PRETO 


\title{
ÚLCERA POR PRESSÃO E FATORES DE RISCO EM PACIENTES HOSPITALIZADOS COM FRATURA DE QUADRIL E FÊMUR
}

\author{
Dissertação apresentada à Escola de Enfermagem de \\ Ribeirão Preto da Universidade de São Paulo para a obtenção \\ do título de Mestre em Enfermagem \\ Área de Concentração: Enfermagem Fundamental
}

Linha de Pesquisa: Fundamentação Teórica, Metodológica e Tecnológica do Processo de Cuidar em Enfermagem

Orientadora: Profa. Dra. Maria Helena Larcher Caliri

\section{RIBEIRÃO PRETO}




\section{AUTORIZO A REPRODUÇÃO E DIVULGAÇÃO TOTAL OU PARCIAL DESTE TRABALHO, POR QUALQUER MEIO CONVENCIONAL OU ELETRÔNICO, PARA FINS DE ESTUDO OU PESQUISA, DESDE QUE CITADA A FONTE.}

Faustino, Andréa Mathes

Úlcera por Pressão e Fatores de Risco em Pacientes Hospitalizados com Fratura de Quadril e Fêmur. Ribeirão Preto, 2008. 131 p.: il. ; 30cm

Dissertação de Mestrado, apresentada à Escola de Enfermagem de Ribeirão Preto/USP.

Área de concentração: Enfermagem Fundamental

Orientadora: Caliri, Maria Helena Larcher

1. Úlcera de Pressão. 2. Fraturas de Fêmur. 3. Fraturas de Quadril 4. Fatores de Risco 


\section{FOLHA DE APROVAÇÃO}

Andréa Mathes Faustino

Úlcera Por Pressão e Fatores de Risco em Pacientes Hospitalizados com Fratura de Quadril e Fêmur

Dissertação apresentada à Escola de Enfermagem de Ribeirão Preto da Universidade de São Paulo Programa de Pós-Graduação em Enfermagem Fundamental, para a obtenção do título de Mestre em Enfermagem Área de Concentração: Enfermagem Fundamental

Aprovada em:

\section{BANCA EXAMINADORA}

Profa. Dra. Maria Helena Larcher Caliri Instituição: EERP-USP

Assinatura

Profa. Dra. Sueli Marques

Instituição: EERP-USP

Assinatura

Prof. Dra. Soraia Assad Nasbine Rabeh Instituição: Centro Universitário Barão de Mauá

Assinatura 


\section{DEDICATÓRIA}

A Deus e Nossa Senhora que sempre me protegeram e me fizeram chegar onde estou!

Aos meus pais Wilson Faustino e Hilda Mathes Faustino que sempre me incentivaram e dedicaram uma vida de amor e exemplo a mim.

Ao meu esposo José Alberto Guimarães Tolentino, que com sua presença companheira e carinhosa, mostrou-se sempre pronto a me ajudar e me ouvir com tanta ternura.

À minha querida irmã Silvia Maria Mathes Faustino, que sempre foi meu exemplo bom a seguir.

À querida Profa. Maria Helena Larcher Caliri, que desde a graduação despertou em mim o gosto pelo estudo em Feridas Crônicas e os Cuidados com Adultos e Idosos, é um exemplo de profissional e pessoa que tanto admiro e respeito!

Aos meus amigos e familiares que me apoiaram nesta caminhada!

Amo todos vocês! 


\section{AGRADECIMENTOS}

Às queridas Professoras Sueli Marques e Soraia Assad Nasbine Rabeh que com suas práticas de vida profissional e docência souberam me orientar tanto neste percurso!

A Profa. Mieko Hayashida, pela ajuda final tão importante com os dados estatísticos!

À querida amiga Margareth Yuri Miyazaki, e companheira de sempre que tanto admiro!

Aos amigos, colegas e alunos da Universidade Paulista - UNIP de Ribeirão Preto, em especial na figura das Professoras Alessandra Mazzo, Aidê Amabile, Termutes Pezzuto, Zigmar Nunes, Ivany Risso, Maria Regina, Danielle Martins e Kelli Paiva, pelo apoio em tantos momentos!

Às Queridas professoras da Escola de Enfermagem de Ribeirão Preto, em especial Profa. Maria Suely Nogueira, Maria Manuela Rino Mendes e Ana Emília Pace que em muitos momentos de minha vida profissional souberam me ensinar a admirar cada vez mais o "Ser Enfermeira", sempre com muito profissionalismo e dedicação!

Às queridas tias Neiry, Nilda e Nils Faustino, que sempre me apoiaram e me incentivaram a ser o que sou!

À querida prima Maristela Gavioli que sempre esteve por perto sabendo dar bons conselhos!

Aos colegas do Programa Gestão Saúde e Home Care da AMIL - DF, em especial na figura do Dr. Bruno Siqueira e Paula Fraga e à minha equipe querida: Cleidiane, Maria Alice, Priscila e Weidman; que tanto me apoiaram nestes momentos finais!

Aos queridos pacientes que me ajudaram na realização do trabalho e aos profissionais da Unidade de Emergência e Campus - HCRP / USP em especial da Unidade de Ortopedia. 
"Guardar uma coisa não é escondê-la ou trancá-la.

Em cofre não se guarda coisa alguma.

Em cofre perde-se a coisa à vista.

Guardar uma coisa é olhá-la, fitá-la, mirá-la por admirá-la, isto é, iluminá-la ou ser por ela iluminado. Guardar uma coisa é vigiá-la, isto é, fazer vigília por ela, isto é, velar por ela, isto é, estar acordado por ela, isto é, estar por ela ou ser por ela. Por isso, melhor se guarda o vôo de um pássaro Do que de um pássaro sem vôos. Por isso se escreve, por isso se diz, por isso se publica, por isso se declara e declama um poema: Para guardá-lo:

Para que ele, por sua vez, guarde o que guarda: Guarde o que quer que guarda um poema: Por isso o lance do poema: Por guardar-se o que se quer guardar." 


\section{RESUMO}

FAUSTINO, A.M. Ùlcera por Pressão e Fatores de Risco em Pacientes Hospitalizados com Fratura de Quadril e Fêmur. 2008. 131f. Dissertação (Mestrado). Escola de Enfermagem de Ribeirão Preto da Universidade de São Paulo, Ribeirão Preto (SP), 2008.

Fraturas de quadril e fêmur são um problema de saúde pública emergente, associado a um elevado índice de mortalidade e morbidade em todo mundo, com alto impacto na qualidade de vida dos pacientes. A Úlcera por Pressão (UP) é uma complicação que pode interferir para aumento destes índices. O estudo teve como objetivos identificar e caracterizar os pacientes que sofreram fratura de quadril e fêmur atendidos em um Hospital Universitário do interior Paulista; verificar a incidência e prevalência da UP e descrever a evolução das lesões até a alta; relacionar a presença de UP com as variáveis clinicas, incluindo o risco para UP por meio da Escala de Braden e o grau de independência para as Atividades de Vida Diária (AVD) pelo Índice de Katz; e analisar o valor preditivo dos escores da escala de Braden para esta população. Após aprovação pelo Comitê de Ética, foram incluídos na amostra 30 pacientes que aceitaram participar. Os dados foram coletados na admissão, no $1^{\circ}$ dia pós-operatório ou no $5^{\circ}$ dia de internação e na alta. Os participantes eram predominantemente do sexo feminino $(53,3 \%)$, brancos $(76,7 \%)$, acima dos 60 anos de idade (56,7\%), alfabetizados (60\%) e aposentados $(33,3 \%)$. O local anatômico mais comum da fratura foi o colo do fêmur. A comorbidade mais comum foi do Sistema Cardiocirculatório (53,3\%). O tempo médio entre a admissão e a cirurgia foi de 2,92 dias. O tempo total de cirurgia variou entre 2 a 4 horas. O tempo médio de internação foi 14,20 dias. A complicação mais comum no pós-operatório foi a confusão e agitação $(66,7 \%)$. Em relação à independência funcional para as AVD, 50\% eram totalmente dependentes na primeira e segunda avaliação e $40 \%$ no momento da alta. Quanto ao risco para UP, o escore médio da Escala de Braden na admissão foi 12,66 (DP: 2,52), no segundo momento 13,73 (DP: 3,10) e na Alta 15,03 (DP: 3,83). Para os pacientes que tiveram UP durante a internação os escores foram menores em todos os momentos $\left(p^{\prime \prime} 0,05\right)$. A prevalência de UP foi de $33,3 \%$ e a incidência $26,6 \%$. No momento da Alta, dos 10 casos considerados no estudo de prevalência, 9 ainda apresentavam UP. Na análise dos resultados pela regressão logística identificou-se que das covariáveis sócio-demográficas e clínicas investigadas apenas o escore da escala de Braden explicava a ocorrência da UP $\left(p^{\prime \prime} 0,05\right)$. A análise do valor preditivo dos escores da escala de Braden pelo Teste de Fisher identificou que quanto menor a pontuação na escala, maior a quantidade de pacientes com UP no segundo e terceiro momentos $\left(p^{\prime \prime} 0,05\right)$.

Palavras-chave: 1.Úlcera de Pressão . 2. Fraturas de Fêmur. 3. Fratura de Quadril. 4.Fatores de Risco. 


\section{ABSTRACT}

FAUSTINO, A.M. Pressure Ulcer and Risk Factors in Patients with Hip and Femur Fracture in the Hospital. 2008. 131f. Dissertation (Masters). Ribeirão Preto College of Nursing, Ribeirão Preto (SP), 2008.

Fractures of hip and femur are an emerging public health problem, associated with a high rate of mortality and morbidity worldwide, with a high impact on the quality of life of patients. The Pressure Ulcer by (PU) is a complication that can interfere to increase these rates. The study aimed to identify and characterize the patients who suffered from hip and femur fracture treated in a University Hospital from inside Paulista; check the incidence and prevalence of UP and describe the evolution of the injury until discharge; relate the presence of the UP clinical variables, including the risk to UP by Scale of Braden and the degree of independence for the Activities of Daily Living (AVD) by Katz Index, and examine the predictive value of the scores of the scale of Braden for this population. After approval by the Ethics Committee, were included in the sample 30 patients who agreed to participate. Data were collected at admission, at 1 postoperative day or on the 5th day of hospitalization and discharge. Participants were predominantly female (53.3\%), white $(76.7 \%)$, over 60 years of age (56.7\%), literacy (60\%) and retirees (33.3\%). The most common anatomical location of the fracture was the lap of the femur The most common comorbidity was System Cardiac (53.3\%). The average time between admission and surgery was 2.92 days. The total time of surgery ranged from 2 to 4 hours. The average length of stay was 14.20 days. The most common complication in the postoperative period was the confusion and agitation (66.7\%). Regarding the functional independence for the AVD, $50 \%$ were totally dependent on the first and second evaluation, and $40 \%$ at the time of discharge. The likelihood for UP, the scoring average of Braden Scale at admission was 12,66 (SD: 2,52), the second time 13,73 (SD: 3,10) and the High 15.03 (SD: 3,83). For patients who had UP during hospitalization the scores were lower at all times ( $p$ 0.05). The prevalence of UP was $33.3 \%$ and $26.6 \%$ incidence. At the time of Discharge, of the 10 cases considered in the study of prevalence, 9 still had UP. In the analysis of the results by logistic regression identified that the covariates socio-demographic and clinical investigated only the score of the scale of Braden explained the occurrence of UP ( $p$ 0.05). The analysis of the predictive value of the scores of the scale of the test Braden Fisher identified that the lower the score on the scale, the greater the number of patients with UP in the second and third times (p 0.05).

Key-words: 1.Pressure Ulcer.2. Femur Fracture. 3. Hip Fracture. 4.Risk Factors. 


\section{RESUMEN}

FAUSTINO, A.M. Úlcera por Presión y Factores de Riesgo en Pacientes con Fractura de la cadera y Fémur en el Hospital. 2008. 131f. Tesis (Maestría). Escuela de Enfermería de Ribeirão Preto, Ribeirão Preto (SP), 2008.

Las fracturas de cadera y fémur son un problema de salud pública emergente, asociado a una alta tasa de mortalidad y morbilidad en todo el mundo, con un alto impacto en la calidad de vida de los pacientes. La Úlcera por presión (UPP) es una complicación que puede interferir para aumentar estas tasas. El estudio tuvo como objetivo identificar y caracterizar a los pacientes que sufren de cadera y fractura de fémur tratadas en el Hospital de Clínicas desde el interior Paulista; comprobar la incidencia y prevalencia de la UP y describir la evolución de la lesión hasta el alta; refieren la presencia de la UP variables clínicas, Incluido el riesgo de UP por Escala de Braden y el grado de independencia para las Actividades de la Vida Diaria (AVD) por Índice Katz, y examinar el valor predictivo de las puntuaciones de la escala de Braden para esta población. Tras la aprobación por el Comité de Ética, se incluyeron en la muestra 30 pacientes que aceptaron participar. Los datos fueron recolectados en la admisión, a 1 día postoperatorio o en el $5^{\circ}$ día de hospitalización y de la gestión. Los participantes fueron en su mayoría mujeres $(53,3 \%)$, blancos $(76,7 \%)$, más de 60 años de edad (56,7\%), de alfabetización (60\%) y los jubilados $(33,3 \%)$. La ubicación anatómica más común de la fractura fue la vuelta del fémur El más común es el sistema comorbilidad cardiaca $(53,3 \%)$. El promedio de tiempo entre la admisión y la cirugía fue de 2,92 días. El tiempo total de la cirugía varió de 2 a 4 horas. El promedio de estancia fue 14,20 días. La complicación más común en el período postoperatorio fue la confusión y la agitación $(66,7 \%)$. En cuanto a la independencia funcional para las AVD, el $50 \%$ son totalmente dependientes de la primera y la segunda evaluación, y el $40 \%$ en el momento del alta. La probabilidad de UP, la puntuación media de la Escala Braden al ingreso fue 12,66 (SD: 2,52), la segunda vez 13,73 (SD: 3,10) y el Alto 15.03 (SD: 3,83). Para los pacientes que habían UP durante la hospitalización fueron las puntuaciones más bajas en todo momento ( $p 0,05)$. La prevalencia de la UP fue $33,3 \%$ y $26,6 \%$ de incidencia. En el momento de la gestión, de los 10 casos examinados en el estudio de prevalencia, 9 aún había UP. En el análisis de los resultados por regresión logística identificó que las covariables sociodemográficas y clínicas investigadas sólo la puntuación de la escala de Braden explica la aparición de UP $(p 0,05)$. El análisis del valor predictivo de las puntuaciones de la escala de la prueba de Fisher Braden identificado el menor que la puntuación en la escala, mayor será el número de pacientes con UP en el segundo y tercer veces ( $p 0,05)$.

Palabras-clave: 1.Úlcera por Presión. 2. Fractura fémur. 3. Fractura de la cadera. 4.Factores de Riesgo. 


\section{LISTA DE TABELAS}

Tabela 1 Distribuição dos pacientes segundo variáveis sócio - demográficas.

Ribeirão Preto, SP, $2007(n=30)$

Tabela 2 Distribuição dos pacientes segundo variáveis clínicas. Ribeirão Preto,

SP, $2007(n=30)$ 53

Tabela 3 Distribuição dos pacientes segundo tipo de anestesia, tempo de permanência na Sala de Recuperação, presença e tipo de complicações no período pós-operatório imediato. Ribeirão Preto, SP, $2007(n=28)$

Tabela 4 Distribuição dos pacientes segundo avaliação de risco para UP por meio da Escala de Bradam, nos três momentos de Avaliação. Ribeirão Preto, SP, $2007(n=30)$

Tabela 5 Distribuição dos pacientes segundo os subescores médios da escala de Braden nos três momentos de avaliação. Ribeirão Preto, SP, 2007 $(n=30)$

Tabela 6 Distribuição dos pacientes segundo o estado mental nos três momentos de Avaliação. Ribeirão Preto, SP, $2007(n=30)$

Tabela 7 Distribuição dos pacientes segundo a avaliação da capacidade funcional por Índice de Katz. Ribeirão Preto, SP, 2007 ( $n=30)$

Tabela 8 Distribuição dos pacientes segundo o número de UP e sua distribuição por região anatômica na Admissão. $1^{\circ} \mathrm{PO} / 5^{\circ} \mathrm{DI}$ e Alta.

Ribeirão Preto, SP, $2007(n=10)$

Tabela 9 Distribuição do Número UP pelo estágio e localização e estágio das UP identificadas nos pacientes durante o momento de Tabela detecção. Ribeirão Preto, SP, 2007

Tabela 10 Distribuição dos pacientes segundo o diagnóstico secundário na Admissão e a presença / ausência de UP durante a internação. Ribeirão Preto, SP, $2007(n=30)$ 
Tabela 11 Distribuição dos pacientes segundo o IMC e a presença / ausência de UP durante a internação. Ribeirão Preto, SP, $2007(n=30)$

Tabela 12 Distribuição dos pacientes considerando o valor do Escore Total da Escala de Braden, obtido na admissão e a ocorrência de UP na internação. Ribeirão Preto, $2007(n=28)$

Tabela 13 Distribuição dos pacientes considerando o valor do Escore Total da Escala de Braden, obtido em $2^{\circ}$ momento de avaliação e a ocorrência de UP na internação. Ribeirão Preto, SP, $2007(n=28)$

Tabela 14 Distribuição dos pacientes considerando o Escore de Katz na admissão e a ocorrência de UP na internação. Ribeirão Preto, SP, $2007(n=28)$

Tabela 15 Distribuição dos pacientes considerando o Escore de Katz em $2^{\circ}$ momento de avaliação e a ocorrência de UP na internação. Ribeirão Preto, SP, $2007(n=28)$

Tabela 16 Distribuição dos pacientes considerando o Escore de Katz no momento da saída hospitalar e a ocorrência de UP na internação. Ribeirão Preto, SP, $2007(n=28)$

Tabela 17 Distribuição dos pacientes considerando a classificação de risco da Escala de Braden e a presença / ausência de UP na Admissão. Ribeirão Preto, SP, $2007(n=30)$

Tabela 18 Distribuição dos pacientes considerando a classificação de risco da Escala de Braden e a presença / ausência de UP no $1^{\circ} \mathrm{PO} / 5^{\circ} \mathrm{DI}$. Ribeirão Preto, SP, $2007(n=30)$

Tabela 19 Distribuição dos pacientes considerando a classificação de risco da Escala de Braden e a presença / ausência de UP na Alta. Ribeirão Preto, SP, $2007(n=30)$ 


\section{LISTA DE GRÁFICOS}

Gráfico 1 Evolução do Subescore percepção sensorial nos três momentos de avaliação do risco para UP dos pacientes com fratura de

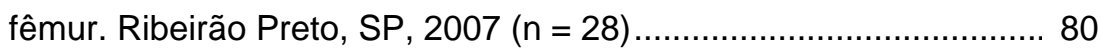

Gráfico 2 Evolução do Subescore Umidade nos três momentos de avaliação do risco para UP dos pacientes com fratura de fêmur. Ribeirão Preto, SP, $2007(n=28)$

Gráfico 3 Evolução do Subescore Atividade nos três momentos de avaliação do risco para UP dos pacientes com fratura de fêmur. Ribeirão Preto, SP, $2007(n=28)$

Gráfico 4 Evolução do Subescore Mobilidade nos três momentos de avaliação do risco para UP dos pacientes com fratura de fêmur. Ribeirão Preto, SP, $2007(n=28)$

Gráfico 5 Evolução do Subescore de Nutrição nos três momentos de avaliação do risco para UP dos pacientes com fratura de fêmur. Ribeirão Preto, SP, $2007(n=28)$

Tabela 6 Evolução do Subescore Fricção e Cisalhamento nos três momentos de avaliação do risco para UP dos pacientes com fratura de fêmur. Ribeirão Preto, SP, $2007(n=28)$ 


\section{LISTA DE QUADROS}




\section{LISTA DE FIGURAS}

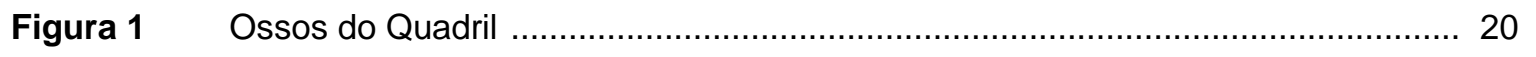

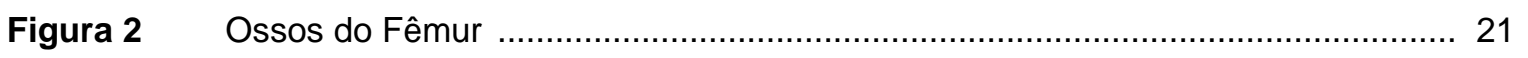




\section{SUMÁRIO}

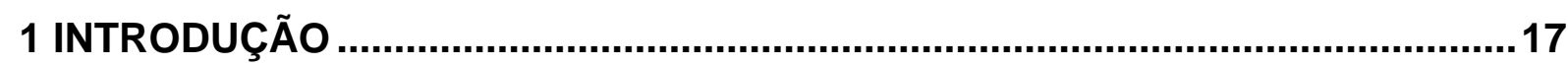

1.1 Epidemiologia da Fratura de Quadril e Fêmur ..................................... 18

1.2 Anatomia dos Ossos do Quadril e Fêmur ............................................ 19

1.3 Classificação e Tratamento da Fratura de Quadril e Fêmur........................21

1.4 Complicações da Fratura de Quadril e Fêmur ..........................................23

1.5 Diagnóstico da Úlcera por Pressão e Intervenções para Prevenção ............25

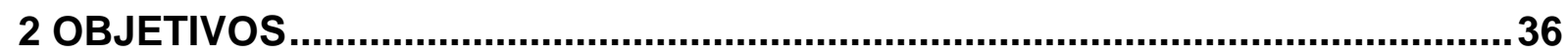

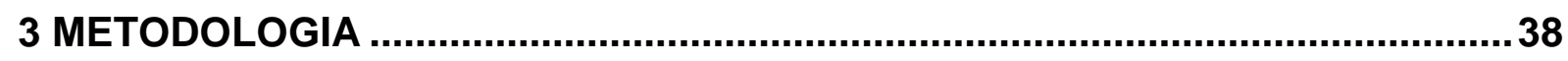

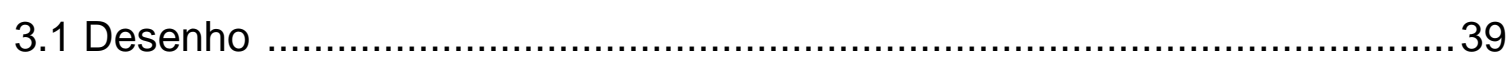

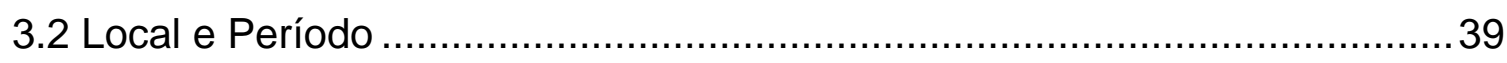

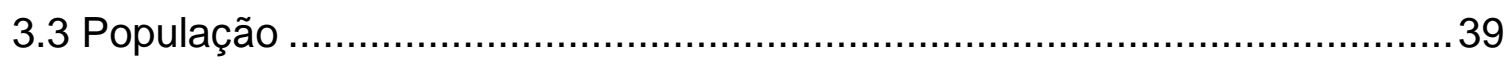

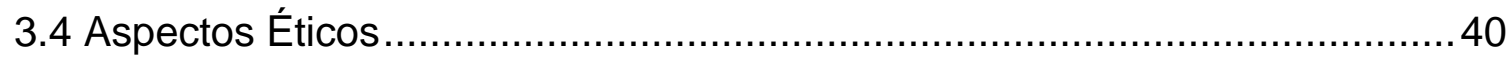

3.5 Procedimentos para a Coleta de Dados........................................... 40

3.6 Análise dos Resultados ......................................................... 45

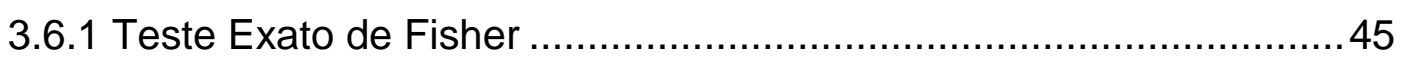

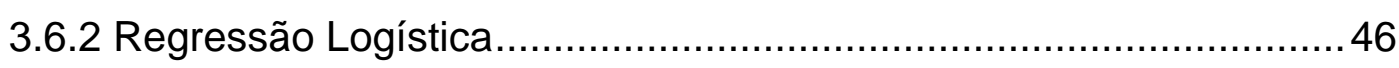

4 RESULTADOS E DISCUSSÃO .................................................................... 48

4.1 Caracterização sócio-demográfica e clínica dos pacientes........................49

4.2 Estudo de Prevalência e Incidência e Evolução das UP ............................67

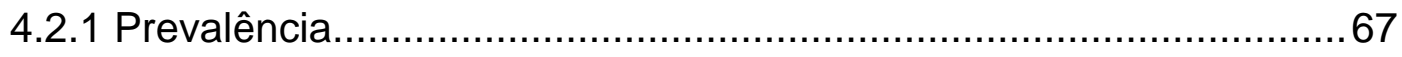

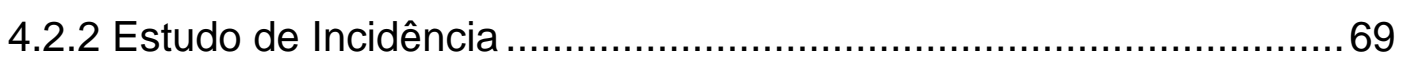

4.2.3 Evolução das úlceras por pressão .........................................71

4.3 Relação entre a presença de UP e variáveis demográficas e clínicas ........74

4.4 Valor Preditivo dos Escores da Escala de Braden ................................ 92

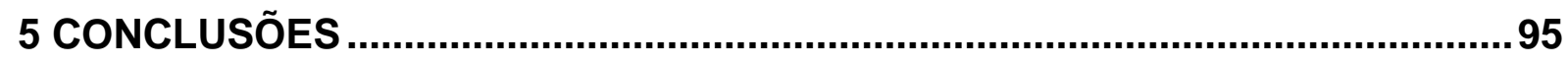

5.1 Quanto à caracterização dos pacientes ............................................ 96

5.2 Quanto à incidência e prevalência da UP ........................................... 97 
5.3 Descrição e evolução das lesões até a alta 98

5.4 Em relação à presença de UP com as variáveis clinicas 98

5.5 Em relação à avaliação de risco para UP por meio da Escala de Braden ...99

5.6 Quanto ao valor preditivo dos Escores de Braden para esta população .... 100

6 CONSIDERAÇÕES FINAIS 101

REFERÊNCIAS BIBLIOGRÁFICAS 109

APÊNDICES 124

ANEXOS 


\subsection{Epidemiologia da Fratura de Quadril e Fêmur}

As fraturas que ocorrem nas regiões de quadril e fêmur são consideradas um problema de saúde pública emergente, associado a um elevado índice de mortalidade e morbidade em todo mundo, com alto impacto na qualidade de vida dos pacientes que sofreram o agravo.

Dentre as fraturas, as que ocorrem nestas regiões do corpo são as que apresentam maior impacto na morbidade e maior taxa de mortalidade, principalmente na população idosa. Estimativas apontam que no ano de 2050 ocorrerão, aproximadamente, 6,5 milhões de fratura de fêmur e quadril em todo mundo (SILVEIRA et al, 2005).

A incidência deste tipo de fratura aumenta com a idade, principalmente em decorrência do aumento do número de quedas associado a maior prevalência de osteoporose (ALARCON et al, 2001).

A fratura de fêmur é uma das maiores causas de incapacidade e mortalidade em idosos e sua freqüência aumenta a cada ano cerca de 1 a 3\%, em muitas áreas do mundo, devido ao envelhecimento populacional (PEEL; MCLURE; HENDRIKZ, 2006).

No Brasil, identificaram-se apenas dois estudos de incidência de fraturas de fêmur. Foram desenvolvidos com pessoas acima de sessenta anos de idade e realizados em cidades do interior das regiões Sudeste e Nordeste do país, ambos de natureza retrospectiva. Na cidade de Marília, São Paulo, em 1995, a taxa foi de $50,03 / 10$ mil para o sexo feminino e de $18,73 / 10$ mil para o sexo masculino (KOMATSU et al., 1999). Em Sobral, Ceará, entre os anos de 1996 a 2000, as taxas 
anuais para pessoas acima de sessenta anos foram de $20,7 / 10$ mil para mulheres e 8,9/10 mil para homens (ROCHA; RIBEIRO, 2003).

Vários são os fatores associados ao risco de fraturas, entre eles massa corporal reduzida, dieta pobre em cálcio, menopausa, atividade física diminuída, menor grau de escolaridade e ter pouca atividade física no trabalho (GUIMARÃES, CUNHA, 2004). Além disto, Cummings \& Melton (2002) ressaltam outros aspectos como: história familiar de fratura de quadril, aumento de peso desde os 25 anos de idade, osteoporose, ingestão elevada de cafeína, uso de drogas benzodiazepínicas e ou anticonvulsivantes, entre outros.

\subsection{Anatomia dos Ossos do Quadril e Fêmur}

Os ossos do quadril (figura 1) estão localizados na base da coluna vertebral e são formados a partir de três ossos: o ísquio, a púbis e o ílio. O ísquio é formado pela espinha isquiática, tuber isquiático (estrutura que suporta o peso da pessoa sentada) e pelo forame obturado, onde há a fixação de vários músculos. O Púbis é formado pelos ramos superior e inferior e pelo tubérculo púbico, ponto de fixação do ligamento inguinal além destas estruturas é também composto por uma articulação sinovial esferoidal, formada pela cabeça do fêmur e pelo acetábulo (GRAY, 2000). 


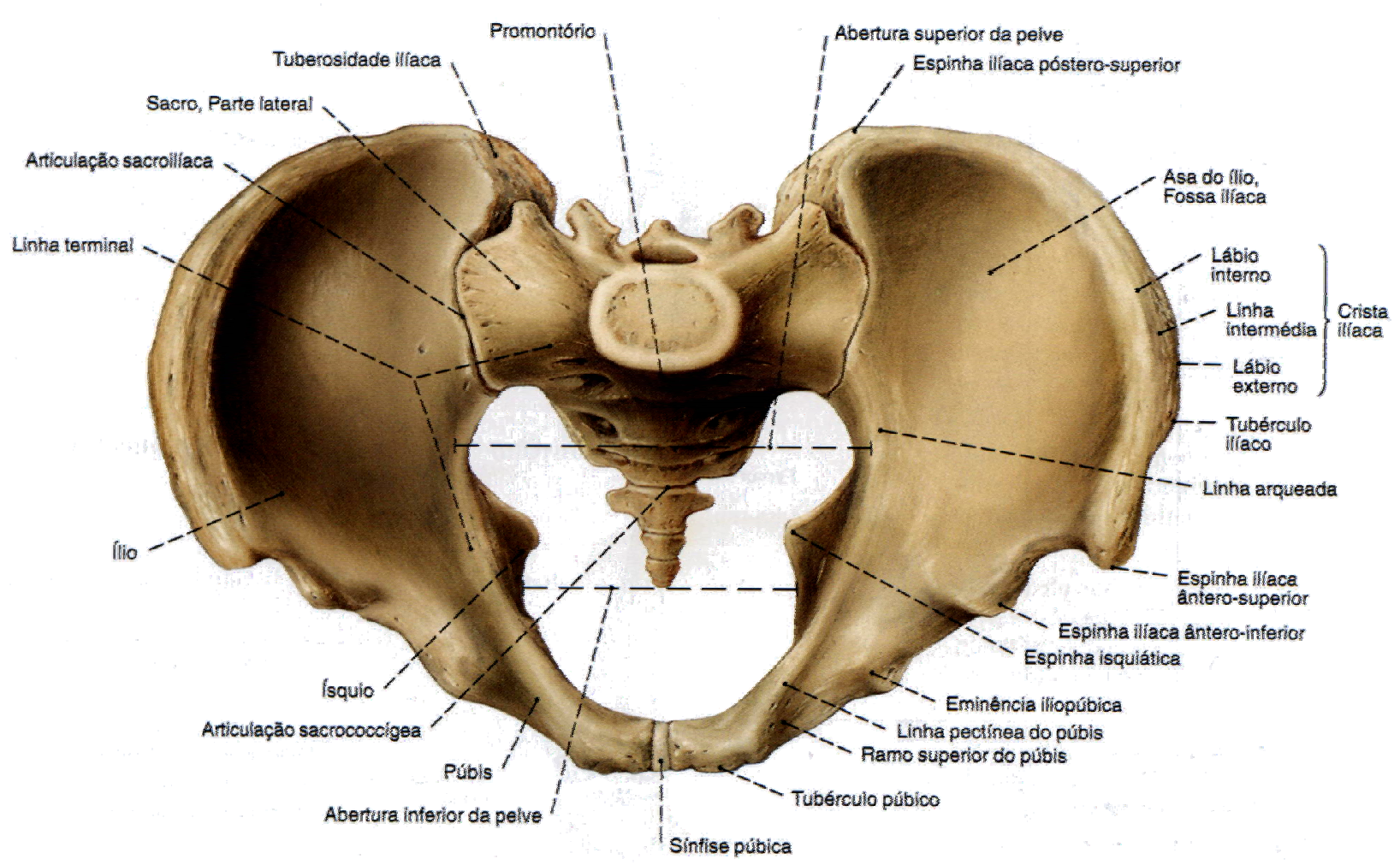

Figura 1. Ossos do Quadril (Fonte: SOBOTTA, 2000).

O fêmur (figura 2) é o osso mais longo e volumoso do corpo humano, e localiza-se na região da coxa. Está dividido em extremidade proximal, corpo do fêmur e extremidade distal. A extremidade proximal também denominada diáfise proximal, se prolonga, através de um colo, até uma cabeça (esférica) - que o articula com o osso do quadril e o corpo do fêmur, também chamado de metáfise; é composta ainda pelo trocânter maior e menor. E a epífise distal que se divide em dois côndilos lateral e medial, que se ligam à tíbia, à patela e à fíbula (GRAY, 2000). 


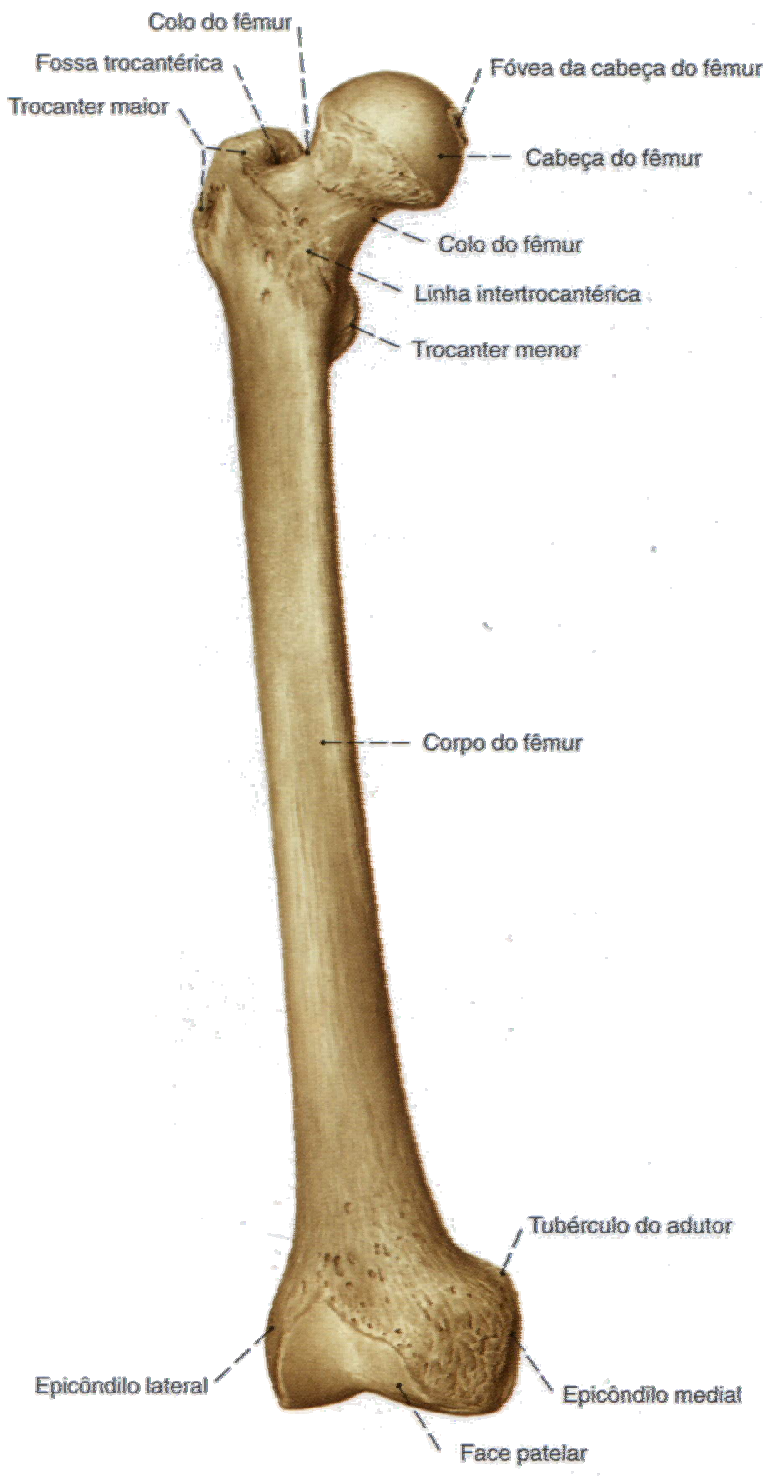

Figura 2. Osso Fêmur (Fonte: SOBOTTA, 2000).

\subsection{Classificação e Tratamento de Fratura de Quadril e Fêmur}

Muitos autores definem as fraturas de quadril como as ocorridas em regiões do quadril e fêmur englobando as duas estruturas, principalmente utilizando a 
determinação da estrutura coxofemoral. Para classificar essas fraturas alguns especialistas as classificam pelo deslocamento, quanto ao traço de fratura e quanto à situação anatômica (ROCKWOOD; et al, 1993).

Em termos de classificação pelo procedimento cirúrgico, os tipos de tratamentos estão divididos em Fraturas do Quadril, que são as fraturas que ocorrem nos ossos do quadril (pelve) e as localizadas em região de fêmur proximal (colo femoral, regiões intertrocantéricas, trocânter maior e menor, subtrocantéricas e acetábulo). Fraturas ocorridas em região de fêmur distal, as diafisárias, são denominadas fraturas de fêmur distal ou diafisárias; podem ainda ser divididas em intra e extracapsulares (KOVAL; ZUCKERMAN, 1999).

As fraturas mais comuns são as ocorridas em região do colo femoral e as transtrocanterianas (BARROS FILHO; NAPOLI, 2000).

O tratamento é cirúrgico na maioria dos casos de fratura, podendo variar de colocação de pinos e parafusos até substituição da articulação com colocação de próteses. Para cada tipo de fratura existe um tipo de tratamento; conforme a descrição de KOBERLE (2004), para alguns destes casos:

- fraturas transtrocanterianas, extracapsulares: os pacientes apresentam impotência funcional total, encurtamento visível e rotação externa. O tratamento é essencialmente cirúrgico. No pós-operatório os pacientes são colocados em posição ortostática no $2^{\circ}$ ou $3^{\circ}$ dia com carga total ou com a carga que suportarem, seja a fratura estável ou não (KOBERLE, 2001), o que diminui os riscos de complicações para os pacientes.

- fratura de colo femoral, intracapsulares: são as fraturas causadas por quedas da própria altura, classificadas como impactantes. O paciente pode ser capaz de deambular e assim retardar o tratamento, pois não há sinais de rotação do membro, hematomas locais ou mesmo encurtamento; seu tratamento é apenas cirúrgico. São 
as cirurgias denominadas Artroplastia ou Prótese Total do Quadril que se caracteriza pela substituição ou troca da articulação do quadril.

- fratura da cabeça femoral, intracapsulares: são raras e decorrem de uma luxação coxo-femoral. O tratamento pode ser conservador se a articulação estiver estável após redução por tratamento não cirúrgico (incruento) ou cirúrgico (cruento).

O tratamento conservador é feito na maior parte dos casos de fratura de acetábulo, ou de fraturas diafisárias, e mais utilizados em pessoas jovens, com pouco risco de complicações pelo fato de ser um tratamento de longa duração (CANALE, 2007). A escolha do tratamento conservador ou cirúrgico está diretamente ligada ao tipo de fratura, à idade do paciente e, ao grau de alteração funcional em decorrência da fratura. Os tratamentos conservadores para fraturas de quadril consistem em realizar uso de aparelho gessado na região afetada e o uso de tração esquelética ou cutânea. Este método é muito utilizado em crianças (SANTILI et al, 2005).

A importância de uma cirurgia de urgência em pacientes com fratura de fêmur é bem conhecida. Se uma fratura é estabilizada dentro do período de 24 horas a recuperação é potencialmente melhor (HOMMEL; ULANDER; THORNGREN, 2003).

\subsection{Complicações da Fratura de Quadril e Fêmur}

Sabe-se que em pacientes com fratura de fêmur que sofreram algum tipo de complicação, há um aumento nas taxas de mortalidade (MERCHANT et al., 2005). As taxas de mortalidade variam de 15,0 a $50,0 \%$ no primeiro ano, com maior número 
de óbitos ocorrendo nos primeiros seis meses após o evento (LEIBSON et al., 2002; KOBERLE, 2004).

Quanto maior o tempo em que o paciente permanece acamado, maiores são as chances de ter complicações (KOBERLE, 2004). Durante o período de hospitalização, é necessária a prevenção para diminuir a ocorrência de complicações como infecção em sítio cirúrgico, úlcera por pressão (UP), trombose, pneumonia, infecção urinária e confusão mental (BAUMGARTEN et al., 2003).

Em termos de potencial de reabilitação, no máximo, 25\% dos pacientes se recuperam totalmente e os demais podem apresentar: dor persistente, dificuldade para deambulação, alteração do equilíbrio e dificuldade para subir escadas (KOBERLE, 2004). É fato que metade dos pacientes que sofreram fratura de quadril, até um ano após o evento, pode se tornar totalmente dependente para realizar as atividades básicas de vida diária. Cerca de 25\% a 35\% daqueles que conseguem retornar ao domicílio irão precisar de cuidadores ou de algum dispositivo para auxiliar na locomoção (CUMMINGS; MELTON, 2002).

Desta forma as fraturas de fêmur e quadril trazem conseqüências também para os familiares e para o sistema de saúde. A dependência para o cuidado implica que pelo menos um familiar abandonará a atividade econômica ativa por um longo período de tempo. As complicações aumentam os custos da atenção à saúde (MINISTÉRIO DA SAÚDE; SECRETARIA DE POLÍTICAS DE SAÚDE, 2000).

No Brasil em um estudo realizado no Sistema de Saúde Suplementar, o custo referente ao paciente com fratura de fêmur, foi feito com o custo da hospitalização, considerando em média 9,21 dias de internação, o custo médio total foi de $\mathrm{R} \$$ 24.000, isto segundo os autores foi atribuído a maior parcela ao material médico utilizado, na cirurgia (ARAUJO; OLIVEIRA; BRACCO, 2005). 
Em países desenvolvidos como a Suécia, chega-se a gastar anualmente 40 mil dólares por paciente que sofreu fratura de fêmur e desenvolveu algum tipo de complicação (ZETHRAEUS et al., 1997).

\subsection{Diagnóstico da UP e Intervenções para a prevenção}

A UP é uma lesão localizada na pele e/ou no tecido ou estrutura subjacente, geralmente sobre uma proeminência óssea, resultante de pressão isolada ou de pressão combinada com fricção e/ou cisalhamento. Inúmeros fatores contribuintes ou fatores de confusão, como por exemplo, idade, sexo, comorbidades entre outros, podem também estar associados às UP; posteriormente o significado desses fatores, será elucidado. As UP são classificadas conforme o estágio de apresentação segundo o National Pressure Ulcer Advisory Panel - NPUAP (2007):

- Suspeita de lesão tissular profunda: Área localizada de pele intacta de coloração púrpura ou castanha ou bolha sanguinolenta devidas a dano no tecido mole, decorrente de pressão e/ou cisalhamento. A área pode ser precedida por um tecido que se apresenta dolorido, endurecido, amolecido, esponjoso e mais quente ou frio comparativamente ao tecido adjacente.

Descrição adicional: Lesão tissular profunda pode ser de difícil detecção em indivíduos com pele de tonalidades mais escuras. A sua evolução pode incluir uma pequena bolha sobre o leito escurecido da ferida. A lesão pode evoluir e ficar coberta por uma fina escara. A 
evolução pode ser rápida com exposição de camadas tissulares adicionais mesmo com tratamento adequado.

- Estáqio I: Pele intacta com hiperemia de uma área localizada que não embranquece, geralmente sobre proeminência óssea. A pele de cor escura pode não apresentar embranquecimento visível: sua cor pode diferir da pele ao redor.

Descrição adicional: A área pode apresentar-se dolorosa, endurecida, amolecida, mais quente ou mais fria comparativamente ao tecido adjacente. Feridas em estágio I podem ser difíceis de detectar em pessoas de pele com tonalidades escuras. Pode indicar pessoas "em risco" (um sinal precursor de risco).

- Estágio II: Perda parcial da espessura dérmica. Apresenta-se como úlcera superficial com o leito de coloração vermelho pálida, sem esfacelo. Pode apresentar-se ainda como uma bolha (preenchida com exsudato seroso), intacta ou aberta/ rompida.

Descrição adicional: Apresenta-se como uma úlcera superficial brilhante ou seca sem esfacelo ou arroxeamento (aspecto de equimose) *. Este estágio não deve ser usado para descrever skin tears, abrasões por adesivos, dermatite perineal, maceração ou escoriação.

* indica suspeita de lesão tissular profunda.

- Estágio III: Perda de tecido em sua espessura total. A gordura subcutânea pode estar visível, sem exposição de osso, tendão ou músculo. Esfacelo pode estar presente sem prejudicar a identificação da profundidade da perda tissular. Pode incluir descolamento e túneis. 
Descrição adicional: A profundidade da úlcera por pressão em estágio III varia conforme a localização anatômica. A asa do nariz, orelha, as regiões occipital e maleolar não possuem tecido subcutâneo e, portanto, as úlceras podem ser rasas neste estágio. Em contraste, áreas com adiposidade significativa podem desenvolver úlceras por pressão em estágio III bastante profundas. Ossos e tendões não são visíveis nem diretamente palpáveis.

- Estágio IV: Perda total de tecido com exposição óssea, de músculo ou tendão. Pode haver presença de esfacelo ou escara em algumas partes do leito da ferida. Freqüentemente, inclui descolamento e túneis. Descrição adicional: A profundidade da úlcera por pressão em estágio IV varia conforme a localização anatômica. A asa do nariz, orelha, as regiões occipital e maleolar não possuem tecido subcutâneo e, portanto, as úlceras podem ser rasas neste estágio. As úlceras em estágio IV podem estender-se aos músculos e/ou estruturas de suporte (como fáscia, tendão ou cápsula articular), possibilitando a ocorrência de osteomielite. A exposição de osso/ tendão é visível ou diretamente palpável.

- Úlceras que não podem ser classificadas: Lesão com perda total de tecido, na qual a base da úlcera está coberta por esfacelo (amarelo, marrom, cinza, esverdeado ou castanho) e/ou há escara (marrom, castanha ou negra) no leito da lesão.

Descrição adicional: A verdadeira profundidade e, portanto, o estágio da úlcera não pode ser determinado até que suficiente esfacelo e/ou escara sejam removidos para expor a base da úlcera. Escara estável (seca, aderente, intacta, sem eritema ou flutuação) nos calcâneos serve como “cobertura natural (biológica) corporal" e não deve ser removida. 
Pacientes com fratura de fêmur constituem um grupo com elevado risco para desenvolver UP, sendo que este agravo pode ocorrer em qualquer período durante a progressão do paciente no sistema de saúde: antes da admissão no hospital, na sala de urgência e emergência, no serviço de radiologia, na sala operatória, na enfermaria ou durante a reabilitação (GUNNINGBERG et al; 1999). A avaliação da pele, por meio da inspeção de forma sistematizada é um dos domínios da assistência de enfermagem, fazendo parte da prevenção e tratamento de UP (GUNNINGBERG et al, 1999).

A UP ocorre principalmente nas proeminências ósseas tais como em regiões sacra, tuberosidade isquiática, trocânter e calcâneos; porém, poderá desenvolver-se em qualquer parte do corpo sob excesso de pressão (como abaixo de gesso ou tala). Essas áreas são mais propensas à formação de UP devido ao peso da pessoa estar totalmente concentrado nessas partes do corpo durante o repouso prolongado em superfície inadequada. A diminuição da vascularização pela oclusão dos vasos durante intenso período de pressão, em determinada área do corpo, ocasiona redução do fluxo sanguíneo responsável por nutrir e oxigenar os tecidos e, em conseqüência desses fatores, ocorre a isquemia tecidual. Conforme a duração e intensidade da pressão podem ocorrer danos para a pele e tecidos mais profundos como músculos e ossos (NPUAP, 2007).

O uso de dispositivos ortopédicos (tração, colete torácico, colar cervical) durante o atendimento do paciente com fratura de fêmur no Serviço de Emergência ou no Hospital pode contribuir para o desenvolvimento de lesão de pele, assim como, para limitar a movimentação, provocando área de isquemia pelo excessivo contato de uma proeminência óssea com uma superfície rígida, caracterizando a primeira fase de desenvolvimento das UP (BAUMGARTEN et al., 2003). Assim faz- 
se necessária a avaliação rigorosa do paciente desde o atendimento pré-hospitalar, na admissão e durante toda a internação.

A utilização de medidas adequadas para a prevenção de UP, pode ser determinante para seu desenvolvimento ou não. Algumas intervenções são colocadas pela Wound Ostomy and Continence Nurse Society (WOCN, 2003) como, por exemplo: redução de fricção e cisalhamento quando for feita a transferência do paciente da cama para uma cadeira ou maca; mudança de decúbito a cada 2 horas, caso não haja restrições no estado clínico do paciente, no caso de pacientes com fraturas realizar ao menos alívio de pressão nas áreas de proeminência óssea por meio de colchões de ar ou d água; manejo da incontinência fecal e urinária, utilizando-se dispositivos que evitem o contato da pele com estes fluídos. Além disto, é necessário manter um estado nutricional, que dê aporte calórico e protéico adequados ao quadro clínico do paciente.

De acordo com Margolis et al (2003) em estudo que buscou analisar as condições clínicas e os fatores de risco para o desenvolvimento de UP em 75.168 idosos acompanhados em ambiente ambulatorial, identificaram que a Fratura de Quadril entre outras condições clínicas, como por exemplo, Demência de Alzheimer, Diabetes Mellitus, tiveram alta associação em ter ou não UP. Nesta população a ocorrência de UP foi de 1,21\%.

Durante o período de hospitalização, o comprometimento da capacidade do paciente para a realização das Atividades de Vida Diária (AVD) também contribuiu como fator de risco para o desenvolvimento das UP, conforme demonstrado no estudo de Baumgarten et al (2003).

Para realizar uma avaliação funcional quanto o desenvolvimento das Atividades de Vida Diária (AVD), uma escala muito utilizada é o Índice de 
Independência nas Atividades de Vida Diária, desenvolvido por Sidney Katz (ANEXO B) (KATZ et al., 1963). É uma escala destinada a medir a autonomia dos indivíduos nas atividades de vida diária, considerando os aspectos físicos.

A avaliação funcional é a medida realizada de forma objetiva, em que as pessoas são capazes de desempenhar determinadas atividades ou funções, utilizando habilidades diversas. Verifica se há necessidade ou não da pessoa ter ajuda parcial, em maior ou menor grau, ou se precisa de ajuda total, para cuidar de si e de seu ambiente (DUARTE; ANDRADE; LEBRÃO, 2007).

A avaliação é feita qualitativamente, e é útil principalmente para os indivíduos com maior dependência física, a fim de identificar as deficiências e riscos, oferecendo pistas para a estratégia de intervenção seja nas unidades de internação ou no domicílio (GONÇALVES, 1994).

Representa a descrição de um fenômeno em um contexto biológico e social, e está organizado de forma hierárquica na mensuração destas seis funções (DUARTE; ANDRADE; LEBRÃO, 2007):

- a atividade "banhar-se" é em relação ao uso do chuveiro, e ao ato de esfregar-se em qualquer uma dessas situações. Também são considerados independentes os pacientes que recebessem algum auxílio para banhar uma parte específica do corpo como, por exemplo, a região dorsal ou uma das extremidades. Quanto à dependência parcial para esta atividade está relacionado aos pacientes que recebem assistência para banhar-se em mais de uma parte do corpo ou necessitavam de auxílio para entrar ou sair da banheira / chuveiro e de dependência total para aqueles que não eram capazes de banharem-se sozinhos; 
- a função "vestir-se" considera-se o ato de pegar as roupas no armário, bem como 0 ato de se vestir propriamente dito. Compreendendo roupas íntimas, roupas externas, fechos e cintos. Calçar sapatos foi excluído da avaliação. A designação de dependência é dada aos pacientes que recebem alguma assistência pessoal ou que permanecem parcial ou totalmente despidos;

- a função "ir ao banheiro" compreende o ato de ir ao banheiro para as eliminações, higienizar-se e arrumar as próprias roupas. Os pacientes considerados independentes podem ou não utilizar algum equipamento ou ajuda mecânica para desempenhar a função sem que isso alterasse sua classificação. Dependentes são aqueles que recebem qualquer auxílio direto ou que não conseguem desempenhar a função. Os que utilizam "papagaios" ou "comadres" também são considerados dependentes;

- a função "transferência" é avaliada pelo movimento desempenhado pelo paciente para sair da cama e sentar-se em uma cadeira e viceversa. Como na função anterior, o uso de equipamentos ou suporte mecânico não alterava a classificação de independência para a função. Dependentes são os pacientes que recebem qualquer auxílio em qualquer das transferências ou que não realizam uma ou mais transferências;

- a função "continência" refere-se ao ato inteiramente autocontrolado de urinar ou defecar. A dependência está relacionada à presença de incontinência total ou parcial em qualquer das funções. Qualquer tipo de controle externo como enemas, cateterização ou uso regular de fraldas classificava o paciente como dependente; 
- a função "alimentação" relaciona-se ao ato de dirigir a comida do prato à boca. O ato de cortar os alimentos ou prepará-los está excluído da avaliação. São considerados dependentes eram os pacientes que recebem qualquer assistência pessoal. Os que não se alimentam sem ajuda ou que utilizam sondas enterais ou parenterais são considerados dependentes (DUARTE; ANDRADE; LEBRÃO, 2007).

O estado cognitivo do paciente também tem elevada influência sobre o desenvolvimento de UP. É o que descreve o estudo retrospectivo feito por BAUMGARTEN et al., (2003), realizado em 20 Hospitais da Pensilvânia, Texas, Nova Jersey e na Virgínia, dos Estados Unidos. Foram analisados os prontuários de 9400 pacientes idosos, admitidos entre os anos de 1983 a 1993, tendo como objetivo estimar a incidência de UP entre os pacientes hospitalizados para tratamento cirúrgico de fratura do quadril e identificar os fatores extrínsecos associados com o risco aumentado para UP nesta população. Durante a entrevista e exame clínico foram identificados que dos sujeitos da amostra que apresentaram quadro de confusão mental na alta desenvolveram mais UP em relação aos que não apresentaram estado confusional.

Pacientes com fratura de quadril que desenvolvem estado confusional tem mais UP do que pacientes orientados no tempo e espaço (HOMMEL; ULANDER; THORNGREN, 2003). No estudo de Gunninberg et al (1999) pacientes com fratura de quadril que chegavam com algum estado de confusão, desenvolveram mais UP do que os não confusos. Isto mostra a necessidade da avaliação do estado mental deste tipo de paciente pelo enfermeiro em sua assistência diária. 
A percepção sensorial e o estado nutricional são aspectos importantes a serem avaliados nestes pacientes. A diminuição da sensibilidade nas regiões da fratura ou ao seu redor, proporcionam uma elevada possibilidade de desenvolvimento de UP. Já um quadro de desnutrição protéica é um importante determinante para as UP além das infecções como complicação (RADEMAKERS; et al, 2007).

Para a avaliação do risco para o desenvolvimento de UP, o enfermeiro pode utilizar além da avaliação clínica e anamnese, escalas desenvolvidas e testadas, o que facilita o processo da sistematização da assistência, por meio da avaliação, elaboração do diagnóstico de enfermagem, a prescrição e evolução de enfermagem.

Algumas das escalas desenvolvidas para predizer o risco do paciente para desenvolvimento da UP é a escala de Norton, a qual consiste na avaliação de cinco fatores de risco: condição física geral, estado mental, atividade, mobilidade e incontinência. Cada um dos fatores de risco é dividido em vários níveis, e cada nível é pontuado numa escala de 1 a 4, com uma ou duas palavras descritivas para cada nível. Para avaliação de risco o escore de 5 a 11, significa alto risco, de 12 a 14, risco evidente e acima de 14, risco mínimo ou sem risco. (MARUM; et al, 2000). Na versão modificada há o acréscimo da avaliação de ingestão de líquidos e alimentos (GUNNINBERG; et al, 1999). Nesta escala não há avaliação do risco de fricção e cisalhamento e nem da umidade da pele.

Outra escala muito utilizada é a Escala de Braden (ANEXO C) (BRADEN; BERGSTRON, 1987), que demonstrou confiabilidade e validade em vários estudos de avaliação de risco para UP (SMITH, 1995).

A escala de Braden foi construída a partir da conceituação da fisiopatogenia da UP, onde ficaram destacados os dois determinantes críticos para a formação de 
UP: a intensidade e duração da pressão e a tolerância dos tecidos para suportarem essa pressão. É composta de seis sub-escalas: percepção sensorial, mobilidade, atividade, umidade, nutrição, fricção e cisalhamento; sendo possível a obtenção dos escores de 6 a 23. Quanto menor o escore, maior o risco para o desenvolvimento de UP (BERGSTROM; DEMUTH; BRADEN, 1987).

A sub-escala Percepção sensorial verifica a capacidade de sentir e aliviar o desconforto sentido e relatado pelo paciente. A sub-escala umidade mede o quanto a pele está exposta às umidades do tipo incontinência urinária, resíduos de alimentos, presença de secreções na pele entre outros. Já a sub-escala Atividade e Mobilidade são utilizadas para identificar a freqüência e duração das trocas de posição do paciente tanto no leito quanto fora dele. A sub-escala Nutrição mostra a ingestão alimentar do paciente por meio das refeições realizadas. A sub-escala Friç̧ão e Cisalhamento, avalia a capacidade do paciente em se movimentar ou a necessidade de ter auxílio de outra pessoa para as movimentações, deixando a superfície da pele livre do contato com as superfícies de apoio (BERGSTROM; DEMUTH; BRADEN, 1987).

Em um estudo prospectivo com grupo controle e experimental de pacientes com fratura de quadril realizado na Suécia, cujo objetivo foi avaliar o risco e observar a pele durante o período de internação em uma Unidade de Emergência e Acidentes. Foi utilizado um cartão desenvolvido apenas para isto, o qual continha a Escala de Norton, o qual era disponibilizado no prontuário para identificar a que tipo de grupo pertencia o paciente e quais tipos de cuidados deveriam ser realizados. Os pacientes eram distribuídos para o grupo controle e experimental conforme eram avaliados na admissão. Foram alocados para Grupo Experimental os que obtivessem escore $<21$ e as recomendações eram para avaliações e intervenções 
contínuas de enfermagem para a prevenção de UP. Já para o Grupo Controle eram alocados os outros pacientes com escore acima de 21 e a eles eram prestados cuidados rotineiros para prevenção de UP, conforme o que já havia no serviço. Para ambos os grupos eram dadas orientações educativas ao paciente a fim de diminuir o desenvolvimento de UP durante 30 minutos antes da internação. Os resultados obtidos foram que $20 \%$ dos pacientes de ambos os grupos já chegavam com UP, e na alta houve um acréscimo de incidência de UP de $40 \%$ no grupo experimental e $36 \%$ no grupo controle, evidenciando que não houve diferenças significativas entre os dois grupos (GUNNINBERG, et al, 1999).

Em levantamento bibliográfico realizado nos Bancos de Dados nacionais e internacionais LILACS e MEDLINE, utilizando os descritores de assunto: Fraturas do Quadril / Hip Fracture; Fraturas do Fêmur / Femoral Fractures e Úlcera de Pressão / Pressure Ulcer, não foram encontrados estudos brasileiros referentes ao tema.

Assim, este estudo foi planejado para identificar a ocorrência de UP e os fatores associados ao risco em pacientes com fratura de quadril e ou fêmur hospitalizados. 
2 OBJETIVOS 
- Identificar e caracterizar os pacientes que sofreram fratura de quadril e fêmur no período de março à julho de 2007, atendidos no Hospital das Clínicas da Faculdade Medicina Ribeirão Preto da Universidade de São Paulo (HCFMRP-USP) Campus e Unidade de Emergência (UE), considerando variáveis sócio-demográficas e clínicas;

- Identificar a incidência e prevalência da UP e descrever a evolução das lesões até a alta;

- Relacionar a presença de UP com as variáveis clinicas: idade, sexo, cor da pele, Tipo de Tratamento para a Fratura, Uso de Tração, Tempo de Cirurgia, Estado Mental e Nível de Independência Funcional e Escore de Risco para UP na admissão, $1^{\circ}$. PO ou $5^{\circ}$. dia de internação e na saída do hospital;

- Avaliar o risco para UP por meio da Escala de Braden e o valor preditivo dos Escores para esta população. 
3 METODOLOGIA 


\subsection{Desenho}

Estudo descritivo, com delineamento de corte longitudinal e prospectivo com abordagem quantitativa.

\subsection{Local e Período}

O estudo foi desenvolvido nas Unidades de Ortopedia do HCFMRP-USP: Campus e Unidade de Emergência (UE) durante o período de 13 março a 31 julho de 2007.

\subsection{População}

A população foi selecionada considerando os seguintes critérios: pacientes adultos e idosos com o diagnóstico de fratura de quadril e/ou fêmur, internados na Unidade de Ortopedia do Campus e Unidade de Emergência (UE) do HCFMRPUSP. A amostra para este estudo foi selecionada por conveniência. 
O Estudo Piloto foi realizado durante o primeiro mês da coleta com 5 pacientes que foram incluídos na amostra.

\subsection{Aspectos Éticos}

O projeto de pesquisa foi previamente encaminhado para a Chefia do Departamento de Ortopedia e para a Diretora da Divisão de Enfermagem da Instituição para avaliação. Posteriormente foi enviado ao Comitê de Ética em Pesquisa (CEP) do HCFMRP-USP, obedecendo a Resolução 196/96, obtendo a aprovação em 26 de fevereiro de 2007 (ANEXO A).

\subsection{Procedimentos para a Coleta de Dados}

Para a primeira etapa, diariamente era solicitado ao Serviço da Central de Regulação de Leitos e Sala de Trauma da UE-HCFMRP/USP o registro de pacientes vítimas de fratura de quadril e/ou fêmur, atendidos na Sala de Trauma. Após o levantamento destes registros, a pesquisadora se dirigia até a Unidade de Internação na Enfermaria de Ortopedia da UE-HCFMRP/USP ou na Unidade de Ortopedia da Unidade Campus do HCFMRP/USP e verificava nos prontuários se os pacientes atendiam os critérios para inclusão no estudo. 
Posteriormente, eram explicados os objetivos e procedimentos de pesquisa ao paciente e ou familiar responsável e o mesmo era convidado a participar.

Em caso de concordância com a participação, era apresentado o Termo de Consentimento Livre e Esclarecido (TCLE) (APÊNDICE 2). Para os concordantes após a leitura do TCLE, era solicitada a assinatura ou impressão datiloscópica para os analfabetos. Ainda para os pacientes que estavam de alguma forma incapacitados física ou cognitivamente para assinar o TCLE, era solicitada a autorização de familiares responsáveis.

Os procedimentos de coleta de dados foram orientados por um instrumento (APÊNDICE 1), semi-estruturado que foi previamente submetido à avaliação aparente e de conteúdo por profissionais que trabalham na área e testados durante o estudo piloto.

As fontes para a coleta de dados foram primárias (próprio paciente e equipe de saúde) e secundárias (prontuário do paciente).

Os dados foram coletados em 3 diferentes momentos: até 48 horas após a admissão, no $1^{\circ}$ dia Pós-Operatório ou $5^{\circ}$ dia de internação e depois semanalmente até o dia da alta.

Por meio da entrevista foram coletados dados referentes à idade, sexo, cidade de procedência, profissão, outros diagnósticos médicos na admissão, causa da fratura e alguns itens das Escalas de Braden e Katz;

Pela observação e inspeção foram coletados os dados de cor da pele, tipo de tração utilizada, tipo de colchão utilizado na enfermaria, estado mental, outros itens da Escala de Braden e Katz e condições da pele.

$\mathrm{Na}$ avaliação do estado mental o paciente foi classificado em orientado; desorientado, consciente e inconsciente. Foi considerado consciente o paciente que 
estava acordado, alerta, respondia adequadamente ao estímulo verbal, estava orientado em tempo e espaço, enquanto que o paciente considerado inconsciente foi o que estava em estado de coma, em sono profundo, com os olhos fechados, que não emitia som verbal, não interagia consigo mesmo ou com o meio ambiente (WHITAKER; DICCINI, 2002).

$\mathrm{Na}$ avaliação dos pacientes quanto ao Risco para UP utilizando a Escala de Braden foi considerada a seguinte classificação: 15 - 16: em risco; 13 - 14: risco moderado; 10 - 12: risco elevado; $\leq$ 9: risco muito elevado. Os pacientes com sessenta anos ou mais e com escores 17 e 18, também foram considerados como em risco, conforme as recomendações de AYELLO (2007).

Para a avaliação do Estado Funcional pelas Atividades de Vida Diária foi utilizado o Índice de Katz, cujos escores estão definidos de acordo com a seguinte escala, que na publicação original (Katz, 1963) está classificada por letras e neste estudo foi feita a codificação por números conforme Quadro 1 a seguir:

Quadro 1. Tipo de Classificação por Katz e o Índice correspondente.

\begin{tabular}{|c|c|}
\hline Índice de AVD (Katz) & Tipo de Classificação \\
\hline $1(\mathrm{~A})$ & Independente para todas as atividades \\
\hline $2(\mathrm{~B})$ & Independente para todas as atividades menos uma \\
\hline $3(\mathrm{C})$ & Independente para todas as atividades menos banho e mais uma adicional \\
\hline $4(\mathrm{D})$ & Independente para todas as atividades menos banho, vestir-se e mais uma adicional \\
\hline $5(\mathrm{E})$ & $\begin{array}{l}\text { Independente para todas as atividades menos banho, vestir-se, ir ao banheiro e mais } \\
\text { uma adicional }\end{array}$ \\
\hline $6(\mathrm{~F})$ & $\begin{array}{l}\text { Independente para todas as atividades menos banho, vestir-se, ir ao banheiro, } \\
\text { transferência e mais uma adicional }\end{array}$ \\
\hline $7(\mathrm{G})$ & Dependente para todas as atividades \\
\hline 8 (outros) & $\begin{array}{l}\text { Dependente em pelo menos duas funções, mas que não se classificassem em } C, D, E \\
\text { e F }\end{array}$ \\
\hline
\end{tabular}


Apesar de terem sido publicadas outras versões para a análise do Índice de Katz, muitos autores preferem utilizar a original, por ser a mais completa, tendo mais categorias para inserção do grupo a ser estudado. Além disto, a escala original de interpretação é a mais utilizada, o que fica mais adequada os estudos comparativos.

$\mathrm{Na}$ análise documental do prontuário, durante o período de hospitalização do paciente, foram confirmados os dados da entrevista e também coletados dados referentes às variáveis: tempo entre momento da fratura e admissão no hospital, tipo de tratamento da fratura (cirúrgico ou conservador); tempo entre admissão e tratamento cirúrgico, tempo de uso de tração, tempo de internação total, variáveis específicas do transoperatório como tipo de cirurgia, tipo de anestesia, tempo de cirurgia, tipo de colchonete e coxins (acomodadores) utilizados na mesa cirúrgica, tipo de colchão utilizado durante a internação e mudanças de decúbito registradas no dia anterior.

A presença da UP foi avaliada por meio da inspeção da pele e descrição das características e localização da lesão. Para a caracterização da UP foram considerados os estágios de I a IV (NPUAP, 2007).

A prevalência com relação à população exposta é chamada de coeficiente de prevalência. Isto é, CP= [P/N]x10000 (MORETTIN; BUSSAB, 2005).

Para a identificação da prevalência foram incluídos todos os pacientes com UP, independente do momento de detecção da lesão.

Para a identificação da incidência de UP, foram excluídos pacientes que no momento da avaliação inicial já apresentavam a UP em qualquer estágio. A Incidência foi calculada considerando o número de número de casos novos (de pacientes) com UP em relação ao número de pacientes com fratura de quadril e/ou fêmur internados (população exposta) durante o período de seguimento do estudo multiplicado por 10000 . 
A investigação da adequação dos níveis de risco para UP pelos escores da Escala de Braden para os pacientes com fratura de quadril, foi feita utilizando o Teste de Fisher.

No fluxograma a seguir estão representados os passos de desenvolvimento do estudo:

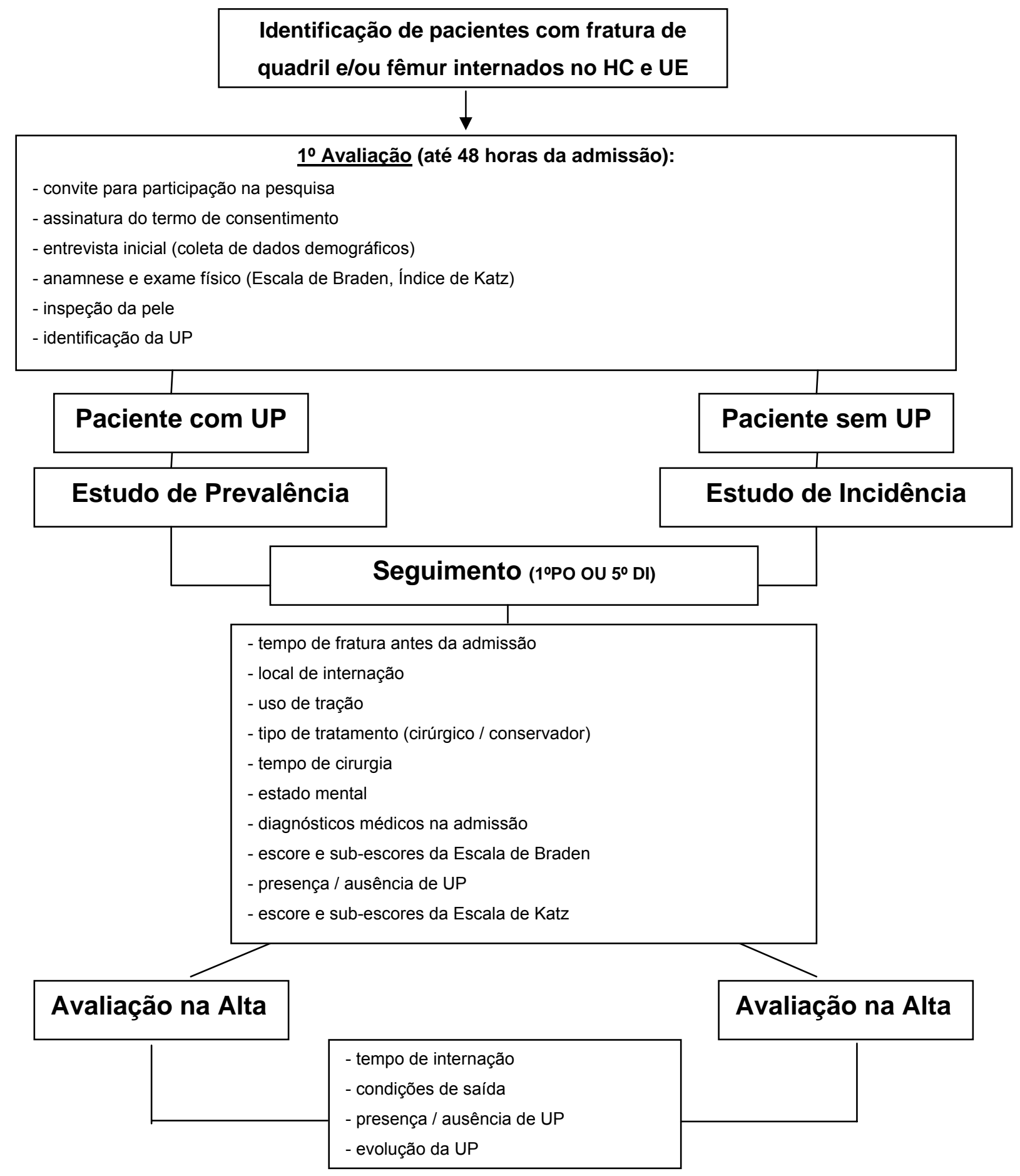




\subsection{Análise dos Resultados}

Foi utilizado o aplicativo Microsoft Excel da Suíte para Escritório Microsoft Office, para a digitação dos dados sob a forma de dupla entrada para a verificação de erros de digitação. A análise estatística se deu por meio do Statistical Analysis System (SAS) e do EPI-Info e os métodos utilizados foram:

\subsubsection{Teste Exato de Fisher}

O Teste Exato de Fisher foi utilizado para calcular a probabilidade de associação das características que estão em análise, ou seja, a probabilidade de tais características serem independentes, quando o número total de dados é pequeno. Esse método é utilizado quando a Amostra é pequena $(\mathrm{N}<20)$ ou se $20<$ $N<40$ e a menor freqüência esperada for menor que 5.

As hipóteses que foram verificadas foram:

- Hipótese Nula $\left(\mathrm{H}_{0}\right)$ : não existe relação entre as variáveis (são independentes), - Hipótese Alternativa $\left(\mathrm{H}_{1}\right)$ : existe relação entre as variáveis (são dependentes).

Se a probabilidade associada ao teste fosse menor que uma significância $\alpha$ (pré-estabelecida), rejeitar-se-ia a Hipótese Nula, ou seja, existe evidência estatística que indica a existência de relação entre as variáveis. Caso contrário se aceitaria a Hipótese Nula, ou seja, não existe evidência estatística que indica a existência de 
relação entre as variáveis. Para as análises deste estudo foi adotado o nível de significância de 0,05.

\subsubsection{Regressão Logística}

A Regressão Logística é um modelo de regressão linear paramétrico e foi utilizado para averiguar a relação entre a variável dependente (presença de UP) e uma ou mais variáveis independentes quantitativas ou qualitativas, no caso da variável resposta ser dicotômica, isto é, admitir apenas dois resultados. Existe, no entanto, a possibilidade de aplicar métodos de Regressão Logística mesmo em variáveis que não sejam binárias, transformando-as em probabilidades da ocorrência de um determinado evento em estudo (MORETTIN; BUSSAB, 2005).

O objetivo da Regressão Logística é predizer corretamente a categoria de uma variável resposta para casos individuais usando o modelo mais parcimonioso. Para tanto, um modelo é criado com todas as variáveis independentes que são utilizadas na predição da variável resposta.

O fato da função associada ao modelo de Regressão Logística variar entre zero e um é a razão primária de sua utilização, pois não se observa tal característica em outros modelos. O modelo é utilizado para descrever uma probabilidade, que, em termos epidemiológicos, é o risco de um indivíduo adquirir uma doença. Outra razão para sua utilização é o fato da função logística adquirir forma de S. Tal formato, em um caso epidemiológico, pode ser visto como a representação de um índice que combina a contribuição de diversos fatores de risco, constituindo a probabilidade de 
risco de um indivíduo dados os valores das covariáveis. Logo, a forma de $\mathrm{S}$ da função indica que o efeito das covariáveis no risco de um indivíduo é mínimo (próximo de zero) até certo valor do índice. Então, o risco aumenta rapidamente em uma determinada escala de valores intermediários do índice, e depois se mantém extremamente alto (próximo de um) uma vez que o índice cresça suficientemente (MORETTIN; BUSSAB, 2005). 
4 RESULTADOS E DISCUSSÃO 
O estudo foi desenvolvido com uma amostra de 30 pacientes, que se enquadravam nos critérios de inclusão para a pesquisa e concordaram em participar assinando o TCLE.

Durante a coleta, outros 8 pacientes que atendiam aos critérios de inclusão foram convidados a participar, porém após o convite e a explicação dos objetivos da pesquisa se recusaram. Um outro paciente que aceitou participar e que atendia a todos os critérios foi excluído, por ter sido transferido para outro hospital.

Dos 30 pacientes, 23 estavam internados inicialmente na UE-HCFMRP/USP e foram abordados neste local, para participarem da pesquisa e os outros 7 já se encontravam no HCFMRP/USP - Campus, na admissão. Contudo 4 pacientes admitidos na UE-HCFMRP/USP, foram posteriormente transferidos para o HCFMRP/USP - Campus onde permaneceram até a alta.

\subsection{Caracterização sócio-demográfica e clínica dos pacientes}

Na Tabela 1 são apresentados os dados referentes à caracterização sóciodemográfica dos pacientes participantes da pesquisa. 
Tabela 1. Distribuição dos pacientes segundo variáveis sócio - demográficas. Ribeirão Preto, SP, 2007 (n = 30)

\begin{tabular}{|c|c|c|}
\hline Variáveis & f & $\%$ \\
\hline \multicolumn{3}{|l|}{$\underline{\text { Sexo }}$} \\
\hline Feminino & 16 & 53,3 \\
\hline Masculino & 14 & 46,7 \\
\hline \multicolumn{3}{|l|}{ Faixa Etária } \\
\hline $30-60$ & 13 & 43,3 \\
\hline $61-90$ & 17 & 56,7 \\
\hline \multicolumn{3}{|l|}{ Cor } \\
\hline Branca & 23 & 76,7 \\
\hline Parda & 3 & 10,0 \\
\hline Amarela & 2 & 6,7 \\
\hline Negra & 2 & 6,7 \\
\hline \multicolumn{3}{|l|}{ Alfabetizado } \\
\hline Sim & 18 & 60,0 \\
\hline Não & 12 & 40,0 \\
\hline \multicolumn{3}{|l|}{ Procedência } \\
\hline Residência & 29 & 96,7 \\
\hline Instituição de Longa Permanência & 1 & 3,3 \\
\hline \multicolumn{3}{|l|}{ Cidade de Procedência } \\
\hline Ribeirão Preto & 14 & 46,7 \\
\hline Região de Ribeirão Preto (DRS XVIII) & 11 & 36,7 \\
\hline Outras DRS & 5 & 16,7 \\
\hline \multicolumn{3}{|l|}{ Ocupação } \\
\hline Aposentado & 10 & 33,3 \\
\hline Do lar & 9 & 30,0 \\
\hline Desempregado & 1 & 3,3 \\
\hline $\begin{array}{l}\text { Trabalhadores dos serviços, vendedores do comércio em lojas e mercados } \\
\text { (Comerciante Varejista, Caminhoneiro Autônomo, Doméstica, Manicure, } \\
\text { Padeiro/Confeiteiro, Pedreiro, Movimentador de Mercadorias) }\end{array}$ & 8 & 26,7 \\
\hline $\begin{array}{l}\text { Trabalhadores agropecuários, florestais, da caça e pesca (Diarista da } \\
\text { agricultura) }\end{array}$ & 1 & 3,3 \\
\hline Trabalhadores de manutenção e reparação (Supervisor de Manutenção) & 1 & 3,3 \\
\hline
\end{tabular}


Identificou-se que $53,3 \%$ dos pacientes eram do sexo feminino. A idade dos pacientes variou de 30 a 90 anos com média de 68,3 anos (DP 17,06), e a faixa etária predominante foi de indivíduos acima de 60 anos (56,7\%) caracterizando uma população em sua maioria de idosos. Em estudos internacionais como o de Endres et al, (2006) na Alemanha foram observados os casos de admissão de pacientes com fratura de fêmur, independente da idade, em hospitais de todas as regiões do país na área urbana e rural, a média de idade dos pacientes foi 77,5 anos.

Já no Brasil, nos estudos epidemiológicos com pacientes com fratura de quadril, a média de idade foi também de 77,5 anos no Nordeste brasileiro, na região Sudeste (Botucatu, SP) a média de idade foi de 70,5 anos e na Região Sul (Londrina) 78,64 anos (SILVEIRA et al, 2005; PEREIRA et al, 1993; MUNIZ et al, 2007). No estudo de Fabrício, Rodrigues e Costa Júnior (2004) com idosos que sofreram quedas e foram hospitalizados, $66 \%$ eram mulheres com idade média de 76 anos.

Observou-se uma predominância de sujeitos de cor branca $(76,7 \%)$ e $60 \%$ eram alfabetizados. Quanto ao local de procedência, $96,7 \%$ veio da própria residência, local onde também ocorreu o acidente ou evento que resultou na Fratura de Fêmur. Quanto à cidade de procedência, 46,7\% eram de Ribeirão Preto, 36,7\% de municípios pertencentes ao Departamento Regional de Saúde de Ribeirão Preto (DRS) e o restante de outras cidades do Estado de São Paulo.

Quanto à ocupação, por se tratar de uma população na maioria de idosos, $33,4 \%$ eram de aposentados, $30 \%$ eram do lar e o restante se dividiu em ocupações como, por exemplo, comerciante, caminhoneiro, entre outras. A distribuição foi segundo a Classificação Brasileira de Ocupações (MINISTÉRIO DO TRABALHO E EMPREGO, 2002). 
Este perfil de distribuição em relação à ocupação também foi identificado no estudo epidemiológico de Rocha et al, (2001), em pacientes com fraturas do fêmur atendidos em Hospital Escola do Triângulo Mineiro, no qual se concentravam os pacientes que eram aposentados ou do lar, por se tratar de uma população com variação de idade entre 60 a 102 anos.

Na Tabela 2, são apresentados os dados referentes às variáveis clínicas. 
Tabela 2. Distribuição dos pacientes segundo variáveis clínicas. Ribeirão Preto, SP, $2007(n=30)$

\begin{tabular}{|c|c|c|}
\hline Variáveis & $f$ & $\%$ \\
\hline \multicolumn{3}{|l|}{ Local de Internação } \\
\hline Unidade de Emergência - EU & 24 & 80,0 \\
\hline Hospital das Clínicas - Campus & 6 & 20,0 \\
\hline \multicolumn{3}{|l|}{ Tempo de Internacão em Dias } \\
\hline $3-5$ & 10 & 33,3 \\
\hline $6-10$ & 10 & 33,3 \\
\hline $11-20$ & 4 & 13,3 \\
\hline $21-30$ & 3 & 3,3 \\
\hline$>31$ & 3 & 3,3 \\
\hline \multicolumn{3}{|l|}{ Causa da Fratura } \\
\hline Queda da Própria Altura & 18 & 60,0 \\
\hline Acidente Automobilístico & 3 & 10,0 \\
\hline Fratura Espontânea & 3 & 10,0 \\
\hline Queda de Altura Superior a própria Altura & 3 & 10,0 \\
\hline Acidente Motociclístico & 1 & 3,3 \\
\hline Atropelamento & 1 & 3,3 \\
\hline Trauma por Objeto & 1 & 3,3 \\
\hline \multicolumn{3}{|l|}{ Localização da Fratura } \\
\hline \multicolumn{3}{|l|}{ Fratura de Quadril } \\
\hline Fratura de Acetábulo & 3 & 10,0 \\
\hline Fratura de Colo Femoral & 13 & 40,1 \\
\hline Fratura Transtrocanteriana & 10 & 43,4 \\
\hline Fratura Subtrocanteriana & 1 & 3,3 \\
\hline \multicolumn{3}{|l|}{ Fratura do Fêmur } \\
\hline Fratura Diafisária de Fêmur & 1 & 3,3 \\
\hline Fratura de Fêmur Distal & 1 & 3,3 \\
\hline \multicolumn{3}{|l|}{ Fratura de Quadril e Fêmur } \\
\hline Fratura de acetábulo + cabeça femoral & 1 & 3,3 \\
\hline \multicolumn{3}{|l|}{$\underline{\text { Tipo de Tratamento }}$} \\
\hline Cirúrgico & 28 & 93,3 \\
\hline Osteossíntese & 19 & 63,3 \\
\hline Prótese Total de Quadril & 4 & 13,3 \\
\hline Osteossíntese + Placa de Reconstrução & 2 & 6,7 \\
\hline Prótese Bipolar de Quadril & 2 & 6,7 \\
\hline Endoprótese de Quadril & 1 & 3,3 \\
\hline Tratamento conservador & 2 & 6,7 \\
\hline \multicolumn{3}{|l|}{ Tempo Total de Cirurgia (horas) } \\
\hline $1-4$ & 16 & 57,2 \\
\hline$>4$ & 12 & 42,8 \\
\hline \multicolumn{3}{|l|}{ Uso de Tração no Pré-Operatório } \\
\hline $\operatorname{Sim}$ & 10 & 35,7 \\
\hline Não & 18 & 64,3 \\
\hline \multicolumn{3}{|l|}{ Tipo de Tração Utilizada } \\
\hline Tração Esquelética & 6 & 60,0 \\
\hline Tração Percutânea & 4 & 40,0 \\
\hline
\end{tabular}


O preconizado pelo SUS é que o acesso dos usuários aos serviços de saúde, deve ser realizado, preferencialmente, a partir das unidades de atenção básica (Unidades Básicas de Saúde e Unidades de Saúde da Família), e quando necessário realizar a referência para outros níveis, de acordo com as necessidades de recursos humanos e tecnológicos destinadas ao tipo de problema ou patologia apresentada pelo paciente que procurou a rede (SANTOS; et al, 2003).

Nota-se que $80 \%$, das internações ocorreram na Unidade de Emergência por se tratar de um dos Serviços de Referência para as Unidades Básicas e Distritais da Cidade de Ribeirão Preto e Região.

Quanto aos outros diagnósticos médicos presentes na admissão, além da fratura de fêmur ou quadril, a maioria era referente a doenças crônicas, relacionadas ao Sistema Cardiocirculatório $(53,3 \%)$, seguido de Doenças do Sistema Nervoso $(26,6 \%)$ e outras patologias como Câncer (13,3\%) e Diabetes Mellitus (13,3\%). Quanto ao número de patologias presentes no momento da admissão observou-se que $59,9 \%$ tinham 2 patologias, com a média de 1,5 patologias por paciente.

Resultado semelhante também foi encontrado por Souza et al, 2007, em um estudo retrospectivo por análise de prontuários em um Hospital Escola na cidade do Rio de Janeiro onde foi encontrada a média de 1,9 patologias por paciente e sendo que $70 \%$ apresentaram até 2 comorbidades; desta forma o número de patologias não influenciou no resultado final referente à mortalidade do paciente e sim a gravidade da patologia pelo Índice de Comorbidade de Charlson (ICC), o qual atribui um risco de morte ao paciente, de acordo com os diagnósticos secundários. $\mathrm{O}$ número elevado de patologias associadas tem sua relação com a própria característica da população estudada, a maioria de idosos. 
O tempo médio de internações foi de 14,20 dias (DP 15,66) com o mínimo de 3 e máximo de 62 dias, sendo que $66,7 \%$ da população ficou internada por 6 ou mais dias. Muitos estudos evidenciam que o tempo de internação varia de acordo com a evolução do paciente, principalmente no pós-operatório da fratura de quadril, em conseqüência das possíveis complicações. No estudo já citado, realizado na cidade de Uberaba, com pacientes com o diagnóstico de fraturas do fêmur proximal, a média de internação foi de 10 dias, com alterações de acordo com a presença ou não de intercorrências clínicas (ROCHA; et al, 2001). No estudo epidemiológico de Pereira et al, (1993) sobre o perfil de pacientes com fratura de fêmur na cidade de Botucatu, o tempo de internação foi de 15,69 dias, próximo ao que foi encontrado em nosso estudo.

Quanto ao tipo de saída hospitalar, 93,3\% deu-se como alta médica e 6,7\% por óbito.

Quanto à causa da Fratura, $60 \%$ dos pacientes haviam sofrido queda da própria altura. Em outros estudos também realizados no Brasil, a queda foi citada como a principal causa das fraturas, sendo responsável por $73,53 \%$ dos casos no estudo de ROCHA et al, 2001; e por $78,16 \%$ dos casos no estudo de MUNIZ et al, (2007). Em nosso estudo esta causa pode estar relacionada às próprias condições de idade da amostra, que na sua maioria eram pessoas idosas com maior chance de sofrer quedas.

A maioria das fraturas estava localizada na região de Colo Femoral $(40,0 \%)$ e na região transtrocanteriana do fêmur (33,0\%). Estes locais são regiões freqüentes para fraturas em idosos, que tiveram como causa pequenos traumas, como queda da própria altura (KÖBERLE; CHRISTIAN; TAKATA, 1998). 
Os resultados encontrados são confirmados na literatura, no estudo retrospectivo de Muniz, et al; (2007) que na análise dos prontuários de 89 indivíduos em um Hospital Escola no Paraná encontraram uma prevalência de $58,43 \%$ de fraturas transtrocanterianas e $38,20 \%$ de fraturas do colo de fêmur. O tipo de tratamento mais freqüente foi o cirúrgico em $93,3 \%$ dos casos e a osteossíntese foi o tipo de cirurgia predominante em $63,7 \%$. Na literatura há um consenso de que as fraturas da região intertrocanteriana do fêmur devam ser fixadas cirurgicamente através de cirurgia de osteossíntese (LIMA; et al, 2003).

O manejo da cirurgia ainda é muito inespecífico, particularmente os procedimentos para fraturas do colo femoral. O uso de parafuso, placas é considerado padrão nos cuidados em fraturas intertrocantéricas ou extracapsulares. Para as de colo de fêmur ou intracapsulares, o tipo de tratamento dependerá do paciente, em relação à idade, nível de atividade, estado de saúde. Poucos estudos têm analisado o tratamento conservador, porque o tratamento cirúrgico é considerado superior se os doentes forem aptos para realizar (BEAUPRE; et al, 2005).

O tempo médio desde a data de admissão até a data de cirurgia foi de 2,92 dias. Em relação ao tempo total de cirurgia, para $57,2 \%$ da amostra, foi entre 2 a 4 horas e o restante acima de 4 horas (42,8\%), sendo o tempo mais curto para os procedimentos de osteossíntese e o mais longos para os de prótese total de quadril. Esta relação também foi observada em outros estudos, como o realizado na cidade de São Paulo, que avaliou 46 pacientes submetidos à cirurgia de prótese total de quadril onde o tempo de cirurgia variou entre meia hora a 5 horas, com tempo médio de 2 horas e meia (LIMA; BARONE, 2001). 
O uso de tração no período pré-operatório, ocorreu em $35,7 \%$ dos casos observados, sendo a tração esquelética realizada para $60 \%$ dos casos e a tração percutânea em 40\%. A maioria das ocorrências a foi de fraturas de colo femoral, cujo tratamento preconizado é que se faça a intervenção cirúrgica o mais precoce possível, pois se sabe que o uso de tração pode resultar em complicações como, por exemplo: encurtamento do membro afetado, rigidez do joelho, desvio rotacional do membro, além disto, o uso de tração esquelética pode propiciar um aumento no tempo de internação, acarretando em maiores custos para o sistema, pois aumentam as chances de complicações pulmonares entre outras (KÖBERLE; CHRISTIAN; TAKATA, 1998, FERNANDES; JORGE; REIS, 1998).

A prática do uso de tração no período pré-operatório é destinada em alguns casos para diminuir a dor neste período. No entanto alguns estudos relataram que não existe benefício nesta prática. Foram evidenciados que não houve diferenças na dor, com ou sem tração, além disto, o uso de analgésico aumentou com o uso da tração e não melhorou na redução da fratura (BEAUPRE; et al, 2005). 
Tabela 3. Distribuição dos pacientes segundo tipo de anestesia, tempo de permanência na Sala de Recuperação, presença e tipo de complicações no período pós-operatório imediato. Ribeirão Preto, SP, $2007(n=28)$

\begin{tabular}{|c|c|c|}
\hline Variáveis & f & $\%$ \\
\hline \multicolumn{3}{|l|}{ Tipo de Anestesia } \\
\hline Raquianestesia & 19 & 67,8 \\
\hline Geral & 7 & 25,0 \\
\hline Bloqueio & 2 & 7,2 \\
\hline \multicolumn{3}{|c|}{ Tempo Total de Permanência na Sala de Recuperação (horas) } \\
\hline $2-4$ & 13 & 46,4 \\
\hline $5-10$ & 9 & 32,2 \\
\hline $11-10$ & 6 & 21,4 \\
\hline \multicolumn{3}{|l|}{ Complicações no Pré-Operatório } \\
\hline Sim & 6 & 21,4 \\
\hline Não & 22 & 78,6 \\
\hline \multicolumn{3}{|l|}{ Tipos de Complicações no Pré-Operatório Imediato } \\
\hline Choque Hipovolêmico & 2 & 33,3 \\
\hline Confusão e Agitação & 4 & 66,7 \\
\hline
\end{tabular}


O tipo de anestesia mais freqüente foi a Raquianestesia, em $67,8 \%$ dos casos. A anestesia Regional, quando comparada com a anestesia geral, foi identificada em alguns estudos como associada à redução da incidência de mortalidade em $30 \%$ dos casos de pacientes submetidos à cirurgia de correção de fratura de fêmur e artroplastia total. Cita-se que está associada à diminuição das chances de desenvolvimento de trombose venosa profunda, embolismo pulmonar, pneumonia, depressão respiratória, infarto agudo do miocárdio, insuficiência renal e necessidade de transfusão sangüínea, tornando-se assim o tipo de anestesia mais recomendável para estes tipos de pacientes (IMBELONI; BEATO, 2002). O uso de anestesia geral em idosos também tem sido associado com aumento de delirium no pós-operatório.

Delirium é definido como um transtorno mental agudo de início com um curso flutuante, caracterizado por distúrbios na consciência, atenção, orientação, memória, Pensamento, de percepção e de comportamento. É reconhecido que delirium em pacientes mais idosos está associado a inúmeras complicações que incluem declínio cognitivo e funcional, bem como aumento da morbidade e mortalidade, além disto, também foi identificado um risco maior para o desenvolvimento de UP, quedas e pneumonia (VOYER, et al, 2008). É considerada a complicação mais freqüente entre os idosos hospitalizados, especialmente entre aqueles que sofrem cirurgias ortopédicas (FURLANETTO; GARCEZ-LEME, 2006).

O recomendado pelos estudos já realizados é o uso de anestesia regional ao invés da geral; para diminuir as chances destas complicações (BEAUPRE; et al, 2005).

Em nosso estudo, $21,4 \%$ dos pacientes submetidos ao tratamento cirúrgico, apresentaram alguma complicação no pós-operatório sendo mais freqüente $(66,7 \%)$ 
a confusão e agitação. Alguns estudos mostram que pacientes com fratura de fêmur e com alteração cognitiva, têm mais chances de desenvolver complicações em relação aos que não apresentam este quadro (SÖDERQVIST; PONZER; TIDERMARK, 2007). A hospitalização súbita após a fratura de quadril é um dos principais fatores etiológicos apresentados para o desenvolvimento de delirium em idosos com fratura de quadril. O confinamento obrigatório na cama, o uso de analgésicos além de outros fatores, proporcionam alterações no nível de consciência, atenção, mudanças no padrão cognitivo, caracterizando o quadro de delirium (MILISEN et al, 2001).

Em relação ao tempo total de permanência na Sala de Recuperação PósAnestésica (SRPA), em 53,6\% dos casos foi superior a 4 horas, o que contradiz com o tempo menor que é esperado para a recuperação após a anestesia regional. Identificou-se pela observação em relação às condições de transferência dos pacientes da SRPA para a Unidade de Internação, onde acontecia uma demora para liberação da vaga do leito, pois na maioria dos casos, o paciente era direcionado da Sala de Urgência para o Centro Cirúrgico, conforme foi observado durante a coleta de dados, nos prontuários e entrevistas.

Os resultados da avaliação de risco para UP nos diferentes momentos do estudo utilizando a escala de Braden são apresentados na Tabela 4. 
Tabela 4. Distribuição dos pacientes segundo avaliação de risco para UP por meio da Escala de Braden, nos três momentos de Avaliação. Ribeirão Preto, SP, $2007(n=30)$

\begin{tabular}{|c|c|c|c|c|c|c|}
\hline \multirow[t]{2}{*}{ Nível de risco } & \multicolumn{2}{|c|}{ Admissão } & \multicolumn{2}{|c|}{$1^{\circ} \mathrm{PO} / 5^{\circ} \mathrm{DI}$} & \multicolumn{2}{|c|}{ Alta } \\
\hline & $f$ & $\%$ & $\mathbf{f}$ & $\%$ & $f$ & $\%$ \\
\hline 9 & 2 & 6,7 & 1 & 3,3 & 2 & 6,7 \\
\hline $10-12$ & 14 & 46,6 & 11 & 36,7 & 6 & 20,0 \\
\hline $13-14$ & 6 & 20,0 & 6 & 20,0 & 4 & \\
\hline $15-16$ & 6 & 20,0 & 7 & 23,3 & 6 & 20,0 \\
\hline $17-18$ & 2 & 6,7 & 5 & 16,7 & 6 & 20,0 \\
\hline $19-20$ & - & - & - & - & 5 & 16,7 \\
\hline$\geq 21$ & - & - & - & - & 1 & 3,3 \\
\hline Total & 30 & 100 & 30 & 100 & 30 & 100 \\
\hline
\end{tabular}

Encontrou-se que a maior parte dos pacientes tinha risco para UP nos três momentos de avaliação. Na admissão, o escore médio da Escala de Braden foi de 12,66 (DP: 2,52) (risco elevado), no segundo momento ( $1^{\circ} \mathrm{PO} / 5^{\circ} \mathrm{DI}$ ) foi 13,73 (DP: 3,10 ) (risco moderado) e no terceiro momento correspondente a saída por alta ou óbito foram 15,03 (DP: 3,83) (em risco). Provavelmente relacionado ao estado de imobilidade muito presente nos três momentos pelas condições clínicas destes pacientes. A subescala de imobilidade foi a que menos teve modificações no sentido de melhora do subescore médio.

Os valores médios encontrados nas subescalas nos diferentes momentos de avaliação são apresentados na Tabela 5. 
Tabela 5. Distribuição dos pacientes segundo os subescores médios da escala de Braden nos três momentos de avaliação. Ribeirão Preto, SP, 2007 ( $n=30)$

\begin{tabular}{|c|c|c|c|}
\hline Subescala & $\begin{array}{l}\text { Admissão } \\
\text { Escore médio }\end{array}$ & $\begin{array}{l}1^{\circ} \mathrm{PO} / 5^{\circ} \mathrm{DI} \\
\text { Escore médio }\end{array}$ & $\begin{array}{c}\text { Alta } \\
\text { Escore médio }\end{array}$ \\
\hline Percepção sensorial & 3,26 & 3,33 & 3,33 \\
\hline Umidade & 3,1 & 3,1 & 3,2 \\
\hline Atividade & 1,13 & 1,53 & 1,83 \\
\hline Mobilidade & 1,53 & 1,9 & 2,3 \\
\hline Nutrição & 2,15 & 2,15 & 2,56 \\
\hline Fricção / Cisalhamento & 1,3 & 1,56 & 1,76 \\
\hline
\end{tabular}

Os resultados da avaliação do risco do indivíduo para UP por meio da escala de Braden, permitem identificar os fatores ou condições que os colocam em risco de forma que medidas de prevenção sejam utilizadas. O escore médio (3) obtido na subescala Percepção sensorial, indica que o individuo está com a capacidade levemente limitada e nem sempre é capaz de comunicar o desconforto ou a necessidade de ser mudado de posição assim depende dos profissionais para esta atividade.

Quanto à condição de umidade da pele, o escore 3 significa que a pele fica ocasionalmente molhada, o que pode requerer uma troca extra de roupa de cama por dia.

Quanto ao grau de atividade física os subescores 1 e 2 implica que a capacidade de andar está gravemente limitada ou inexistente estando confinado ao leito ou a cadeira. Quanto à mobilidade, os escores 1 e 2 indicam que a capacidade de mudar e controlar a posição do corpo para aliviar as pressões nas proeminências ósseas está totalmente limitada ou bastante limitada e necessita de ajuda dos profissionais para mudanças de decúbito. Na subescala nutrição que avalia o padrão usual de consumo alimentar o escore 2 indica que a ingestão provavelmente está 
inadequada adequada. No terceiro momento de avaliação o escore mais próximo de 3 indica uma melhora no padrão dos pacientes avaliados.

A subescala fricção e cisalhamento avalia se existe o problema ou o potencial em decorrência da movimentação, espasticidade, contratura ou agitação. Os subescores médios obtidos indicam que os indivíduos estudados no momento da internação requeriam assistência moderada ou máxima para a movimentação (escore 1) e que no momento da alta continuavam com potencial para apresentarem problema, portanto necessitando de assistência para evitar a UP.

A avaliação do estado mental é outro dado importante que é coletado pela equipe de enfermagem e que pode auxiliar a identificação do risco do paciente para UP. Na tabela 6 os resultados da avaliação feita nos 3 momentos do estudo são apresentados a seguir.

Tabela 6. Distribuição dos pacientes segundo o estado mental nos três momentos de Avaliação. Ribeirão Preto, SP, $2007(n=30)$

\begin{tabular}{|c|c|c|c|c|c|c|}
\hline \multirow[t]{2}{*}{ Estado mental } & \multicolumn{2}{|c|}{ Admissão } & \multicolumn{2}{|c|}{$1^{\circ} \mathrm{PO} / 5^{\circ} \mathrm{DI}$} & \multicolumn{2}{|c|}{ Alta } \\
\hline & $\mathbf{f}$ & $\%$ & $\mathbf{f}$ & $\%$ & $\mathbf{f}$ & $\%$ \\
\hline Consciente e desorientado & 4 & 13,3 & 8 & 26,7 & 4 & 13,3 \\
\hline Total & 30 & 100 & 30 & 100 & 30 & 100 \\
\hline
\end{tabular}

Identificou-se que nos três momentos a maioria dos pacientes encontrava-se consciente e orientado. Entretanto, na avaliação feita no $1^{\circ} \mathrm{PO}$ ou $5^{\circ} \mathrm{DI}$, alguns pacientes se apresentaram conscientes, contudo desorientados $26,7 \%$, sendo $75 \%$ idosos. Na última avaliação, um paciente que era idoso, encontrava-se inconsciente, por ter evoluído com outras complicações hemodinâmicas, foi internada no Centro de Terapia Intensiva e a seguir foi a óbito. Fernandes (2006) em estudo 
desenvolvido com pacientes hospitalizados em CTI identificou que aqueles com menores escores na escala de Glasgow tinham maior chance de apresentarem UP durante a internação e menores escores na escala de Braden.

Também a avaliação da independência funcional para as AVD (tabela 7) identificou que no primeiro e segundo momentos $50 \%$ dos pacientes estavam dependentes para todas as atividades incluindo o banho, vestir-se, ir ao banheiro e transferência, estando assim com dificuldades de realizar o auto cuidado incluindo a prevenção da UP.

Tabela 7. Distribuição dos pacientes segundo a avaliação da independência funcional pelo índice de Katz. Ribeirão Preto, SP, 2007 ( $n=30)$

\begin{tabular}{|c|c|c|c|c|c|c|}
\hline \multirow[t]{2}{*}{ İndice de Katz } & \multicolumn{2}{|c|}{ Admissão } & \multicolumn{2}{|c|}{$1^{\circ} \mathrm{PO} / 5^{\circ} \mathrm{DI}$} & \multicolumn{2}{|c|}{ Alta } \\
\hline & $\mathbf{f}$ & $\%$ & f & $\%$ & f & $\%$ \\
\hline 3 & - & & - & & 2 & 6,7 \\
\hline 4 & - & & - & & 2 & 6,7 \\
\hline 5 & 8 & 26,7 & 8 & 26,7 & 13 & 43,3 \\
\hline 6 & 7 & 23,3 & 7 & 23,3 & 1 & 3,3 \\
\hline 7 & 15 & 50,0 & 15 & 50,0 & 12 & 40,0 \\
\hline Total & 30 & 100 & 30 & 100 & 30 & 100 \\
\hline
\end{tabular}

O estado de dependência dos pacientes, evidenciados pelas avaliações auxiliadas pela escala de Braden, Katz e do nível de consciência indicam o aumento do risco para o desenvolvimento da UP o que requeria o uso de medidas preventivas básicas preconizadas dentre as quais a mudança de decúbito e o uso de colchão ou colchonete especial, tanto no leito hospitalar quanto na mesa cirúrgica.

Muitos estudos mostram alguns protocolos que devem ser utilizados em pacientes hospitalizados com risco para UP, como por exemplo, utilizar superfícies de alívio, entre elas almofadas, pois diminuem pressão e evitam que haja um atrito 
maior entre as partes do corpo com ela mesma. Além disto, auxiliam a manter o paciente em decúbito lateral, aliviando a pressão sobre as costas (STOELTING; et al, 2007). Assim não só o uso de colchões pode servir como dispositivo de alívio de pressão, outros almofadas, coxins podem auxiliar também.

Entretanto, durante a internação 23 pacientes faziam uso de leitos com o colchão hospitalar padrão e somente 7 tinham, acima do colchão, o colchonete "caixa de ovos". No atendimento inicial, na Sala de Trauma e durante o período de espera para o encaminhamento dos pacientes para a Unidade de Internação ou para o Centro Cirúrgico, não foi identificada tal medida de prevenção. Durante a cirurgia, somente em um dos prontuários foi localizado o registro de enfermagem do uso de almofada de gel visco-elástico para alívio da pressão enquanto o paciente estava na mesa cirúrgica.

O uso de colchonete "caixa de ovos" pelos pacientes durante a internação foi distribuído da seguinte forma: 6 pacientes faziam uso no momento de avaliação da admissão e estavam na Sala de Emergência. Além destes apenas um paciente na admissão estava em uso de colchão de ar e depois não o usou mais. No segundo momento de coleta quando, os pacientes já se encontravam na enfermaria, mais um começou a fazer uso do colchonete, totalizando 7 pacientes. Na observação na alta, outros 2 pacientes estavam usando este tipo de dispositivo, totalizando 9.

Em uma revisão sistemática da literatura pode-se observar que pacientes com fratura de quadril com necessidade de internação prolongada tiveram incidência reduzida de UP, quando substituíram o uso do colchão de espuma convencional por um colchão de pressão alternada (BEAUPRE; et al; 2005).

Em relação ao registro da mudança de decúbito dos pacientes, nos três momentos avaliados em nenhum dos prontuários foram encontradas anotações de 
enfermagem em relação a este cuidado, mesmo em pacientes que já haviam desenvolvidos a UP. A documentação incompleta em relação ao cuidado de enfermagem também ocorre em outros serviços no Brasil e em outros países. Em um estudo realizado na Suécia, um resultado de destaque foi a deficiência no registro de medidas preventivas por parte da equipe de enfermagem, mesmo após o uso de escalas de avaliação de risco em pacientes com fratura de quadril. O registro de prevenção, só começou a ocorrer após o aparecimento das UP nos pacientes (GUNNINBERG et al, 2000).

No estudo de Fernandes (2006), onde trabalhou com avaliação pré e pósintervenção educativa dos profissionais de enfermagem em CTI quanto à importância no cuidado preventivo de UP, o registro da mudança de decúbito foi observado apenas na avaliação pré-intervenção. A anotação da mudança de decúbito de $2 / 2$ horas foi feita nos prontuários de $13,13 \%$ dos pacientes que desenvolveram UP e em $11,1 \%$ dos que não tiveram UP. Já no momento pósintervenção educativa, não foi observado em nenhum prontuário o registro da mudança de decúbito.

O cuidado de enfermagem é de responsabilidade da equipe de enfermagem, e o registro das evoluções é da competência do Enfermeiro após a avaliação do estado geral do paciente. Neste registro devem constar os problemas novos identificados, um resumo sucinto dos resultados dos cuidados prescritos e os problemas a serem abordados nas 24 horas subseqüentes, segundo a Resolução COFEN No 272/2002 (CONSELHO FEDERAL DE ENFERMAGEM, 2002) assim devem estar registrados não apenas relatos de mudanças de estado de saúde, mas a descrição do cuidado prestado, equipamentos utilizados, tipo de cuidado oferecido previsto em prescrição de enfermagem. Prontuários com informações inconsistentes, 
ou que contradizem as prescrições de qualquer membro da equipe de saúde, ou ainda que não tragam substratos técnico-científicos, são evidências de falta de profissionalismo e de conhecimento por parte da equipe de enfermagem (OGUISSO, 2003).

\subsection{Estudo de Prevalência e Incidência e Evolução das UP}

\subsubsection{Prevalência}

Dos 30 pacientes, identificou-se durante a avaliação na Admissão (momento 1) pelo exame físico, que dois (6,66\%) apresentavam UP e 28 (93,34\%) apresentavam a pele íntegra.

Os dois indivíduos com UP presentes já na admissão eram 2 mulheres, com média de idade de 83 anos (DP = 1,41). Nos dois casos, o tipo de fratura era a de colo femoral. Na avaliação inicial, uma possuía escore de Katz 7, o que significa que era dependente para todas as AVD e a outra obteve escore 6 indicando que era dependente para a atividade de banho, vestir-se, ir ao banheiro, transferência e alimentação. $\mathrm{Na}$ avaliação quanto ao risco para UP pela escala de Braden tinham risco elevado, pois uma obteve o escore 11 e a outra 12.

$\mathrm{Na}$ inspeção da pele identificou-se que uma paciente apresentava hiperemia na região sacral com $1,0 \times 1,5 \mathrm{~cm}$ que não apresentou embranquecimento após a mudança de posição e observação por duas horas (UP em estágio I). No segundo 
momento de coleta de dados ( $1^{\circ} \mathrm{PO}$ ou $\left.5^{\circ} \mathrm{DI}\right)$ a área apresentava perda parcial da espessura dérmica (UP em estágio II) com dimensão 1,5 x 2,5 cm e manteve-se assim até a saída por alta hospitalar. Além desta lesão ainda desenvolveu UP em escápula estágio I, com tecido de epitelização, dimensão $0,5 \times 1,0 \mathrm{~cm}$, identificada no terceiro momento de coleta de dados, por ocasião da alta hospitalar.

A outra paciente, na admissão apresentava hiperemia na região de calcâneo D que não regrediu após o alívio da pressão (UP em estágio I) com dimensão 2,0 x $2,0 \mathrm{~cm}$. Manteve as mesmas dimensões nos outros momentos de avaliação até a saída do hospital.

Nestes casos, esta evolução de nova formação de UP pode ter acontecido além de todo componente extrínseco já descrito anteriormente, ainda tivemos como contribuição o fator idade. A pele da pessoa idosa fica com maior propensão para desenvolver lesões do que a pele do indivíduo jovem. No idoso a derme costuma ser menos espessa, apresentando diminuição do número de células, da vascularização e há um aumento na degeneração das fibras de elastina, ficando assim mais exposta a processos inflamatórios, lacerações e escoriações, associados a estas mudanças fisiológicas (MOI, 2004).

Durante a avaliação nos outros momentos de coleta de dados, foi observado que 8 indivíduos que não tinham UP na admissão a desenvolveram, sendo 5 no segundo momento e 3 no terceiro momento de avaliação. Assim o coeficiente de prevalência considerando os 2 casos antigos e os 8 casos novos foi de 3333.333 , ou seja, para cada 10 mil pessoas (nas mesmas condições que as do estudo), aproximadamente 3333 pessoas terão a UP entre o tempo de Admissão e a Alta. O índice de prevalência foi de 33,33\%. 
Em Londres em 1986, foi publicado um estudo que avaliou 100 pacientes com diagnóstico de lesão ortopédica, sendo em sua maioria com fratura de colo femoral, avaliou como se dava o desenvolvimento de UP em pacientes imobilizados. Quanto à prevalência $11,00 \%$ dos pacientes avaliados tinham UP na admissão (VERLUYSEN, 1986). Este índice foi bem maior em nossos pacientes, apesar de ter havido uma evolução em relação aos equipamentos e métodos de prevenção de UP, a incidência foi maior que neste estudo realizado há mais de vinte anos. Infelizmente foi observado que apesar de toda tecnologia já disponível e do conhecimento que se tem sobre UP os processos de prevenção não estão sendo utilizados de forma eficaz.

\subsubsection{Estudo de Incidência}

Os 8 novos casos de UP que ocorreram após a admissão permitiram obter um Coeficiente de incidência de 2666.666, ou seja, para cada 10 mil pessoas (nas mesmas condições que as do estudo), aproximadamente 2666 pessoas desenvolverão UP entre o tempo de Admissão e Alta. O índice de incidência de UP na internação foi de $26,66 \%$, um índice muito elevado se comparado com outros estudos internacionais.

No estudo de Baumgarten, et al (2003) a incidência encontrada entre os 9400 pacientes com fratura de quadril analisados, foi de $8,8 \%$, durante todo período de internação. Em relação a incidência no estudo de Rademakers et al. (2007) foram analisado 722 pacientes com fratura de quadril, e identificaram que estava diretamente relacionado o tempo de espera até a realização da cirurgia com o 
desenvolvimento de UP. Observaram entre os pacientes que tiveram uma média de espera de até 23,1 horas, uma maior incidência de UP sendo $30 \%$ do total. Enquanto que os pacientes que esperaram em média até 17,5 horas para a cirurgia apenas $19 \%$ desenvolveram UP.

No estudo de Baumgarten et al., (2003), a incidência de UP foi de 8,8\%, sendo que neste estudo a média de dias de internação foi de 13 dias enquanto em nosso estudo a média ficou em torno de 14,2 dias. Os fatores extrínsecos observados que tiveram maior impacto de associação com UP e também chamados de variáveis de confusão foram: espera prolongada para a realização da cirurgia, tempo de permanência na unidade de cuidado intensivo, procedimento cirúrgico com maior duração, restrição física e a anestesia geral. Desta forma a longa espera pelo procedimento cirúrgico ou conservador, em situações de imobilidade completa ou parcial em superfícies rígidas como pranchas e macas faz com que os pacientes com fratura de quadril tenham um risco maior em desenvolver a UP. Embora não seja possível eliminar fatores tais como ter a necessidade de permanecer em Unidade de Cuidados Intensivos ou ter um procedimento cirúrgico longo, é possível desenvolver ações de intervenções que minimizam o risco da UP nos pacientes que experimentam esta situação.

Em nosso estudo entre os pacientes que desenvolveram UP durante a internação, (excluindo os pacientes que já possuíam UP na admissão e os de Tratamento Conservador) e que foram submetidos ao tratamento cirúrgico, os que esperaram mais de $24 \mathrm{~h}$ pela cirurgia, $19,23 \%$ desenvolveram UP enquanto os que esperaram menos de 24 horas, apenas 7,70\% desenvolveram UP em algum período de avaliação. 


\subsubsection{Evolução das úlceras por pressão}

Durante a hospitalização, foram identificadas UP em 10 pacientes. Na tabela 8 é apresentada a distribuição das UP considerando a região anatômica e o momento de avaliação.

Tabela 8. Distribuição dos pacientes segundo o número de UP e sua distribuição por região anatômica na Admissão. $1^{\circ} \mathrm{PO} / 5^{\circ} \mathrm{DI}$ e Alta. Ribeirão Preto, SP, 2007 ( $\left.\mathrm{n}=10\right)$

\begin{tabular}{|c|c|c|c|c|c|c|c|c|}
\hline \multirow[t]{2}{*}{ Região Anatômica } & \multicolumn{2}{|c|}{ Admissão } & \multicolumn{2}{|c|}{$\begin{array}{c}1^{\circ} \mathrm{PO} / 5^{\circ} \\
\mathrm{DI}\end{array}$} & \multicolumn{2}{|c|}{ Alta } & \multicolumn{2}{|c|}{ Total } \\
\hline & $f$ & $\%$ & $f$ & $\%$ & $f$ & $\%$ & $f$ & $\%$ \\
\hline Sacral & 1 & & 3 & & 2 & & 6 & \\
\hline Calcâneo & 1 & & 1 & & 1 & & 3 & \\
\hline Escápula & 0 & 0 & 0 & 0 & 2 & & 2 & \\
\hline Trocânter & 0 & 0 & 1 & & 0 & 0 & 1 & \\
\hline Cotovelo & 0 & 0 & 1 & & 0 & 0 & 1 & \\
\hline Total & 2 & 100 & 6 & 100 & 5 & 100 & 13 & 100 \\
\hline
\end{tabular}

Em relação à localização de maior freqüência para UP, em nosso estudo foram as localizadas em região sacral (42,85\%) seguida de calcâneo $(28,57 \%)$, como também no estudo de Rogenski \& Santos (2005) cujo percentual mais elevado foi para localização sacral $(33,6 \%)$ e calcâneo $(24,6 \%)$.

No estudo de Nogueira, Caliri \& Haas (2006), a região sacra representou $36,9 \%$ dos casos e seguida de calcâneo $17,4 \%$ em pacientes que haviam sofrido lesão traumática da medula espinhal. Isto se deve à própria condição dos pacientes em internação hospitalar, onde a área de maior contato com o leito torna-se a região posterior do corpo e principalmente a região sacral e calcâneo, para pacientes acamados são áreas de apoio para o corpo, durante a movimentação. 
Em relação ao estágio da UP no momento de detecção, quer no momento da admissão até o momento da alta, todas as UP estavam em estágio I, ou seja, todos os pacientes apresentavam região de pele intacta com hiperemia que não embranqueceu após mudança de posição e nova observação.

Tabela 9. Distribuição do Número UP pelo estágio e localização e estágio das UP identificadas nos pacientes durante o momento de detecção. Ribeirão Preto, SP, 2007

\begin{tabular}{ccccc}
\hline Local & \multicolumn{2}{c}{ Estágio } & \multicolumn{2}{c}{ Total } \\
\cline { 2 - 5 } & I & II & f & $\%$ \\
\hline Escápula & 2 & 0 & 2 & 14,28 \\
Cotovelos & 1 & 0 & 1 & 7,15 \\
Sacro & 6 & 0 & 6 & 42,85 \\
Calcâneo & 3 & 0 & 3 & 28,57 \\
Trocânter & 1 & 0 & 1 & 7,15 \\
\hline Total & $\mathbf{1 3}$ & $\mathbf{0}$ & $\mathbf{1 3}$ & $\mathbf{1 0 0}$ \\
\hline
\end{tabular}

No momento de avaliação no dia do $1^{\circ} \mathrm{PO}$ ou $5^{\circ} \mathrm{DI}$, foram identificados 5 pacientes com UP em estágio I. Dois indivíduos apresentaram UP na região sacral em estágio I. Na avaliação de alta, apresentavam-se no mesmo estágio, porém, com alteração na área em um deles de $1 \mathrm{~cm}^{2}$ maior.

Um apresentou UP em calcâneo Direito e Esquerdo com estágio I, que na avaliação de alta continuava presente com as mesmas características e dimensão. Entretanto apresentava também uma outra UP estágio I no momento da alta na região sacral com área de $5 \mathrm{~cm}^{2}$.

Outro individuo teve uma UP, estágio I na região do cotovelo com área de 5,2 $\mathrm{cm}^{2}$ que se manteve na avaliação da alta, porém com regressão em $3,7 \mathrm{~cm}^{2}$ de área. 
E por último em um indivíduo foi identificada uma UP em estágio I na região de trocânter do fêmur em avaliação em $11^{\circ}$ dia de internação (e $7^{\circ} \mathrm{PO}$ ) e evoluiu para estágio II no $19^{\circ} \mathrm{DI}$ tendo sua resolução quando reavaliado no $40^{\circ} \mathrm{DI}$. A alta ocorreu no $62^{\circ} \mathrm{DI}$.

Já no momento de alta ainda foram identificadas mais 3 pacientes com UP. Todas as UP em estágio I com pele intacta com hiperemia que não embranqueceu após mudança de posição e nova observação.

Um teve 2 UP sendo uma na região sacral com área de $4 \mathrm{~cm}^{2}$ e a outra na região da escápula com área de $2 \mathrm{~cm}^{2}$.

Outro teve uma UP na região do sacro, com área de $5 \mathrm{~cm}^{2}$. E um último indivíduo apresentou UP na região de calcâneo, com área de $1,5 \mathrm{~cm}^{2}$.

No momento da Alta, dos 10 pacientes que tiveram UP, 9 ainda apresentavam o problema. Um dos pacientes teve resolução da UP antes de sua alta.

Muitos fatores podem estar associados a este aumento em alguns pacientes desta área de lesão. Um deles pode estar relacionado ao não alívio correto da pressão no local, outro pode ser a falta do dispositivo de alívio. Além disto, existia o fator limitação física devido à fratura, o que pode ter impossibilitado para os pacientes conscientes e orientados realizar sozinhos a mudança de decúbito.

No estudo de Gunninberg et al (1999), foram avaliados pacientes com Fratura de quadril, e no momento da alta foi observado que as localizações mais comuns para UP foram as regiões: sacral $28 \%$, ísquio $32 \%$ e em calcâneos $19 \%$. Enfatizam que a prevenção de UP deve ser iniciada desde o transporte do paciente até o hospital, durante a admissão e em toda período de internação. 


\subsection{Relação entre a presença de UP e variáveis demográficas e clínicas}

Dos 28 pacientes estudados, 13 tinham menos que 60 anos e desses, 5 $(38,46 \%)$ tiveram UP. Dos 15 que tinham mais do que 60 anos, 3(20\%) tiveram UP. A idade média dos pacientes que tiveram UP foi de 62,35 anos (DP 16,49) e quando comparada com a média de idade da amostra 68,3 (DP: 17,06) evidencia-se que essas são muito próximas. Quanto ao sexo, a UP ocorreu em 2 homens e em 5 mulheres, e com maior freqüência nos de cor branca (23\%) que eram a maioria $(76,6 \%)$ da amostra. Considerando o uso da tração no período pré-operatório a UP ocorreu em 2 dos 10 com tração e em 5 dos 18 sem tração.

Em relação ao tempo total de cirurgia, para os pacientes com UP a média foi 4,40 (DP: 1,4) e sem UP foi 3,92 (DP: 1,37). Nos 16 pacientes em que o tempo foi igual ou menor do que 4 horas a UP ocorreu em $5(31,25 \%)$ e nos 12 pacientes em que o tempo foi maior do que 4 horas a UP ocorreu em 3 (25\%). Quanto ao tempo de internação para os que tiveram UP a média foi 24,37 (DP: 22,07) dias e para os sem UP a média foi de 10,25 (DP: 11,53) dias.

No estudo de Baumgarten et al (2003), pacientes que tiveram a cirurgia de correção da fratura de quadril, com tempo maior que duas horas, tiveram mais UP do que os pacientes com menos de horas de tempo total de cirurgia.

Quanto ao estado mental dos pacientes nos três momentos de avaliação e a presença de UP na internação identificou-se que na Admissão dos pacientes que desenvolveram UP, havia 8 pacientes conscientes e orientados e 2 conscientes e desorientados, sendo um deles com UP na Admissão. No segundo momento de avaliação, $1^{\circ} \mathrm{PO} / 5^{\circ} \mathrm{DI}, 6$ pacientes estavam conscientes e orientados e 4 
conscientes e desorientados. E na avaliação de alta, 7 pacientes conscientes e orientados, 2 conscientes e desorientados e 1 inconsciente.

Dos 20 pacientes que estavam conscientes e orientados em todos os três momentos de avaliação, 4 tiveram UP (20\%). Dos 4 pacientes que estavam conscientes e desorientados no segundo momento de avaliação 2 tiveram UP $(50 \%)$. E no último momento de avaliação um paciente que estava inconsciente e que teve UP, logo em seguida foi a óbito, por complicações hemodinâmicas.

Ainda no estudo de Baumgarten et al (2003), na avaliação de alta, 7,5\% dos pacientes que não estavam com alteração cognitiva, confusos apresentaram UP; enquanto os que estavam com quadro de confusão na alta, $12,5 \%$ apresentaram UP.

$\mathrm{Na}$ tabela 10 é apresentada a distribuição dos pacientes segundo o diagnóstico secundário na admissão e presença/ausência de UP na internação. 
Tabela 10. Distribuição dos pacientes segundo o diagnóstico secundário na Admissão e a presença $I$ ausência de UP durante a internação. Ribeirão Preto, SP, 2007 ( $n=30)$

\begin{tabular}{|c|c|c|c|c|}
\hline \multirow{2}{*}{\multicolumn{2}{|c|}{ Diagnóstico }} & \multirow{2}{*}{$\begin{array}{c}\text { UP } \\
\text { SIM }\end{array}$} & \multirow{2}{*}{$\begin{array}{c}\text { UP } \\
\text { NÃO }\end{array}$} & \multirow[t]{2}{*}{$\overline{\text { TOTAL }}$} \\
\hline & & & & \\
\hline \multicolumn{5}{|l|}{ Alcoolismo } \\
\hline Sim & & 2 & 1 & 3 \\
\hline Não & & 6 & 21 & 27 \\
\hline \multicolumn{5}{|l|}{ Demência } \\
\hline $\operatorname{Sim}$ & & 0 & 2 & 2 \\
\hline Não & & 8 & 20 & 28 \\
\hline \multicolumn{5}{|l|}{ Depressão } \\
\hline Sim & & 2 & 0 & 2 \\
\hline Não & & 6 & 23 & 28 \\
\hline \multicolumn{5}{|c|}{ Diabetes Mellitus } \\
\hline $\operatorname{Sim}$ & & 2 & 2 & 4 \\
\hline Não & & 6 & 20 & 26 \\
\hline \multicolumn{5}{|c|}{ Doença Vascular Periférica } \\
\hline $\operatorname{Sim}$ & & 3 & 6 & 9 \\
\hline Não & & 5 & 16 & 21 \\
\hline \multicolumn{5}{|c|}{ Hipertensão Arterial } \\
\hline $\operatorname{Sim}$ & & 1 & 1 & 2 \\
\hline Não & & 7 & 21 & 28 \\
\hline \multicolumn{5}{|c|}{ Insuficiência Cardiocongestiva } \\
\hline Sim & & 1 & 1 & 2 \\
\hline Não & & 7 & 21 & 28 \\
\hline \multicolumn{5}{|l|}{ Câncer } \\
\hline Sim & & 2 & 2 & 4 \\
\hline Não & & 6 & 20 & 26 \\
\hline \multicolumn{5}{|c|}{ Paralisia Infantil } \\
\hline Sim & & 0 & 2 & 2 \\
\hline Não & & 8 & 20 & 28 \\
\hline \multicolumn{5}{|c|}{ Outras comorbidades } \\
\hline Sim & & 3 & 9 & 12 \\
\hline Não & & 5 & 13 & 18 \\
\hline
\end{tabular}


A análise dos resultados dos testes estatísticos não encontrou evidências da associação entre essas variáveis acima e a presença de UP na hospitalização. Já em outros estudos esta foi uma evidência que mostrou que a presença de alguma comorbidade na admissão é fator fundamental no desenvolvimento de UP. A presença de diabetes e outras duas comorbidades levaram os pacientes com fratura de quadril a ter mais UP do que os outros estudados nas mesmas condições, respectivamente 11,6\% e 13,6\% tiveram a lesão (BAUMGARTEN; et al, 2003).

Tabela 11. Distribuição dos pacientes segundo o IMC e a presença / ausência de UP durante a internação. Ribeirão Preto, SP, $2007(n=30)$

\begin{tabular}{lcccc}
\hline & Índice de Massa Corporal (IMC) & UP & UP & TOTAL \\
& SIM & NÃO \\
\hline$<20$ & 5 & 5 & 10 \\
20 a 24,99 & 2 & 4 & 6 \\
25 a 29,99 & 1 & 9 & 10 \\
$\geq 30$ & 2 & 2 & 4 \\
\hline Total & 8 & 22 & 30 \\
\hline
\end{tabular}

Em relação ao IMC observa-se que $50 \%$ dos pacientes abaixo do peso desenvolveram UP. Diferente do estar com Sobrepeso ou Obesidade, onde apenas 3 pacientes neste grupo desenvolveram UP, representando aproximadamente $21,5 \%$.

Em outros estudos foram observados que os pacientes com menor IMC e com comprovado estado de desnutrição, desenvolveram mais UP que os grupos que não tinham este perfil. No estudo de Hommel et al (2007) o índice de redução de ocorrência de UP entre pacientes com fratura de quadril e um bom estado nutricional foi de 50\%. Já no estudo de Oloffson et al (2007) que avaliou o estado nutricional de idosos com fratura de quadril, viu que a intervenção nutricional pode ser benéfica para os casos de curta permanência no hospital, pois nos casos de longa 
permanência não viu diferenças em melhorar o estado nutricional e o não desenvolvimento de UP, isto foi igual neste grupo de pacientes.

Nas tabelas 6 e 7 são apresentadas as distribuições dos 28 pacientes que internaram sem úlcera considerando a faixa etária, os escores da escala de Braden e a presença/ausência de UP durante a hospitalização, nos dois momentos de avaliação.

Quanto ao risco para UP, o Escore Médio da Escala de Braden na admissão foi de 12,75 , no segundo momento 13,82 e na Alta 14,96 . Para os 8 pacientes que tiveram UP durante a internação o escore na admissão foi 11,5 (DP: 0,71 ), no segundo momento 11,83 (DP: 3,66) e na saída 12,67 (DP: 4,61). Conclui-se que os pacientes com UP estavam com risco elevado para UP nos diferentes momentos de avaliação.

Tabela 12. Distribuição dos pacientes considerando o valor do Escore Total da Escala de Braden, obtido na admissão e a ocorrência de UP na internação. Ribeirão Preto, 2007 (n= 28)

\begin{tabular}{|c|c|c|c|c|c|c|c|c|c|c|c|c|}
\hline \multirow{4}{*}{$\begin{array}{l}\text { Escore } \\
\text { Braden }\end{array}$} & \multicolumn{12}{|c|}{ DISTRIBUIÇÃO } \\
\hline & \multicolumn{5}{|c|}{ Menor de 60 anos } & \multicolumn{5}{|c|}{ Maior de 60 anos } & \multirow[t]{3}{*}{ Total } & \multirow[t]{3}{*}{$\%$} \\
\hline & \multicolumn{2}{|c|}{ S/UP } & \multicolumn{2}{|c|}{ C/UP } & \multirow[t]{2}{*}{ Total } & \multicolumn{2}{|c|}{ S/UP } & \multicolumn{2}{|c|}{ C/UP } & \multirow[t]{2}{*}{ Total } & & \\
\hline & $\mathbf{n}$ & $\%$ & $\mathbf{n}$ & $\%$ & & $\mathbf{n}$ & $\%$ & $\mathbf{n}$ & $\%$ & & & \\
\hline $17-18$ & 1 & 50 & 1 & 50 & 2 & 0 & 0 & 0 & 0 & 0 & 2 & 7,14 \\
\hline $15-16$ & 3 & 75 & 1 & 25 & 4 & 1 & 50 & 1 & 50 & 2 & 6 & 21,43 \\
\hline $13-14$ & 2 & 66 & 1 & 34 & 3 & 2 & 66 & 1 & 34 & 3 & 6 & 21,43 \\
\hline $1-12$ & 2 & 66 & 1 & 34 & 3 & 8 & 88,8 & 1 & 11,12 & 9 & 12 & 42,86 \\
\hline$<o u=9$ & 0 & 0 & 1 & 100 & 1 & 1 & 100 & 0 & 0 & 1 & 2 & 7,14 \\
\hline Total & 8 & 61,54 & 5 & 38,46 & 13 & 12 & 80,0 & 3 & 20,0 & 15 & 28 & 100 \\
\hline
\end{tabular}

Observa-se que 2 pacientes com menos de 60 anos obtiveram escores entre 17 e 18 na avaliação da admissão e um teve UP durante a hospitalização. Já no nível em risco, com escores 15 e 16, pacientes com menos de 60 anos (25\%) tiveram menor freqüência de UP do que os mais idosos (50\%). Entretanto, no próximo nível, a percentagem de UP foi a mesma para as duas faixas etárias com 
um aumento nos níveis seguintes para os idosos. Os fatores intrínsecos para o desenvolvimento de UP, relacionados à tolerância tissular são colocados por alguns autores como: idade, pressão arteriolar e nutrição (COSTA, 2003). Assim ter mais idade, ou ter algum dos componentes que faça algum tipo de alteração na nutrição e na pressão dos tecidos, faz com que o idoso tenha maior propensão de UP que o mais jovem.

Tabela 13. Distribuição dos pacientes considerando o valor do Escore Total da Escala de Braden, obtido em $2^{\circ}$ momento de avaliação e a ocorrência de UP na internação. Ribeirão Preto, SP, $2007(n=28)$

\begin{tabular}{|c|c|c|c|c|c|c|c|c|c|c|c|c|}
\hline \multirow{4}{*}{$\begin{array}{c}\text { VARIÁVEL } \\
\text { Escore Braden }\end{array}$} & \multicolumn{12}{|c|}{ DISTRIBUIÇÃO } \\
\hline & \multicolumn{5}{|c|}{ Menor de 60 anos } & \multicolumn{5}{|c|}{ Maior de 60 anos } & \multirow[t]{3}{*}{ Total } & \multirow[t]{3}{*}{$\%$} \\
\hline & \multicolumn{2}{|c|}{ S/UP } & \multicolumn{2}{|c|}{ C/UP } & \multirow[t]{2}{*}{ Total } & \multicolumn{2}{|c|}{ S/UP } & \multicolumn{2}{|c|}{ C/UP } & \multirow[t]{2}{*}{ Total } & & \\
\hline & $\mathbf{N}$ & $\%$ & $\mathbf{n}$ & $\%$ & & $\mathbf{n}$ & $\%$ & $\mathbf{n}$ & $\%$ & & & \\
\hline $17-18$ & 3 & 100 & 0 & 0 & 3 & 1 & 100 & 0 & 0 & 1 & 4 & 14,29 \\
\hline $15-16$ & 1 & 100 & 0 & 0 & 1 & 6 & 100 & 0 & 0 & 6 & 7 & 25 \\
\hline $13-14$ & 2 & 100 & 0 & 0 & 2 & 3 & 75 & 1 & 25 & 4 & 6 & 21,43 \\
\hline $10-12$ & 2 & 28,57 & 5 & 71,43 & 7 & 2 & 50 & 2 & 50 & 4 & 11 & 39,28 \\
\hline Total & 8 & 61,54 & 5 & 38,46 & 13 & 12 & 80 & 3 & 20 & 15 & 28 & \\
\hline
\end{tabular}

Considerando os escores do segundo momento da avaliação, os pacientes com menos de 60 anos que tiveram UP durante a hospitalização tiveram escores menores ou iguais a 12. Já entre os idosos um paciente com o escore entre 13 e 14 também desenvolveu UP.

Muitos estudos apontam que a população idosa é mais suscetível a desenvolver lesões de pele devido às características causadas pelo envelhecimento dérmico, como ter a diminuição da camada dérmica, da vascularização, da proliferação epidérmica e de propriedades de percepção da dor, resposta inflamatória e a função de barreira estarem diminuídas ou alteradas (BLANES; et al, 2004). 
Os escores obtidos nas subescalas permitem identificar os fatores que podem ter maior influência no desenvolvimento da UP e auxiliam a direcionar a assistência preventiva. Nos gráficos a seguir são apresentados esses resultados nos diferentes momentos de avaliação, em relação aos Subescores da Escala de Braden.

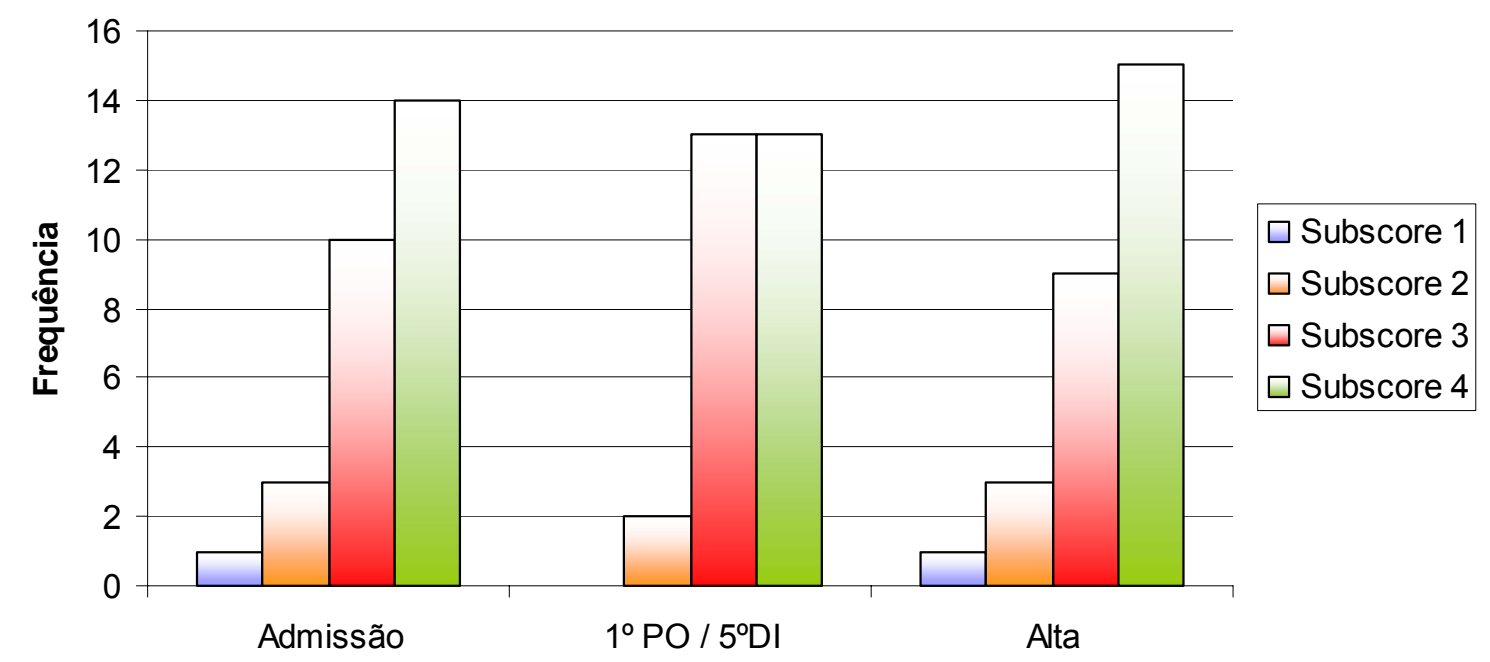

Gráfico 1. Evolução do Subescore percepção sensorial nos três momentos de avaliação do risco para UP dos pacientes com fratura de fêmur. Ribeirão Preto, SP, $2007(n=28)$

Quanto ao subescore Percepção Sensorial na admissão, 50\% (14) dos pacientes da amostra obtiveram subescore 4 implicando que não apresentavam nenhuma limitação na sua capacidade de sentir ou verbalizar a dor ou desconforto, entretanto 3 tinham esta capacidade muito ou totalmente limitada, exigindo cuidados freqüentes para alívio do desconforto relacionado ao excesso de pressão pelo posicionamento no leito. No segundo momento aumenta a freqüência do escore 3 , provavelmente em decorrência de ser para a maior parte dos pacientes o período após a cirurgia e no momento da alta aumenta a freqüência dos que não tem nenhuma limitação desta capacidade. No estudo de Blanes et al (2004) onde a amostra era composta por sua maioria de idosos, e onde foram avaliados pacientes 
de diferentes clínicas que já haviam evoluído com UP, por meio da Escala de Braden, os subescores mais freqüentes para percepção sensorial foram de 1 a 3.

Em nosso estudo para os pacientes que desenvolveram UP, a percepção sensorial estava totalmente preservada em $75 \%$ dos pacientes na admissão. No segundo momento de avaliação este índice diminui para $25 \%$, devido provavelmente aos efeitos da anestesia. E na alta o subescore de maior freqüência é o $3(37,5 \%)$, onde ainda se observa uma restrição na percepção de sensibilidade.

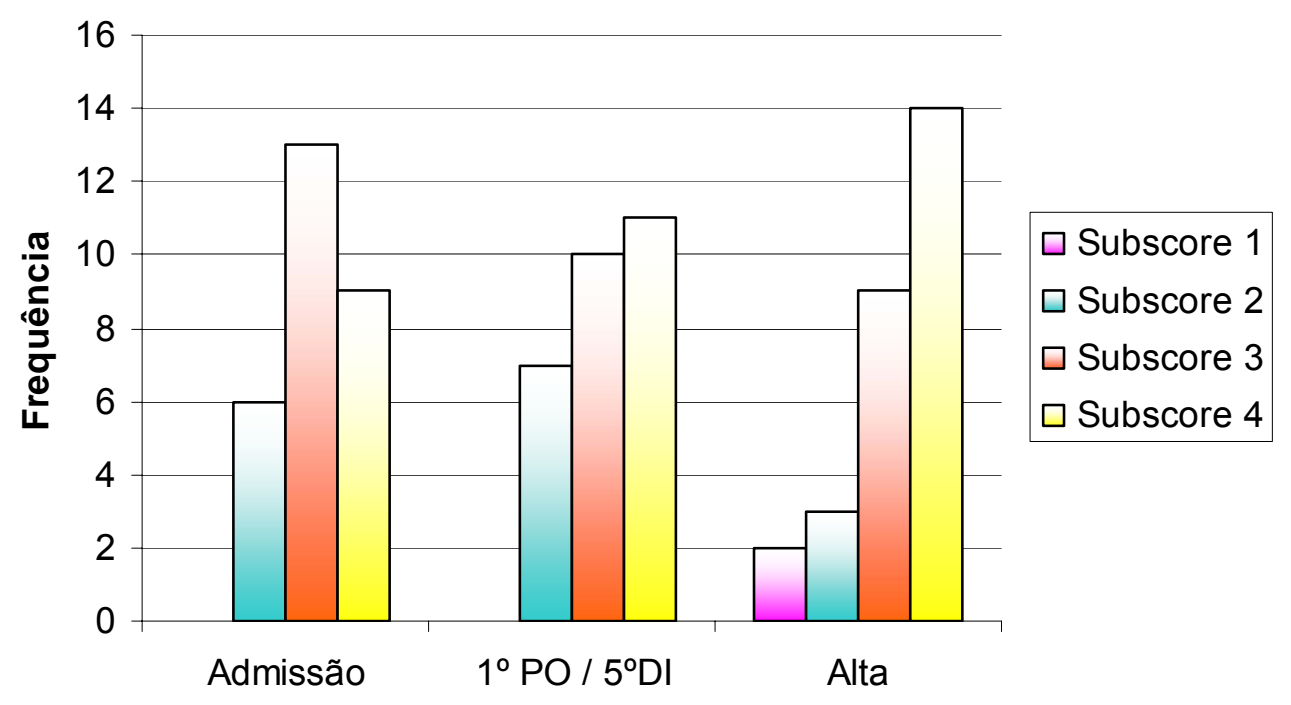

Gráfico 2. Evolução do Subescore Umidade nos três momentos de avaliação do risco para UP dos pacientes com fratura de fêmur. Ribeirão Preto, SP, 2007 ( $n=28)$

Para o subescore Umidade houve uma melhora significativa com a evolução para a alta. Na admissão o escore mais freqüente foi o 3 onde a pele está ocasionalmente úmida, com troca de roupa de cama 1 vez ao dia, nestas condições eram $46,42 \%$. No segundo momento aumenta a freqüência do escore 4 , onde a pele está raramente úmida e a roupa de cama só é trocada nos horários de rotina, isto pode ser devido às condições do paciente, onde a maioria se encontrava em pós- 
operatório, melhorando as condições de posicionamento de uma comadre ou papagaio, pela mobilização estar mais estável do que na situação anterior. E no segundo momento também há um aumento no escore 2 , que significa que a pele está muitas vezes, mas nem sempre úmida, e que a roupa de cama precisa ser trocada ao menos uma vez a cada plantão; o que podemos considerar ser este momento de Pós-Operatório onde alguns pacientes podem estar sofrendo ainda os efeitos da anestesia e terem perdido a sensação e controle dos esfíncteres vesicais e ainda terem a alteração do quadro cognitivo, o que dificulta um maior controle das eliminações.

E na última avaliação de alta há um aumento no escore 4 , o qual pode ser devido à diminuição da restrição ao leito, porém existe o aparecimento do escore 1, onde a pele está constantemente úmida, por suor, urina, a umidade é percebida cada vez que o paciente é movimentado ou posicionado no leito, 2 pacientes se apresentam nestas condições, sendo que um deles neste momento apresentava-se inconsciente.

A umidade da pele em muitos estudos mostrou associação estatisticamente significativa com a presença de UP, principalmente em idosos que apresentavam incontinência urinária (SOUZA; SANTOS, 2007). Em nosso estudo através dos escores pode-se observar a presença de incontinência urinária ocasional entre os pacientes estudados, fator que pode ter levado ao desenvolvimento de UP. Entre os pacientes que desenvolveram UP o fator umidade com subescore de risco entre $1 \mathrm{a}$ 3, na admissão foi de $62,5 \%$, no segundo momento da avaliação representou $87,5 \%$ e na alta este foi de $75 \%$. 


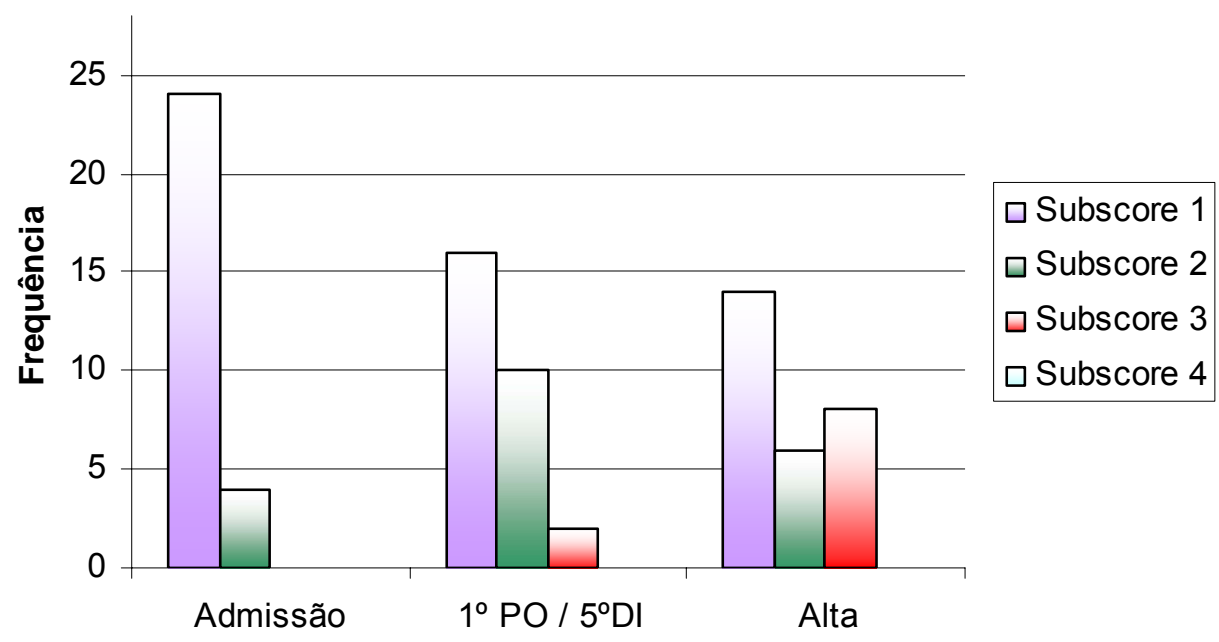

Gráfico 3. Evolução do Subescore Atividade nos três momentos de avaliação do risco para UP dos pacientes com fratura de fêmur. Ribeirão Preto, SP, $2007(n=28)$

Quando analisamos os subescores da Escala de Braden, Atividade há uma evolução bem evidente nos três períodos analisados, na Admissão havia 24 pacientes com subescore 1 , pois estavam em repouso no leito, e os outros 4 com subescore 2, ou seja, tinham a habilidade de caminhar severamente limitada ou inexistente, não agüentavam o próprio peso do corpo e/ou precisavam ser ajudados para sentar-se na cadeira ou cadeira de rodas. No segundo momento, referente ao $1^{\circ} \mathrm{PO}$ ou $5^{\circ} \mathrm{DI}$ quando o paciente já passou pelo procedimento cirúrgico ou está em tratamento conservador o subescore melhora e 10 dos pacientes obtiveram o escore 2, pois embora a capacidade de andar ainda esteja bastante limitada já podem sentar-se na cadeira. Outros 2 que caminham ocasionalmente, tem o subescore 3 . No momento da Alta, 8 pacientes têm o subescore 3, 6 tem o subescore 2 e 14 ainda permanecem acamados (subescore 1), necessitando, portanto de cuidados para prevenir a UP, mesmo após a alta para o domicílio.

Entre os pacientes que desenvolveram UP, 75\% tiveram subescore atividade 1 na admissão, no segundo momento de avaliação o subescore 1 foi identificado em 
$100 \%$ dos pacientes. Já na alta o subescore 1 teve $80 \%$ dos casos e o subescore 2 em $20 \%$, o que leva a afirmar que ausência de atividade em pacientes internados leva a um aumento na chance de desenvolver UP. No estudo de Blanes et al (2004) isto também foi observado em sua amostra, onde a maioria teve subescore de atividade entre 1 e 2 , sua maior concentração, cerca de 98,7\% dos pacientes com UP receberam estes subescores.

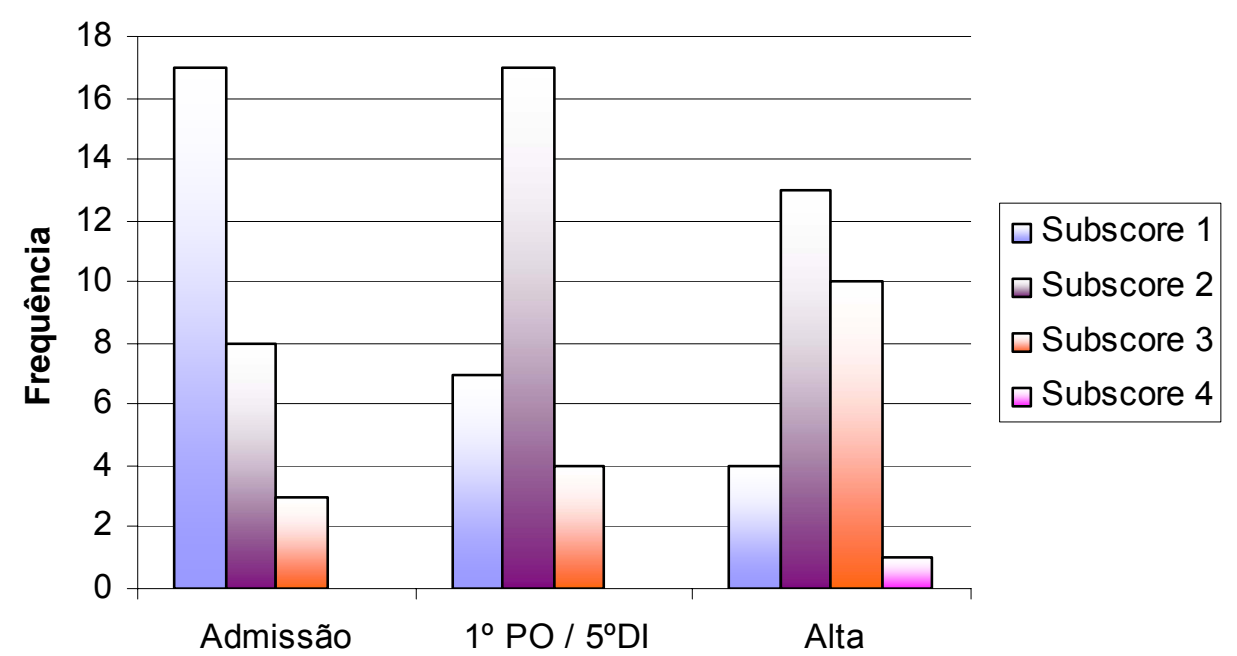

Gráfico 4. Evolução do Subescore Mobilidade nos três momentos de avaliação do risco para UP dos pacientes com fratura de fêmur. Ribeirão Preto, SP, $2007(n=28)$

Quanto à Mobilidade, também houve diferenças nos três momentos de avaliação, na Admissão havia 17 pacientes com subescore 1 indicando que não faziam mudanças no corpo ou extremidades sem ajuda, eram completamente imobilizados; 8 pacientes com subescore 2, eram muito limitados, faziam pequenas mudanças ocasionais na posição do corpo ou em extremidades, porém eram incapazes de realizar mudanças freqüentes ou significativas sem ajuda. E somente 3 pacientes com subescore 3, que eram levemente limitados, faziam mudanças freqüentes embora pequenas na posição do corpo, sem ajuda. No $1^{\circ} \mathrm{PO}$ ou $5^{\circ} \mathrm{DI}$, 
houve diminuição do subescore 1 , apenas 7 pacientes estavam nestas condições, há também um aumento no subescore 2, 17 pacientes e para subescore 3, 4 pacientes. No momento de Alta aparece o subescore $4 \mathrm{em} 1$ paciente, que era bem jovem com 39 anos, este saiu sem nenhuma limitação, fazendo grandes mudanças na posição sem assistência. O subescore 3 aparece em 10 pacientes, o subescore 2 em 13 pacientes e o subescore 1 em 4 pacientes. Em nosso estudo 100\% dos pacientes que evoluíram com UP tiveram seus subescores para mobilidade entre $1 \mathrm{a}$ 3 em todos os momentos.

A ausência de mobilidade no leito é uma das causas principais de UP em pacientes hospitalizados, devendo ser cuidadosamente monitorados no que diz respeito à sua movimentação. O que é preconizado para este tipo de paciente é que seja realizada a mudança de decúbito a cada 2 horas, a fim de evitar o desenvolvimento de UP (WOCN, 2003).

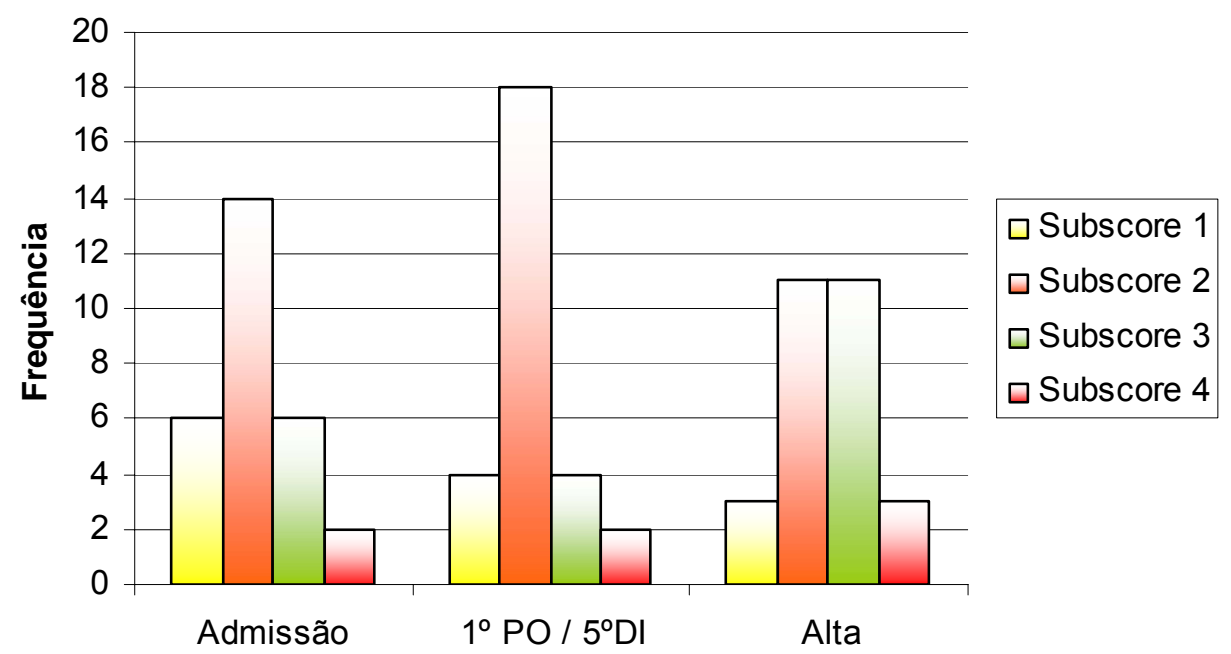

Gráfico 5. Evolução do Subescore de Nutrição nos três momentos de avaliação do risco para UP dos pacientes com fratura de fêmur. Ribeirão Preto, SP, $2007(n=28)$ 
Quanto a Nutrição houve mudanças significativas desde momento de admissão e a alta. Na Admissão 50\% (14) dos pacientes tinham um escore de 2, ou seja, tinham uma nutrição provavelmente inadequada, raramente faziam uma refeição completa e geralmente comiam metade de qualquer alimento oferecido, isto pode ser devido às condições de limitação, ao posicionamento, por estarem a maioria restrita ao leito o que pouco favorecia um ambiente adequado para alimentarem-se. Ainda existiam 6 pacientes com subescore 1, com alimentação muito pobre, que nunca comiam toda a refeição ou estavam em jejum, onde estes já estavam aguardando a cirurgia. Já no segundo momento de avaliação há um aumento do subescore 2 e diminuição no escore 1. E no terceiro momento, há um aumento considerável no escore 3 , onde a nutrição é avaliada como adequada, onde o paciente come mais da metade da maior parte das refeições, e ainda aparecem 3 pacientes com escore de 4, onde a nutrição está excelente, nunca recusa uma refeição e não necessita de suplementação alimentar, o que está diretamente relacionado à própria recuperação da cirurgia ou do trauma.

Entre os pacientes que desenvolveram UP, $87,5 \%$ tiveram o subescore nutrição entre 1 e 3 , na admissão. No $5^{\circ} \mathrm{DI}$ ou $1^{\circ} \mathrm{PO}$ o percentual de pacientes com subescores de risco permaneceu o mesmo. Na alta este subescore teve uma melhora em relação ao subescore 3, aparecendo em 37,5\% destes pacientes.

O estado nutricional inadequado é um fato comum entre a população com fratura de quadril, o que está associado com um aumento na morbidade e mortalidade. Intervenções e avaliações precoces podem reduzir o risco de complicações nestes pacientes. A suplementação de vitaminas e proteínas é recomendada por vários autores, que comprovadamente conseguiram reduzir complicações (BEAUPRE; et al, 2005). 


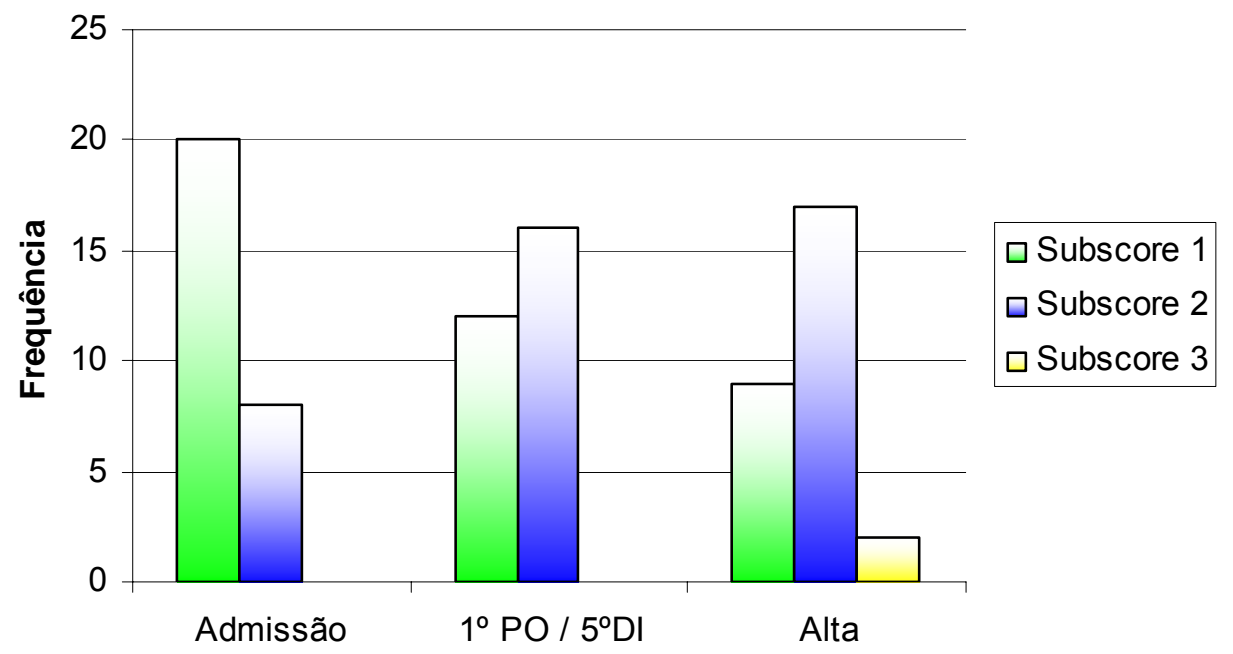

Gráfico 6. Evolução do Subescore Friç̧ão e Cisalhamento nos três momentos de avaliação do risco para UP dos pacientes com fratura de fêmur. Ribeirão Preto, SP, 2007 ( $n=28)$

Em relação ao subescore Fricção e Cisalhamento, existe uma melhora progressiva, mostrando a recuperação do paciente durante a internação. Na Admissão havia $20(72,42 \%)$ pacientes com subescore 1 , onde este é um problema, pois o paciente necessita de assistência máxima para mover-se, sendo impossível levantar-se sem esfregar-se contra os lençóis e 8 com subescore 2, onde existe um potencial problema ao movimentar-se, pois durante $o$ movimento a pele provavelmente esfrega-se em alguma extensão do lençol, cadeiras ou outros equipamentos, e passa a maior parte do tempo relativamente em boa posição, porém de vez em quando escorrega para baixo. No $1^{\circ} \mathrm{PO} / 5^{\circ} \mathrm{DI}$ o subescore 1 diminui para 12 pacientes e o subescore 2 aumenta para 16. E na Alta, o subescore 1 passa a ter apenas 9 pacientes e aparecem 2 pacientes com o subescore 3, onde não existe nenhum problema aparente, o paciente mantém-se o tempo todo em boa posição na cama ou cadeira e movimenta-se de forma independente.

Os pacientes que desenvolveram UP em nosso estudo, na admissão $62,5 \%$ precisavam de assistência máxima para se movimentar. $\mathrm{Na}$ segunda avaliação 
$87,5 \%$ obteve o escore 1 , o que ampliou o número de pacientes com máxima assistência. E na alta o percentual de pacientes com subescore 1 foi igual ao da admissão.

As forças de fricção e cisalhamento são muito comuns em pacientes acamados, que não consegue se movimentar sozinhos e arrastam seu corpo sobre a superfície de apoio ou são arrastados pela equipe de enfermagem, durante o processo de movimentação (COSTA, 2003). Desta forma a recomendação é que se faça a movimentação do paciente utilizando-se dispositivos que evitem a ocorrência destas forças. O uso de lençol móvel, trapézio do quadro balcânico, guindastes ou outros dispositivos associados às técnicas corretas de movimentação, podem diminuir muito a fricção e o cisalhamento nos pacientes acamados (WOCN, 2003).

Tabela 14. Distribuição dos pacientes considerando o Escore de Katz na admissão e a ocorrência de UP na internação. Ribeirão Preto, SP, 2007 ( $n=28)$

\begin{tabular}{|c|c|c|c|c|c|c|c|c|c|c|c|c|}
\hline \multirow{4}{*}{$\begin{array}{c}\text { VARIÁVEL } \\
\text { Escore } \\
\text { Katz }\end{array}$} & \multicolumn{12}{|c|}{ DISTRIBUIÇÃO } \\
\hline & \multicolumn{5}{|c|}{ Menor de 60 anos } & \multicolumn{5}{|c|}{ Maior de 60 anos } & \multirow[t]{3}{*}{ Total } & \multirow[t]{3}{*}{$\%$} \\
\hline & \multicolumn{2}{|c|}{ S/UP } & \multicolumn{2}{|c|}{ C/UP } & \multirow[t]{2}{*}{ Total } & \multicolumn{2}{|c|}{ S/UP } & \multicolumn{2}{|c|}{ C/UP } & \multirow[t]{2}{*}{ Total } & & \\
\hline & $\mathbf{n}$ & $\%$ & $\mathbf{n}$ & $\%$ & & $\mathbf{n}$ & $\%$ & $\mathbf{n}$ & $\%$ & & & \\
\hline 5 & 4 & 66,66 & 2 & 33,34 & 6 & 2 & 100 & 0 & 0 & 2 & 8 & 28,57 \\
\hline 6 & 2 & 66,66 & 1 & 33,34 & 3 & 2 & 66,66 & 1 & 33,34 & 3 & 6 & 21,43 \\
\hline 7 & 3 & 75 & 1 & 25 & 4 & 7 & 70 & 3 & 30 & 10 & 14 & 50 \\
\hline Total & 9 & 69,23 & 4 & 30,77 & 13 & 11 & 78,57 & 4 & 28,57 & 15 & 28 & 100 \\
\hline
\end{tabular}

A avaliação do Estado Funcional pela Escala de Katz no momento da Admissão, identificou que dos 13 pacientes com menos de 60 anos, 4 obtiveram escore 7 (eram dependentes para todas as atividades) e um (25\%) apresentou UP durante a internação pela tabela 14. Dos 15 pacientes com mais de 60 anos, 10 obtiveram o escore 7 e $3(30 \%)$ tiveram UP. Os outros pacientes de ambos os grupos etários obtiveram os escores 5 ou 6 , pois possuíam dependência para pelo menos 4 atividades, podendo se dependentes para o banho, vestir-se, ir ao 
banheiro, transferência e mais uma adicional, como por exemplo, ser não ser continente para as eliminações ou ainda ser dependente para a alimentação, ou seja, necessitar de assistência para as refeições. O que corresponde ao subescores de Braden em relação à mobilidade e atividade em nosso estudo.

No segundo momento de avaliação, observa-se que dos 13 pacientes avaliados, 4 desenvolvem UP e entre estes, metade possuía o escore de 7 , sendo totalmente dependentes para as AVD. Já entre os idosos que eram 15 pacientes, todos que desenvolveram UP tiveram o escore 7 para Katz.

Tabela 15. Distribuição dos pacientes considerando o Escore de Katz em $2^{\circ}$ momento de avaliação e a ocorrência de UP na internação. Ribeirão Preto, SP, 2007 (n = 28)

\begin{tabular}{|c|c|c|c|c|c|c|c|c|c|c|c|c|}
\hline \multirow{4}{*}{$\begin{array}{c}\text { VARIÁVEL } \\
\text { Escore } \\
\text { Katz }\end{array}$} & \multicolumn{12}{|c|}{ DISTRIBUIÇÃO } \\
\hline & \multicolumn{5}{|c|}{ Menor de 60 anos } & \multicolumn{5}{|c|}{ Maior de 60 anos } & \multirow[t]{3}{*}{ Total } & \multirow[t]{3}{*}{$\%$} \\
\hline & \multicolumn{2}{|c|}{ S/UP } & \multicolumn{2}{|c|}{ C/UP } & \multirow[t]{2}{*}{ Total } & \multicolumn{2}{|c|}{ S/UP } & \multicolumn{2}{|c|}{ C/UP } & \multirow[t]{2}{*}{ Total } & & \\
\hline & $\mathbf{n}$ & $\%$ & $\mathbf{n}$ & $\%$ & & $\mathbf{n}$ & $\%$ & $\mathbf{n}$ & $\%$ & & & \\
\hline 5 & 4 & 80,0 & 1 & 20,0 & 5 & 3 & 100,0 & 0 & 0 & 3 & 8 & 28,57 \\
\hline 6 & 2 & 66,6 & 1 & 33,34 & 3 & 3 & 100,0 & 0 & 0 & 3 & 6 & 21,43 \\
\hline 7 & 3 & 60,0 & 2 & 40,0 & 5 & 5 & 55,55 & 4 & 44,45 & 9 & 14 & 50 \\
\hline Total & 9 & 69,23 & 4 & 30,77 & 13 & 11 & 78,57 & 4 & 28,57 & 15 & 28 & 100 \\
\hline
\end{tabular}

No momento da alta, houve uma pequena melhora em relação aos escores, principalmente entre os idosos, pois apenas 4 dos 15 avaliados apresentaram UP $(28,57 \%)$ (tabela 16). Apareceu neste momento de avaliação, dois subescores que não haviam aparecido. Primeiro o escore 4 o que significa estar independente para todas as atividades, exceto banho, vestir-se e mais uma como, por exemplo, transferência; e segundo o escore 3, o que representa ser independente para todas as atividades exceto banho e outra adicional como vestir-se. Em relação aos jovens a maioria possuía escore de 5, mantendo a dependência para as AVD. 
Tabela 16. Distribuição dos pacientes considerando o Escore de Katz no momento da saída hospitalar e a ocorrência de UP na internação. Ribeirão Preto, SP, 2007 (n = 28)

\begin{tabular}{|c|c|c|c|c|c|c|c|c|c|c|c|c|}
\hline \multirow{4}{*}{$\begin{array}{c}\text { VARIÁVEL } \\
\text { Escore } \\
\text { Katz }\end{array}$} & \multicolumn{12}{|c|}{ DISTRIBUIÇÃO } \\
\hline & \multicolumn{5}{|c|}{ Menor de 60 anos } & \multicolumn{5}{|c|}{ Maior de 60 anos } & \multirow[t]{3}{*}{ Total } & \multirow[t]{3}{*}{$\%$} \\
\hline & \multicolumn{2}{|c|}{ S/UP } & \multicolumn{2}{|c|}{ C/UP } & \multirow[t]{2}{*}{ Total } & \multicolumn{2}{|c|}{ S/UP } & \multicolumn{2}{|c|}{ C/UP } & \multirow[t]{2}{*}{ Total } & & \\
\hline & $\mathbf{N}$ & $\%$ & $\mathbf{n}$ & $\%$ & & $\mathbf{n}$ & $\%$ & $\mathbf{N}$ & $\%$ & & & \\
\hline 3 & 1 & 50,0 & 1 & 50,0 & 2 & 0 & 0 & 0 & 0 & 0 & 2 & 7,14 \\
\hline 4 & 0 & 0 & 0 & 0 & 0 & 2 & 100,0 & 0 & 0 & 2 & 2 & 7,14 \\
\hline 5 & 6 & 75,0 & 2 & 25,0 & 8 & 4 & 100,0 & 0 & 0 & 4 & 12 & 42,86 \\
\hline 6 & 0 & 0 & 0 & 0 & 0 & 1 & 100,0 & 0 & 0 & 1 & 1 & 3,57 \\
\hline 7 & 2 & 66,6 & 1 & 33,34 & 3 & 4 & 50,0 & 4 & 50,0 & 8 & 11 & 39,29 \\
\hline Total & 9 & 69,23 & 4 & 30,77 & 13 & 11 & 78,57 & 4 & 28,57 & 15 & 28 & 100 \\
\hline
\end{tabular}

O aumento na dependência funcional para realizar as atividades de vida diária é muito freqüente entre pacientes idosos que sofreram fratura de fêmur ou quadril. Assim há a necessidade em se iniciar o mais precocemente o processo de reabilitação. Alguns estudos apontam que após a inserção do idoso em programas de reabilitação, os ganhos para o retorno às AVD, são significativos pós 6 meses da ocorrência da fratura (BEAUPRE; et al, 2005). O ato de reabilitar algumas funções perdidas após a fratura de quadril, em muitos casos, pode parecer mínimo para a família e cuidadores, mas para o idoso pode significar o retorno ao auto-cuidado.

A análise pela regressão logística buscou identificar se as covariáveis sóciodemográficas e clínicas investigadas influenciaram na presença ou não da UP. Entretanto, todos os parâmetros obtidos eram iguais a zero a um nível de significância de $5 \%$ ou seja, conjuntamente essas variáveis não explicam a ocorrência ou não ocorrência de úlcera de pressão nos pacientes estudados. Posteriormente, o modelo foi refeito considerando apenas uma covariável de cada vez, para os três momentos de avaliação. Encontrou-se que apenas a covariável escore da Escala de Braden foi significativo para o momento de alta, onde conforme 
o aumento do escore da Escala de Braden o risco do paciente desenvolver UP diminuiu.

Os resultados estatísticos são justificados pela grande perda de graus de liberdade na análise, ou seja, foram trabalhadas 21 covariáveis e um total de 44 níveis de avaliação em apenas 30 pacientes, onde 8 apresentaram a UP durante a hospitalização. Embora o pequeno tamanho da amostra tenha sido uma limitação do estudo para o cumprimento adequado deste objetivo, os resultados trazem importante contribuição para os aspectos que envolvem a assistência de enfermagem à população estudada.

Ao analisar os resultados que a Escala de Katz nos mostra no momento da alta, nenhum paciente saiu totalmente independente para as AVD ganhando escore 1, no máximo receberam escore 3 e 4. Em contrapartida pela Escala de Braden, isto também ficou evidente, pois na alta em relação aos itens de Atividade, Mobilidade, Fricção e Cisalhamento foram na escala onde a maioria (exceto 1 paciente que ganhou escore 4 em Mobilidade) obtiveram um escore inferior ao da independência em todos estes subescores. O que em um futuro de alta para o domicílio, implica em um maior grau de dependência de algum cuidador, seja familiar ou não. O ideal nestes casos é que a família pudesse participar no preparo da alta, com orientações de profissionais da saúde para os cuidados mais adequados no domicílio.

A equipe de enfermagem, na figura do enfermeiro, deveria então preparar a família ou responsáveis pelo paciente nos cuidados domiciliares, para evitar complicações recorrentes de falta de orientação, em muitos dos casos, em que este tipo de paciente faz recorrente internação e de forma precoce.

Em relação aos cuidados com as UP que saíram na alta, educando família e paciente, sobre a importância de continuar monitorando possíveis alterações na pele 
em regiões de proeminências ósseas. Além disto, o paciente e família devem estar preparados para realizar os adequados alívios de pressão e nos casos de UP estágio II o enfermeiro tem a função de orientar o tipo de cobertura possível para realização de curativos, antes da alta e orientar manter retornos periódicos no serviço de saúde de referência para paciente para acompanhar a evolução destes casos.

\subsection{Valor Preditivo dos Escores da Escala de Braden}

A avaliação dos valores obtidos na escala Braden foi realizada pelo Teste Exato de Fisher, acreditando que se existisse uma correlação alta entre o fato de o paciente ter ou não UP, com a sua classificação de nível de risco da escala, este estaria correto, pois se acredita que quanto menor os valores relativos na escala, mais pacientes desenvolvem UP durante a hospitalização.

A seguir apresenta-se a tabelas de contingência para o Momento da Admissão, Pós-operatório e Alta, considerando os 30 pacientes internados no período. Na coluna temos a Variável Classificação do nível de risco na Escala Braden, e na linha a Variável Ulcera de Pressão. A análise não levou em consideração a idade do paciente. 
Tabela 17. Distribuição dos pacientes considerando a classificação de risco da Escala de Braden e a presença / ausência de UP na Admissão. Ribeirão Preto, SP, 2007 (n = 30)

\begin{tabular}{|c|c|c|c|c|c|c|}
\hline \multirow[t]{2}{*}{$\begin{array}{l}\text { ULCERA DE } \\
\text { PRESSÃO }\end{array}$} & \multicolumn{5}{|c|}{$\begin{array}{c}\text { CLASSIFICAÇÃO NA ESCALA BRADEN NA ADMISSÃO } \\
\text { NÍVEL DE RISCO }\end{array}$} & \multirow[t]{2}{*}{$\begin{array}{l}\text { TOTAL } \\
\text { GERAL }\end{array}$} \\
\hline & $\begin{array}{l}(\geq 17) \\
\text { Baixo } \\
\text { Risco }\end{array}$ & $\begin{array}{c}(15-16) \\
\text { Em Risco }\end{array}$ & $\begin{array}{c}(13-14) \\
\text { Risco } \\
\text { Moderado }\end{array}$ & $\begin{array}{c}(10-12) \\
\text { Risco } \\
\text { Elevado }\end{array}$ & $\begin{array}{c}(\leq 9) \\
\text { Risco Muito } \\
\text { Elevado }\end{array}$ & \\
\hline SIM & 0 & 0 & 0 & 2 & 0 & 2 \\
\hline NÃO & 1 & 6 & 7 & 12 & 2 & 28 \\
\hline TOTAL GERAL & 1 & 6 & 7 & 14 & 2 & 30 \\
\hline
\end{tabular}

Realizado o Teste Exato de Fisher, verificou-se que a Probabilidade é de aproximadamente 0,209195. Como a significância adotada foi de 0.05 , observa-se que a probabilidade calculada é maior que $\alpha$ ou seja, não existem evidências estatísticas que indicam que os dados sejam correlacionados.

Tabela 18. Distribuição dos pacientes considerando a classificação de risco da Escala de Braden e a presença / ausência de UP no $1^{\circ} \mathrm{PO} / 5^{\circ}$ DI. Ribeirão Preto, SP, 2007 ( $n=30$ )

\begin{tabular}{|c|c|c|c|c|c|c|}
\hline \multirow{2}{*}{$\begin{array}{c}\text { ULCERA DE } \\
\text { PRESSÃO }\end{array}$} & \multicolumn{5}{|c|}{ CLASSIFICAÇÃO NA ESCALA BRADEN } & \multirow{2}{*}{$\begin{array}{l}\text { TOTAL } \\
\text { GERAL }\end{array}$} \\
\hline & $\begin{array}{c}\text { Baixo Risco } \\
\qquad(>=17)\end{array}$ & $\begin{array}{c}\text { Em Risco } \\
(15-16)\end{array}$ & $\begin{array}{c}\text { Risco } \\
\text { Moderado } \\
(13-14)\end{array}$ & $\begin{array}{c}\text { Risco } \\
\text { Elevado } \\
(10-12)\end{array}$ & $\begin{array}{c}\text { Risco Muito } \\
\text { Elevado } \\
\text { (<= 9) }\end{array}$ & \\
\hline SIM & 1 & 0 & 1 & 3 & 1 & 6 \\
\hline NÃO & 4 & 7 & 5 & 8 & 0 & 24 \\
\hline TOTAL GERAL & 5 & 7 & 6 & 11 & 1 & 30 \\
\hline
\end{tabular}

Realizado o Teste Exato de Fisher, verificou-se que a probabilidade é de aproximadamente 0,008336 . Como a significância adotada foi de 0,05 , observa-se que a probabilidade calculada é menor que $\alpha$. Sendo assim, conclui-se que existe evidencias estatísticas que indicam que os dados sejam correlacionados, ou seja, quanto menor a pontuação na Escala Braden, maior a quantidade de pacientes com Ulcera de Pressão neste momento. 
Tabela 19. Distribuição dos pacientes considerando a classificação de risco da Escala de Braden e a presença / ausência de UP na Alta. Ribeirão Preto, SP, 2007 ( $n=30)$

\begin{tabular}{|c|c|c|c|c|c|c|}
\hline \multirow{2}{*}{$\begin{array}{l}\text { ULCERA DE } \\
\text { PRESSÃO }\end{array}$} & \multicolumn{5}{|c|}{ CLASSIFICAÇÃO NA ESCALA BRADEN } & \multirow{2}{*}{$\begin{array}{l}\text { TOTAL } \\
\text { GERAL }\end{array}$} \\
\hline & $\begin{array}{c}\text { Sem Risco } \\
(>=17)\end{array}$ & $\begin{array}{c}\text { Em Risco } \\
(15-16)\end{array}$ & $\begin{array}{c}\text { Risco } \\
\text { Moderado } \\
(13-14)\end{array}$ & $\begin{array}{c}\text { Risco } \\
\text { Elevado } \\
(10-12)\end{array}$ & $\begin{array}{c}\text { Risco Muito } \\
\text { Elevado } \\
(<=9)\end{array}$ & \\
\hline SIM & 2 & 1 & 1 & 3 & 2 & 9 \\
\hline NÃO & 10 & 5 & 4 & 2 & 0 & 21 \\
\hline TOTAL GERAL & 12 & 6 & 5 & 5 & 2 & 30 \\
\hline
\end{tabular}

A análise no momento da alta considerou o número de pacientes que apresentavam a UP independente se o seu início ocorreu durante a hospitalização. O resultado do Teste Exato de Fisher indicou que a Probabilidade é de aproximadamente 0,001383923 . Como a significância adotada foi de 0,05 , observase que a probabilidade calculada é menor que $\alpha$. Sendo assim, se rejeita a Hipótese Nula com 0.05 de significância, ou seja, existem evidências estatísticas que indicam que os dados sejam correlacionados. Quanto menor a pontuação na Escala Braden, maior a quantidade de pacientes com Úlcera de Pressão no momento da alta hospitalar. Assim pode-se concluir que os resultados da escala Braden nesses momentos indicam corretamente que o paciente tem risco para ter Úlcera de Pressão. 
A seguir serão descritos as conclusões obtidas neste estudo de acordo com os objetivos propostos:

\subsection{Quanto à caracterização dos pacientes}

A amostra constituiu-se predominantemente de mulheres, brancas, acima dos 60 anos de idade, alfabetizadas e aposentadas. A maioria era da cidade de Ribeirão Preto, e tiveram como local do trauma resultante na fratura de fêmur, o próprio local da residência, onde houve uma queda da própria altura. A localização das fraturas se deu na região de Colo Femoral $(40,0 \%)$ e na região Transtrocanteriana do fêmur $(33,0 \%)$.

Além disto, a população estudada tinha outros diagnósticos na admissão, predominantemente outras doenças crônicas não transmissíveis como, por exemplo, do Sistema Cardiocirculatório (53,3\%), seguido de Doenças do Sistema Nervoso $(26,6 \%)$ e outras patologias como Câncer $(13,3 \%)$ e Diabetes Mellitus $(13,3 \%)$ característico da população idosa predominante.

O tempo médio desde a data de admissão e a data de cirurgia foi de 2,92 dias. Em relação ao tempo total de cirurgia, 57,2\% da amostra, teve este tempo entre 2 a 4 horas e o restante acima de 4 horas (42,8\%), caracterizando o tipo de cirurgia que era realizado, para as de osteossíntese era um período mais curto e para a colocação de prótese total de quadril um procedimento mais demorado.

O tempo médio em dias de internações foi de 14,20 (DP 15,66), onde a maioria, $66,7 \%$ da população ficou internada por 6 ou mais dias. O uso de tração no 
período pré-operatório, ocorreu em 35,7\%. O tipo de anestesia mais freqüente foi a Raquianestesia, 67,8\% dos casos.

A complicação mais comum no pós-operatório foi a confusão e agitação em $66,7 \%$ dos pacientes.

Para a avaliação da independência funcional para as AVD foi identificado que no primeiro e segundo momentos de avaliação $50 \%$ dos pacientes estavam dependentes para todas as atividades incluindo o banho, vestir-se, ir ao banheiro e transferência, estando assim com dificuldades de realizar o auto cuidado incluindo a prevenção da UP.

\subsection{Quanto à incidência e prevalência da UP}

Dos 30 pacientes, identificou-se durante a avaliação na Admissão (momento 1) pelo exame físico, que dois (6,66\%) apresentavam UP e 28 (93,34\%) apresentavam a pele íntegra.

Destes 28 pacientes durante o período de internação 8 desenvolveram UP em algum momento das avaliações.

O índice de prevalência de UP foi de 33,3\% e o de incidência foi de 26,6\%. 


\subsection{Descrição e evolução das lesões até a alta}

Em relação à localização de maior freqüência para UP, em nosso estudo foram as localizadas em região sacral (42,85\%) seguida de calcâneo (28,57\%).

No momento da admissão até o momento da alta, todas as UP estavam em estágio I. No momento de avaliação no dia do $1^{\circ} \mathrm{PO}$ ou $5^{\circ} \mathrm{DI}$, foram identificados 5 pacientes com UP em estágio I. Já no momento de alta ainda foram identificadas mais 3 pacientes com UP.

\subsection{Em relação à presença de UP com as variáveis clinicas}

Dos 28 pacientes estudados, 13 tinham menos que 60 anos e desses, 5 $(38,46 \%)$ tiveram UP.

Quanto ao sexo, a UP ocorreu em 2 homens e em 5 mulheres, e com maior freqüência nos de cor branca (23\%.

Em relação ao uso da tração no período pré-operatório e o desenvolvimento de UP ocorreu em 2 dos 10 com tração e em 5 dos 18 sem tração.

Quanto ao tempo total de cirurgia, para os pacientes com UP a média foi 4,40 (DP: 1,4 ) e sem UP foi 3,92 (DP: 1,37 ).

O período de internação para os que tiveram UP a média foi 24,37 (DP: 22,07) dias e para os sem UP a média foi de 10,25 (DP: 11,53) dias. 
Dos 20 pacientes que estavam conscientes e orientados em todos os três momentos de avaliação, 4 tiveram UP (20\%). No segundo momento de avaliação dos 4 pacientes que estavam conscientes e desorientados 2 tiveram UP (50\%). E no último momento de avaliação um paciente que estava inconsciente e que teve UP, evoluiu para o óbito.

Quanto à presença de comorbidades na admissão, a análise dos resultados dos testes estatísticos não encontrou evidências da associação entre essas variáveis e UP.

O estado nutricional pode ter influenciado o desenvolvimento de UP, pois em $50 \%$ dos casos que o IMC estava abaixo do normal, os pacientes tiveram UP.

A avaliação do Estado Funcional pela Escala de Katz no momento da Admissão, identificou que dos pacientes menores de 60 anos que obtiveram o escore 7, ou seja, era dependente para todas as atividades apenas um (25\%) apresentou UP durante a internação. Já entre os idosos o percentual foi de $30 \%$.

\subsection{Em relação à avaliação de risco para UP por meio da Escala de Braden}

A maioria dos pacientes tinha risco para UP nos três momentos de avaliação. Na admissão, o escore médio da Escala de Braden foi de 12,66 (risco elevado), no segundo momento $\left(1^{\circ} \mathrm{PO} / 5^{\circ} \mathrm{DI}\right)$ foi 13,73 (risco moderado) e no terceiro momento correspondente a saída por alta ou óbito foi 15,03 (em risco). 
Para os 8 pacientes que tiveram UP durante a internação o escore na admissão foi 11,5 (DP: 0,71), no segundo momento 11,83 (DP3,66) e na saída 12,67 $(4,61)$.

Quanto aos subescores de risco, a percepção sensorial estava diminuída no segundo momento de avaliação, logo após o momento cirúrgico. Para a subescala umidade, também foi a de maior risco no momento do $5^{\circ} \mathrm{DI}$ ou $1^{\circ} \mathrm{PO}$.

Para a avaliação da escala de atividade, observou-se que 100\% dos pacientes ganharam o menor subescore 1, também no segundo momento de avaliação. Quanto à mobilidade, o subescore não teve mudanças significativas entre os momentos avaliados.

Para a avaliação da subescala nutrição, os piores resultados foram os avaliados na admissão e no pós-operatório.

E finalmente para a subescala fricção e cisalhamento o subescore mais crítico foi no momento 2 de avaliação, onde o paciente teve a máxima dependência para realizar mudanças de posição ou transferências.

\subsection{Quanto ao valor preditivo dos Escores de Braden para esta população}

Os valores preditivo dos escores de Braden para os pacientes estudados, tiveram relação nos momentos de segunda avaliação e na alta, ou seja, existiram evidencias estatísticas que indicaram que os dados foram correlacionados, assim a escala foi capaz de predizer o risco somente nestes dois momentos. 
Os resultados da avaliação dos pacientes com fratura de fêmur ou quadril quanto ao risco para o desenvolvimento de UP por meio da Escala de Braden, permitiram identificar os fatores ou condições que colocavam estes pacientes em risco. Identificou-se que todos tinham risco em menor ou maior grau nos diferentes momentos da internação principalmente relacionado à imobilidade e dependência física para as AVD. Entretanto, em poucos foram utilizadas as medidas de alívio da pressão e proteção da pele, requisitos necessários e considerados hoje um padrão esperado para uma assistência de qualidade que visa diminuir as chances de danos e aumentar a segurança do paciente. Não foram encontrados em nenhum prontuário anotação ou registro dos cuidados com a pele, nem mesmo as mudanças de decúbito. Mesmo que este cuidado tenha sido realizado em diferentes momentos que a pesquisadora não esteve presente, se não está registrado no prontuário, não pode ser comprovado em uma auditoria ou avaliação por especialistas em casos de processos legais.

Se o resultado do estudo de incidência for comparado a outros estudos internacionais, a incidência de UP foi muito elevada, cabendo aí futuras análises do processo de cuidado e planejamento de intervenções da equipe de enfermagem que usem as "melhores práticas" para prevenir tal complicação.

Ao final do estudo, nove pacientes saíram na alta com UP e continuavam em risco, não tinham independência para a realização das AVD relacionadas à higiene. Assim, dependiam de cuidador formal ou informal para diminuir a chance do agravamento das úlceras presentes ou para evitar esta complicação. Outras pesquisas necessitam ser realizadas para investigar a situação presente após a alta e qual é a experiência dos cuidadores no domicílio e com os serviços de saúde após a alta. 
Ao final deste estudo podemos concluir que intervenções de avaliação primária para risco de UP na população com fratura de quadril devem fazer parte da rotina de todo serviço de saúde que assiste este paciente onde quer que esteja, seja na Unidade de Emergência, Centro Cirúrgico, seja na Unidade de internação, já que são essenciais para diminuir os riscos para complicações.

Por se tratar de um paciente de longa permanência no hospital, este tipo de paciente precisa ser reavaliado diariamente quanto ao risco de desenvolver UP, por permanecer em estado de grande imobilidade física e dependência de cuidados, aguardando a resolução do seu tratamento.

As úlceras por pressão ocorridas em ambiente hospitalar podem ser determinadas por uma variedade de fatores intrínsecos e extrínsecos. A avaliação de risco do paciente torna-se essencial para o planejamento e para implementar um plano individualizado de cuidado. Existe a necessidade de previsão de recursos humanos e materiais e de qualificação dos membros da equipe e isto deve ser visto dentro de uma abordagem sistêmica de um Programa de Melhoria de Qualidade que enfoque a segurança do paciente. A comunicação entre os membros da equipe que assiste o paciente hospitalizado e a sua sensibilização para o problema é fundamental quando a meta é a prevenção de UP. No estudo de Stoelting; et al (2007) quando foram estabelecidos protocolos de prevenção e cuidados com a pele embasados em evidências, sob o enfoque do programa de melhoria de Qualidade e investimentos na estrutura institucional e no processo de cuidado os resultados foram positivos, com um decréscimo de $7 \%$ para $4 \%$ nas ocorrências de UP durante a hospitalização.

As diretrizes para Prevenção de Úlceras por Pressão elaboradas pela AHCPR (Agency for Health Care Policy and Research) (1994) abordam quatro aspectos do 
cuidado que devem ser implementados em todos os serviços de saúde: avaliação do risco e identificação dos fatores para direcionamento das medidas preventivas; cuidados preventivos da pele e início precoce do tratamento; uso de equipamentos e medidas para redução de carga mecânica que causa o excesso de pressão nos tecidos; implementação de programas educacionais bem estruturados e direcionados para pacientes, cuidadores formais e informais.

\section{I - Realizar avaliação de risco}

- Utilizar a escala de Braden para auxiliar o raciocínio clinico

- Avaliar os pacientes de forma individual e em intervalos regulares;

- Identificar os fatores de risco presentes na escala de Braden e outros (idade, estado nutricional, uso de tração, comorbidades, nível de independência para AVD) para direcionar as medidas preventivas.

- Documentar a avaliação e intervenções.

\section{Cuidados com a pele e tratamento precoce:}

- Inspecionar a pele diariamente e documentar esta avaliação.

- Ao identificar a presença da UP iniciar imediatamente o tratamento e avaliar a adesão do paciente e equipe ás medidas preventivas necessárias.

- Individualizar a freqüência da higiene corporal, para melhor assistência, utilizar agentes de limpeza suave, evitar água quente e fricção da pele.

- . Usar barreira tópica para proteção contra a umidade e se necessário, fraldas absorventes que absorvam a urina e deixem a superfície da pele seca.

- Usar hidratantes adequados, evitar frio e calor excessivos (podem causar ressecamento da pele). 
- Minimizar fatores ambientais que causem o ressecamento da pele como ar frio e de baixa umidade.

- Não massagear proeminências ósseas.

- Usar um posicionamento correto, evitando a pressão e força de cisalhamento.

- Utilizar coberturas protetoras para evitar o atrito sob lesão.

- Identificar e corrigir fatores que comprometam a ingestão calórica e de proteínas.

- Considerar a consulta com nutricionista e a utilização de suplementação nutricional se for necessário para manter nutrição adequada.

- Instituir programas que ajudem a manter ou melhorar o estado de atividade e mobilidade.

- Documentar os resultados.

\section{Redução de Carga Mecânica e Utilização de Superfície de Suporte:}

- Reposicionar o paciente a cada duas horas;

- Utilizar colchões/colchonetes redutores de pressão no leito e na mesa cirúrgica para pacientes em risco;

- Observar a postura do paciente e avaliar a presença de excesso de pressão na região sacral quando em decúbito dorsal.

- Evitar arrastar o paciente durante a mudança de posição.

- Se for necessário, utilizar recursos do tipo trapézio ou lençol móvel para auxiliar na movimentação.

- Manter as proeminências ósseas protegidas com travesseiros de espuma para evitar seu contato com a cama ou com o próprio corpo. 
- Elevar a cabeceira da cama o menos possível (ângulo $30^{\circ}$ graus no máximo) e por pouco tempo.

- Não utilizar almofadas do tipo bóia ou roda de água ou ar, pois aumentam a pressão sob os tecidos subjacentes e o que se pretende é aliviar a pressão.

- Orientar alinhamento postural, distribuição do peso, balanço e estabilidade e o alívio de pressão quando posicionar pessoas em cadeiras / poltronas ou cadeiras de rodas.

- Ensinar às pessoas restritas à cadeira e que são capazes, a realizar a mudança de posição e o alívio de pressão a cada 15 minutos.

\section{Educação:}

- Implementar programas educacionais bem estruturados e direcionados para pacientes e cuidadores durante a internação e no preparo para a alta assim como para os profissionais de saúde de todos os níveis de atenção;

- Fornecer informações sobre: etiologia, fatores de risco, utilização de instrumentos de avaliação do risco, uso de superfícies de suporte, cuidados individualizados com a pele, demonstração de posicionamento a fim de diminuir o risco de perda de integridade dos tecidos, forma de registro correto dos dados no prontuário (BERGSTROM; et al, 1994).

A seguir, um fluxograma sugerido e elaborado pelas autoras deste trabalho, para a prevenção de UP em pacientes com fratura de fêmur ou quadril: 
Identificação de pacientes com fratura de quadril elou fêmur admitidos na Emergência ou unidade de Internação.
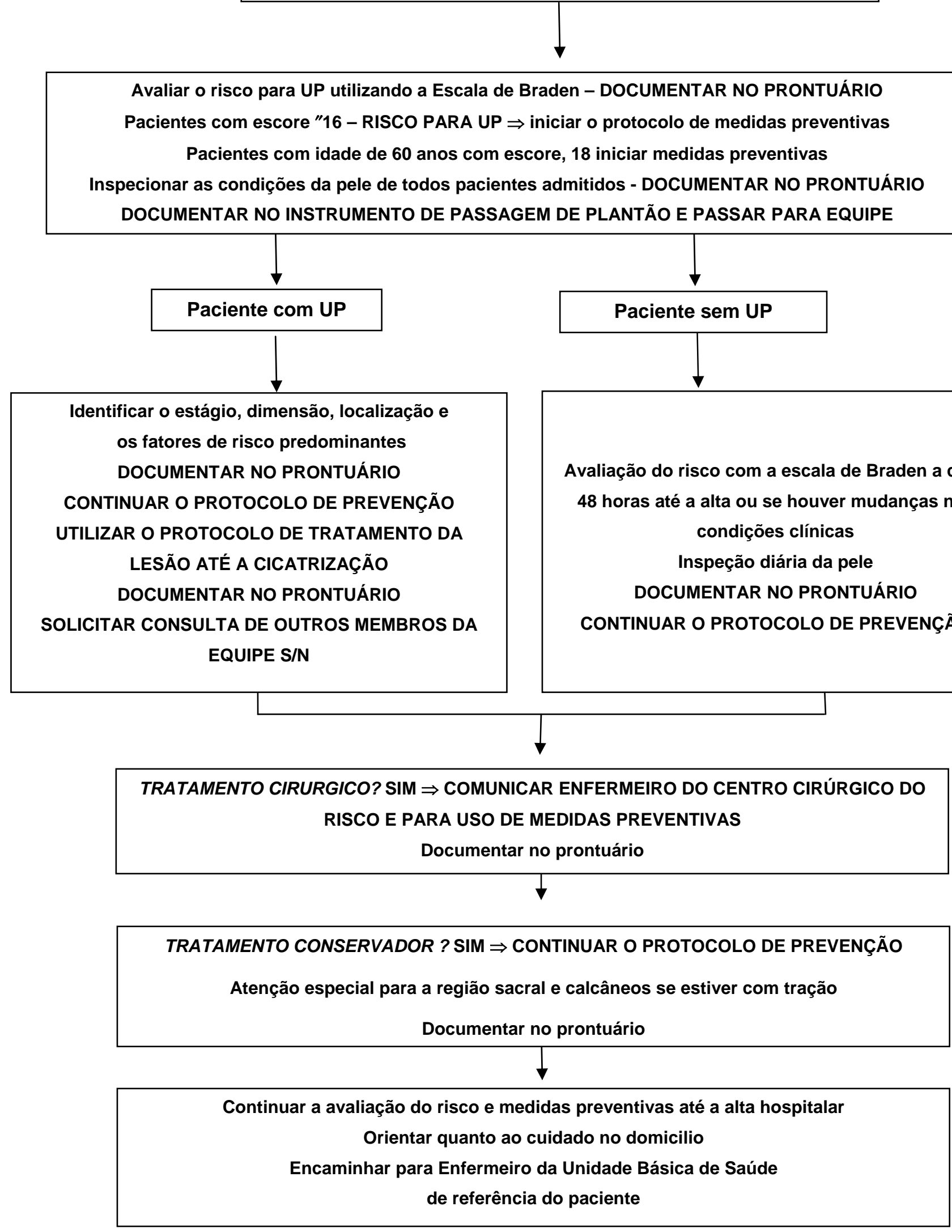
Atualmente, a prevenção da UP é uma questão importante a ser enfrentada pelos serviços de saúde que assistem aos pacientes com fratura de quadril ou fêmur, que por sua condição clínica possuem elevado risco para UP. Embora existam recomendações para as "melhores práticas" essas não podem existir somente na teoria. A literatura demonstra que existe a possibilidade e viabilidade da implantação. Talvez o que falta sejam atitudes positivas e concretas e conscientização dos profissionais envolvidos na prática e ensino dos cuidados assim como maior preocupação das instituições de saúde com a UP, como indicador (negativo) de qualidade. 
REFERÊNCIAS BIBLIOGRÁFICAS 
- AlARCON, T.; GONZALEZ-MONTALVO, J. I.; BARCENA, A.; SAEZ, P. Further experience of nonagenarians with hip fractures. Injury, v.32, p.555-558, 2001.

- ARAUJO, D. V.; OLIVEIRA, J. H. A.; BRACCO, O. L. Custo da fratura osteoporótica de fêmur no sistema de saúde suplementar brasileiro. Arq Bras Endocrinol Metabol. v.49, n.6, p.897-901, 2006.

- AYELlO, E. A. Predicting Pressure Ulcer Risk. Try This: Best Practices in Nursing Care to Older Adults. n.5, 2007. Disponível em: http://www.geronurseonline.org. Acesso em: 15 dez. 2007.

- BARROS FILHO, T. E. P.; NAPOLI, M. M. M. Aspectos Ortopédicos e Traumatológicos. In: CARVALHO FILHO, E. T.; PAPALÉO NETTO, M. Geriatria, fundamentos, clínica e terapêutica. São Paulo; Editora Atheneu, 2000. p.447.

- BAuMgarten, M., MARgOlis, D., BERLIN, J. A.; STROM, B. L.; GARINO, J.; KAGAN, S. H.; KAVESH, W.; CARSON, J. L. Risk factors for pressure ulcers among elderly hip fracture patients. Wound Rep Reg. v.11, p.96-103, 2003. 
- BeAUPRE, L. A.; JONES, C. A.; SAUNDERS, L. D.; JOHNSTON, D. W. C.; BUCKINGHAM, J.; MAJUMDAR, S. R. Best Practices for Elderly Hip Fracture Patients, A Systematic Overview of the Evidence. J Gen Intern Med. v.20, p.10191025, 2005.

- BeRgstrom, N.; DEMUTH, P. J.; BRADEN, B. J. A clinical trial of the Braden Scale for predicting pressure sore risk. Nursing Clinical North America, v.22, n.2, p.417427, 1987.

- Bergstrom, N.; Allman, R. M.; AlVARES, O. M.; CARLON, C. E.; EAGLESETEIN, W.; FRANTZ, R. A.; GARBER, S. L.; GOSNELL, D.; JACKSON, B. S.; KAMINSKI, M. V.; KEMP, M. G.; KROUSKOP, T. A.; LEWIS, V. L.; MAKLEBUST, J.; MARGOLIS, D. J.; MARVEL, E. M.; REGER, S. L.; RODCHEAVER, G. T.; SALCIDO, R.; XAKELLIS, G. C.; YARKONY, G. M. Pressure ulcer treatment Clinical Practice Guideline. Quick Reference Guide for Clinicians. US Departament of Health and Human Services, Public Health Service, Agency for Health Care Policy and Research. Publication 95-0652. December, 1994.

- BlANES, L.; DUARTE, I. S.; CALIL, J. A.; FERREIRA, L. M. Avaliação Clínica e Epidemiológica das Úlceras por Pressão em Pacientes Internados no Hospital São Paulo. Rev Assoc Med Bras. v.50, n.2, p.182-187, 2004. 
- BRADEN, B.; BERGSTROM, N. A conceptual schema for the study of the etiology of pressure sore. Validada para o português por Paranhos \& Santos, 1999. Rehab Nurs. jan-fev, v.12, n.1, p.8-12, 1987.

- CANALE, S. T. Cirurgia Ortopédica de Campbell. v.2, Editora Manole, São Paulo, 10ª edição, 2007, p.2440.

- CONSELHO FEDERAL DE ENFERMAGEM. Resolução COFEN nº 272/2002. Dispõe sobre a Sistematização da Assistência de Enfermagem - SAE - nas Instituições de Saúde Brasileiras. Rio de Janeiro, 2002.

- COSTA, I. G. Incidência de úlcera de pressão e fatores de risco relacionados em pacientes de um centro de terapia intensiva. 2003. 150f. Dissertação (Mestrado) Escola de Enfermagem de Ribeirão Preto, Universidade de São Paulo, Ribeirão Preto, 2003.

- CUMMINGS, S. R.; MELTON, L. J. Epidemiology and outcomes of osteoporotic fractures. Lancet. v.359, p.1761-7, 2002. 
- DUARTE, Y. A. O.; ANDRADE, C. L.; LEBRÃO, M. L. O Index de Katz na Avaliação da Funcionalidade dos Idosos. Rev Esc Enferm USP. v.41, n.2, p.317-325, 2007.

- ENDRES, H. G.; DASCH, B.; LUNGENHAUSEN, M.; MAIER, C.; SMEKTALA, R.; TRAMPISCH, H. J.; PIENTKA, L. Patients with femoral or distal forearm fracture in Germany: a prospective observational study on health care situation and outcome. BMC Public Health. v.6, n.87, p.1-14, 2006.

- FABRICIO, S. C.C.; RODRIGUES, R. A. P.; COSTA JUNIOR, M. L. Falls among older adults seen at a São Paulo State public hospital: causes and consequences. Rev Saúde Pública. São Paulo, v.38, n.1, 2004.

- FERNANDES, H. J. A.; JORGE, S. R.; REIS, F. B. Fraturas da Diáfise do Fêmur. In: REIS, F.B. Traumatologia: Membro Inferior. São Paulo, 1998. p.68.

- FERNANDES, L. M. Efeitos de intervenções educativas no conhecimento e práticas de profissionais de enfermagem e na incidência de úlcera de pressão em centro de terapia intensiva. 2006. 215f. Tese (Doutorado) - Escola de Enfermagem de Ribeirão Preto, Universidade de São Paulo, Ribeirão Preto, 2006. 
- FURLANETO, M. E.; GARCEZ-LEME, L. E. Delirium in elderly individuals with hip fracture: causes, incidence, prevalence, and risk factors. Clinics. São Paulo, v.61, n.1, 2006.

- GONÇALVES, L. H. T. Guia instrucional para uso do modelo geronte na avaliação da autonomia dos idosos. In: BARBOSA, L. T. et al. Uma proposta humanizada de cuidado ao idoso asilado. Florianópolis: UFSC, 1994.

- GRAY, H. Anatomy of the Human Body. Ed. Philadelphia: Lea \& Febiger. 2000, p.1918.

- GUIMARÃES, R. M.; CUNHA, U. G. V. Sinais e Sintomas em Geriatria. $2^{a}$. Ed. São Paulo, Rio de Janeiro, Ribeirão Preto, Belo Horizonte. Editora Atheneu, cap.27, p. 278-285, 2004.

- GUNNINGBERG L.; LINDHOLM C.; CARLSSON M.; SJÖDÉN P. O. The development of pressure ulcers in patients with hip fractures: inadequate nursing documentation is still a problem. J Adv Nurs. v.31, n.5, p.1155-64, 2000. 
- GUNNINGBERG, L.; LINDHOLM, C.; CARLSSON, M.; SJÖDEN, P.O. Implementation of risk assesment and classification of pressure ulcers as quality indicators for patients with hip fractures. J Clin Nurs. v.8, p.396-406, 1999.

- HOMMEL, A.; ULANDER, K.; THORNGREN, K. G. Improvements in pain relief, handling time and pressure ulcers through internal audits of hip fracture patients. Scand J Caring Sci. v.17, p.78-83, 2003.

- HOMMEL, A.; BJORKELUND, K.B.; THORNGREN, K.G.; ULANDER, K. Nutritional status among patients with hip fracture in relation to pressure ulcers. Clin Nutr. v.26, n.5, p.589-96, 2007.

- IMBELLONI, L. E.; BEATO, L. Comparison between spinal, combined spinal-epidural and continuous spinal anesthesias for hip surgeries in elderly patients: a retrospective study. Rev Bras Anestesiol. Campinas, v.52, n.3, p.316-325, 2002.

- KATZ, S.; FORD, A. B.; MOSKOWITZ, R. W.; JACKSON, B. A.; JAFFE, M. W. Studies of Ilness in the Aged. Jama. v.185, n.12, p.914 - 919, 1963. 
- KÖBERLE, G. Fraturas de Fêmur Proximal. In: SOCIEDADE BRASILEIRA DE ORTOPEDIA E TRAUMATOLOGIA (SBOT). Traumatologia ortopédica. Rio de Janeiro: Ed. Revinter, 2004. Cap. 20, p.225-235.

- KÖBERLE, G. Fraturas Transtrocanterianas. Rev Bras Ortop. v.36, n.9. p.325-329, 2001.

- KÖBERLE, G.; CHRISTIAN, R. W.; TAKATA, E. T. Fraturas do Colo Femoral. In: REIS, F. B. Traumatologia: Membro Inferior. São Paulo, 1998. p.68.

- $\quad$ KOMATSU, R. S.; SIMÕES, M. F. J.; RAMOS, L. R.; SZEJNFELD, V. L. Incidência de fraturas do fêmur proximal em Marília, São Paulo, Brasil, 1994 e 1995. Rev Bras Reumatol. v.39, n.6, nov-dez, p.325-31, 1999.

- $\quad$ LeIBSON, C. L.; TOSTESON, A. N.; GABRiEL, S. E.; RANSOM, J. E.; MELTON, L. J. Mortality, disability, and nursing home use for persons with and without hip fracture: a population-based study. J Am Geriatr Soc. v.50, p.1644-50, 2002.

- LIMA, A. L. L. M.; BARONE, A. A. Infecções Hospitalares em 46 Pacientes Submetidos à Artroplastia Total do Quadril. Acta Ortop Bras. n.9, v.1, p.36-41, 2001. 
- LIMA, A. L. P.; AZEVEdO FILHO, A. J.; AMARAL, N. P.; FRANKLIN, C. E.; GIORDANO, V. Tratamento das fraturas intertrocanterianas com placa e parafuso deslizante. Rev Bras Ortop. v.38, n.5, Maio, 2003.

- MARGOLIS, D. J.; KNAUSS, J.; BILKER, W.; BAUMGARTEN, M. Medical conditions as risk factors for pressure ulcers in an outpatient setting. Age Ageing. v.32, n. 3, p.259-264, 2003.

- MARUM, R. J.; OOMS, M. E.; RIBBE, M. W.; EIJK, J. T. The Dutch pressure sore assessment score or the Norton scale for identifying at-risk nursing home patients? Age Ageing. v.29, n.1, p.63-68, 2000.

- MERCHANT, R. A.; LUI, K. L.; ISMAIL, N. H.; WONG, H. P.; SITOH, Y. Y. The relationship between postoperative complications and outcomes after hip fracture surgery. Ann Acad Med Singapore. v.34, n.2, march, 2005.

- MILISEN, K.; FOREMAN, M. D.; ABRAHAN, I. L.; GEEST, S.; GODDERIS, J.; VANDERMEULEN, E.; FISCHLER, B.; DELOOZ, H. H.; SPIESSENS, B.; BROOS, P. L. O. A nurse-led interdisciplinary intervention program for delirium in elderly hipfracture patients. JAGS. v.49, n.5, p.523-532, 2001. 
- MiNISTÉRIO DA SAÚde; SECRETARIA DE POlíticAs DE SAÚdE. Política nacional de redução da morbimortalidade por acidentes e violência - Informes Técnicos Institucionais. Rev Saúde Pública. v.34, n.4, p.427-30, 2000.

- MINISTÉRIO DO TRABALHO E EMPREGO. Classificação Brasileira de Ocupações. Brasília. 2002. Disponível em: http:// www.mte.gov.br/. Acesso em: 10 jan. 2008.

- MOI, R. C. Envelhecimento do Sistema Tegumentar: Revisão Sistemática da Literatura. 2004. 111f. Dissertação (Mestrado) - Escola de Enfermagem de Ribeirão Preto, Universidade de São Paulo, Ribeirão Preto, 2004.

- MORETTIN, P. A.; BUSSAB, W. O. Estatística básica. São Paulo: Editora Saraiva, 5a. Edição, 2005.

- MUNIZ, C. F.; ARNAUT, A. C.; YOSHIDA, M.; TRELHA, C. S. Caracterização dos Idosos com Fratura de Fêmur Proximal Atendidos em Hospital Escola Público. Rev Espaço Saúde. Londrina, v.8, n.2, p.33-38, Junho, 2007. 
- NATIONAL PRESSURE ULCER ADVISORY PANEL (NPUAP). Pressure Ulcer Definition and Stages. Tradução Vera Conceição de Gouveia Santos; Maria Helena Caliri. February, 2007. Disponível em: http://www.npuap.org. Acesso em: 27 nov. 2007.

- NOGUEIRA, P. C.; CALIRI, M. H. L.; HASS, V. J. Perfil de pacientes com lesão traumática da medula espinhal e ocorrência de úlcera por pressão em um Hospital Universitário. Rev Latino-am Enfermagem. Ribeirão Preto, v.14, n.3, p.372-377, 2006.

- OGUISSO, T. Dimensões ético-legais das anotações de enfermagem no prontuário do paciente. Rev Paul Enfermagem. São Paulo, v.22, n. 3, p. 245-254, 2003.

- OLOFSSON, B.; STENVALL, M.; LUNDSTRÖM, M.; SVENSSON, O.; GUSTAFSON, Y. Malnutrition in hip fracture patients: an intervention study. J Clin Nurs. V.16, n.11, p.2027-38, 2007.

- VOYER, P.; RICHARD, S.; DOUCET, L.; DANJOU, C.; CARMICHAEL, P-H. Detection of delirium by nurses among long-term care residents with dementia. BMC Nursing. v.7, February, 2008. 
- PEEL, N. M.; MCLURE, R. J.; HENDRIKZ, J. K. Health-protective behaviours and risk of fall-related hip fractures: a population-based case-control study. Age Ageing, v.13, p. 1-7, june, 2006.

- PereirA, G. J. C.; BARReto, A. A.; CuRCElli, E. C.; PEREIRA, H. R.; GÉRIOS, J. C.; GALVÃO, M. P. L.; FUNCHAL, L. F. Z. Estudo epidemiológico retrospectivo das fraturas do terço proximal do fêmur na região de Botucatu. Rev Bras Ortop. v.28, n.7, p.504-510, Julho, 1993.

- RADEMAKERS, L. M. F.; VAINAS, T.; ZUTPHEN, S. W. A. M.; BRINK, P. R. G.; HEIDEN, S. H. H. Pressure Ulcers and Prolonged Hospital Stay in Hip Fracture Patients affected by time-to-surgery. Europ J Trauma Emergency Surgery. n.3, p.238-244, 2007.

- ROCHA, F. A. C.; RIBEIRO, A. R. Low incidence of hip fractures in an equatorial area. Osteoporos Int. v.14, p. 496-9, 2003.

- ROChA, M. A.; CARVAlho, W. S. 0.; ZANQUeTA, C.; LeMOS, S. C. Estudo epidemiológico retrospectivo das fraturas do fêmur proximal tratados no Hospital Escola da Faculdade de Medicina do Triângulo Mineiro. Rev Bras Ortop. v.36, n.8, p.311-316, Agosto, 2001. 
- ROGENSKI, N. M. B. ; SANTOS, V. L.C. G. Estudo sobre a incidência de úlceras por pressão em um hospital universitário. Rev Latino-am Enfermagem. v.13, p.474-480, 2005.

- SAKAKI, M. H.; OlIVEIRA, A. R.; COELHO, F. F.; LEME, L. E. G.; SUZUKI, I.; AMATUZZI, M. M. Estudo da mortalidade na fratura do fêmur proximal em idosos. Acta Ortop Bras. v.12, n.4, p.242-249, out-dez, 2004.

- SANTOS, J. S.; SCARPELINI, S.; BRASILEIRO, S. L. L.; FERRAZ, C. A.; DALLORA, M. E. L. V.; SÁ, M. F. S. Avaliação do Modelo de Organização da Unidade de Emergência do HCFMRP-USP, adotando como referência as Políticas Nacionais de Atenção às Urgências e de Humanização. Medicina, Ribeirão Preto. n.36, p.498515, 2003.

- SILVEIRA, V. A. L.; MEDEIROS, M. M. C.; COELHO-FILHO, J. M.; MOTA, R. S.; NOLETO, J. C. S.; COSTA, F. S.; PONTES, F. J. O.; SOBRAL, J. B.; AGUIAR, R. F.; LEAL, A. C.; CLEMENTE, C. M. Incidência de fratura do quadril em área urbana do Nordeste brasileiro. Cad Saúde Pública. Rio de Janeiro, v.21, n.3, p.907-912, 2005.

- SMITH, L. N. A critical of "at risk" pressure sore assessment tools. J Clin Nurs, v.3, p.153-9, 1995. 
- SOBOtTA, J. Atlas de Anatomia Humana. Rio de Janeiro, Editora Guanabara Koogan, Vol. I e II, 2000.

- SODERQVIST, A.; PONZER, S.; TIDEMARK, J. Cognitive function and pressure ulcers in hip fracture patients. Scandinavian Journal of Caring Sciences. n. 21, p.79-83, 2007.

- SOUZA, D. M. S. T.; SANTOS, V. L. C. G. Fatores de risco para o desenvolvimento de úlceras por pressão em idosos institucionalizados. Rev Latino-am Enfermagem. v.15, n.5, p.958-964, 2007.

- SOUZA, R. C.; PINHEIRO, R. S.; COELI, C. M.; CAMARGO JÚNIOR, K. R.; TORRES, T. Z. G. Risk adjustment measures for mortality after hip fracture. Rev. Saúde Pública. São Paulo, v.41, n.4, p.625-31, 2007.

- StOElting, J.; MCKENNA, L.; TAGgART, E.; MOTTAR, R.; JEFFERS, B. R.; WENDLER, M. C. Prevention of Nosocomial Pressure Ulcers A Process Improvement Project. J Wound Ostomy Continence Nurs. v.34, n.4, p.382-388, 2007. 
- VERLUYSEN, M. How elderly patients with femoral fracture develop pressure sores in hospital. Britsh Medical Journal. v.292, p.1311-1313, 1986.

- WHITAKER, I. Y.; DICCINI, S. Exame Neurológico. In: BARROS, A. L. B. L. \& cols. Anamnese e Exame Físico: avaliação diagnóstica de Enfermagem no Adulto. Porto Alegre: Artmed, 2002. p.95 -111.

- WOUND OSTOMY AND CONTINENCE NURSES SOCIETY (WOCN). Guideline for prevention and management of pressure ulcers. Glenview, 2003, p. 52.

- ZeTHRAEUS, N.; STROMBERG, L.; JONSSON, B.; SUENSSON, O.; OHLEN, G. The cost of a hip fracture. Estimates for 1709 patients in Sweden. Acta Orthop Scand. v.68, p.13-7, 1997. 
APÊNDICES 


\section{APÊNDICE 1. INSTRUMENTO PARA COLETA DE DADOS}

\section{DADOS DEMOGRÁFICOS}

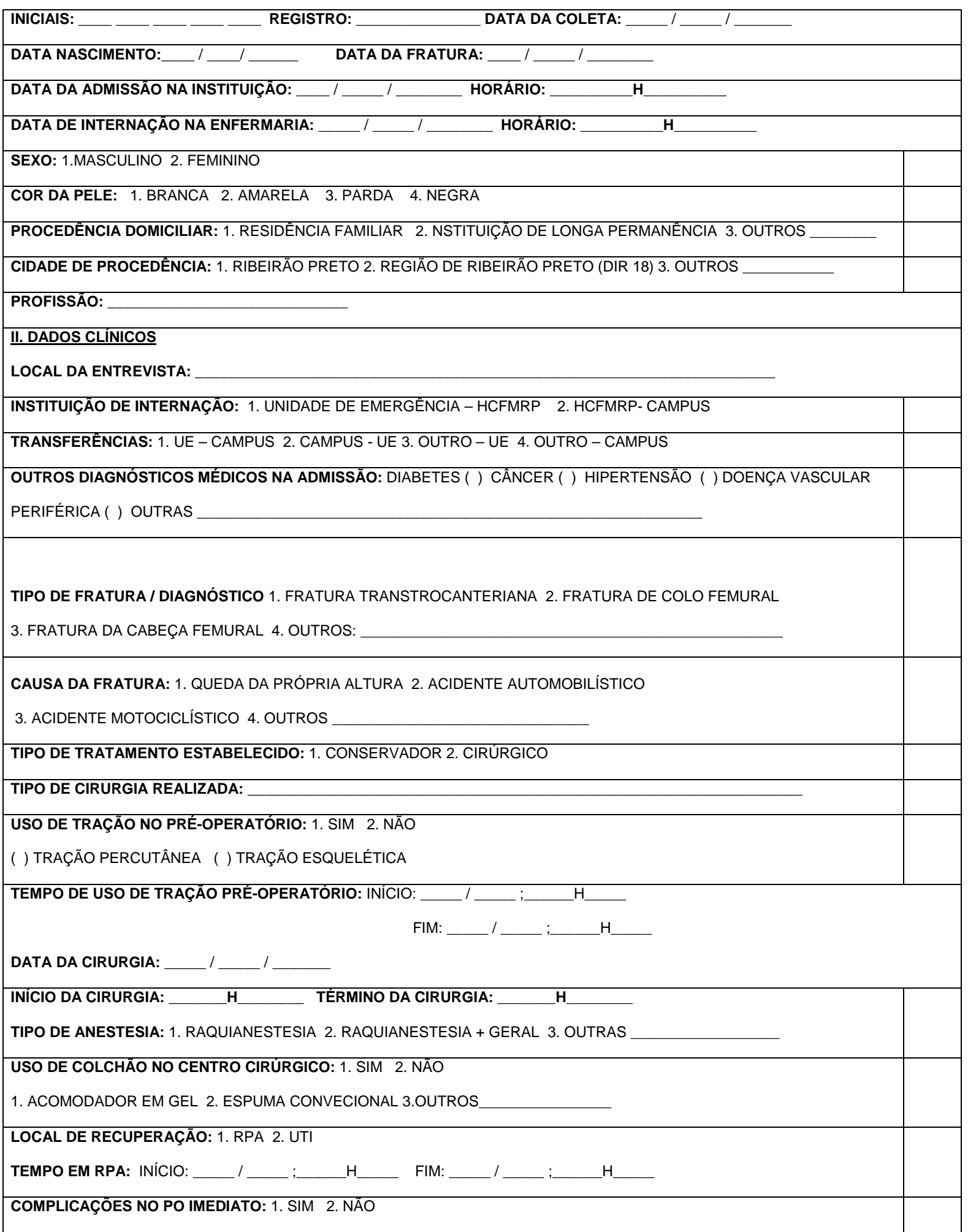




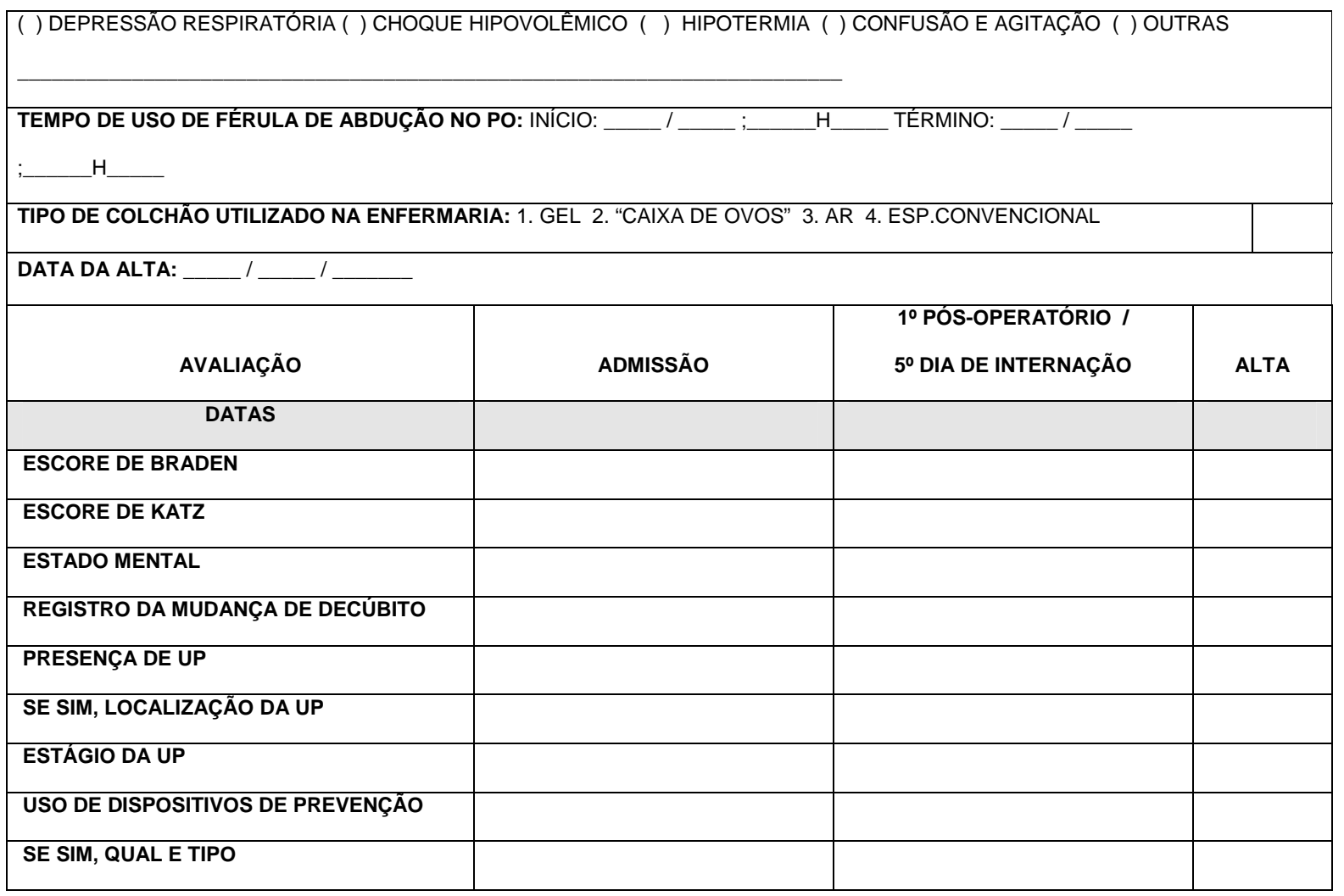




\section{APÊNDICE 2. TERMO DE CONSENTIMENTO LIVRE E ESCLARECIDO}

\section{Título do Projeto: "ÚLCERA POR PRESSÃO E FATORES DE RISCO EM PACIENTES HOSPITALIZADOS COM FRATURA DE QUADRIL E FÊMUR"}

Estou realizando um estudo sobre a presença de úlcera por pressão, um problema que o paciente com fratura de fêmur / quadril pode desenvolver durante seu período de internação no hospital.

Venho por meio desta convidá-lo (a) a participar deste estudo, para realizar este trabalho precisarei fazer uma entrevista, coletar dados de internação no seu prontuário e realizar um exame físico no (a) Sr. (a) no momento da sua admissão, no primeiro pós-operatório ou quinto dia de internação e outro na sua alta hospitalar, para avaliar como está sua pele nestes dois momentos.

A úlcera por pressão é uma ferida que aparece quando há uma grande pressão de superfícies duras como, por exemplo, cama ou maca - em regiões do corpo de ossos e cartilagens, em pacientes que permanecem na mesma posição por um longo período e tem vários estágios na sua formação.

Este estudo tem o objetivo de relatar o aparecimento ou não desta ferida em pacientes internados aqui neste hospital de acordo com os fatores de risco para o desenvolvimento destas feridas.

O (a) senhor (a) terá a liberdade para se recusar a participar da pesquisa, podendo se retirar a qualquer momento durante a entrevista ou exame físico, sem que isto the traga nenhum tipo de prejuízo, pois sua participação é voluntária.

Declaro que não haverá nenhuma forma de identificação em relação a sua participação, ficando todas as suas informações pessoais e/ou de identificação em sigilo com a pesquisadora, podendo os dados não identificados ser publicados em revistas ou congressos científicos.

Esta pesquisa também não Ihe trará nenhum tipo danos pessoais, de despesas, gastos e nenhum tipo de recompensa financeira, além de não interferir no seu tratamento ou assistência aqui no hospital durante o seu período de internação ou nos retornos no ambulatório.

Após seu consentimento uma cópia deste Termo ficará com o (a) Sr. (Sra.) e outra com a pesquisadora.

Espero merecer sua confiança e coloco-me à disposição para qualquer informação adicional sobre a pesquisa no telefone (16) 3602-4764.

Atenciosamente,

Andréa Mathes Faustino

Pesquisadora Principal

$\mathrm{Eu}$,

declaro estar ciente das informações recebidas e concordo participar voluntariamente desta pesquisa.

$$
\text { Ribeirão Preto, }
$$
1 
ANEXOS 
ANEXO A. CARTA DE APROVAÇÃO DO COMITÊ DE ÉTICA EM PESQUISA

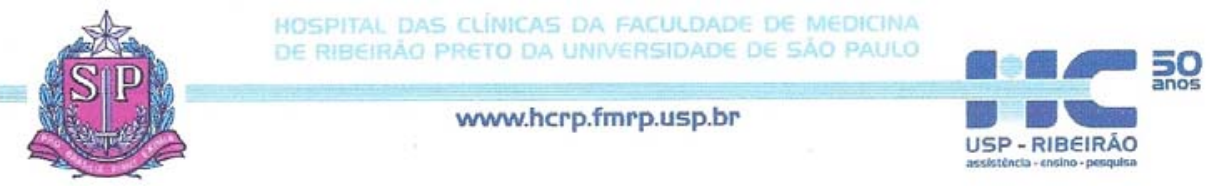

Ribeirão Preto, 28 de fevereiro de 2007

Oficio $n^{\circ} 539 / 2007$

$\mathrm{CEP} / \mathrm{MGV}$

Prezada Professora,

O trabalho intitulado "ÚLCERA POR PRESSÃO EM PACIENTES INTERNADOS COM FRATURA DE FÊMUR E FATORES DE RISCO", foi analisado pelo Comitê de Ética em Pesquisa, em sua $241^{\text {a }}$ Reunião Ordinária realizada em 26/02/2007, e enquadrado na categoria: APROVADO, bem como o Termo de Consentimento Livre e Esclarecido, de acordo com o Processo HCRP nº 983/2007.

Atenciosamente.

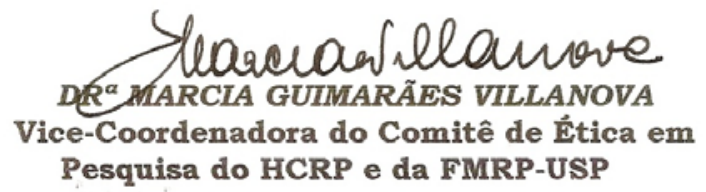

Ilustríssima Senhora

PROF $^{a}$ DR $^{\text {a }}$ MARIA HELENA LARCHER CALIRI

ANDRÉA MATHES FAUSTINO (Pós-Graduanda)

Escola de Enfermagem de Ribeirão Preto-USP

Comitê de Ética em Pesquisa HC e FMRP-USP - Campus Universitário

FWA - $00002733 ;$ IRB - 00002186

Fone (16) 3602-2228 - E-mail : cep $a$ herp.finrp.usp.br

Monte Alegre 14048-900 Ribeirão Preto SP 
ANEXO B. ESCALA DE ATIVIDADE DE VIDA DIÁRIA (AVD - ESCALA DE KATZ MODIFICADA)

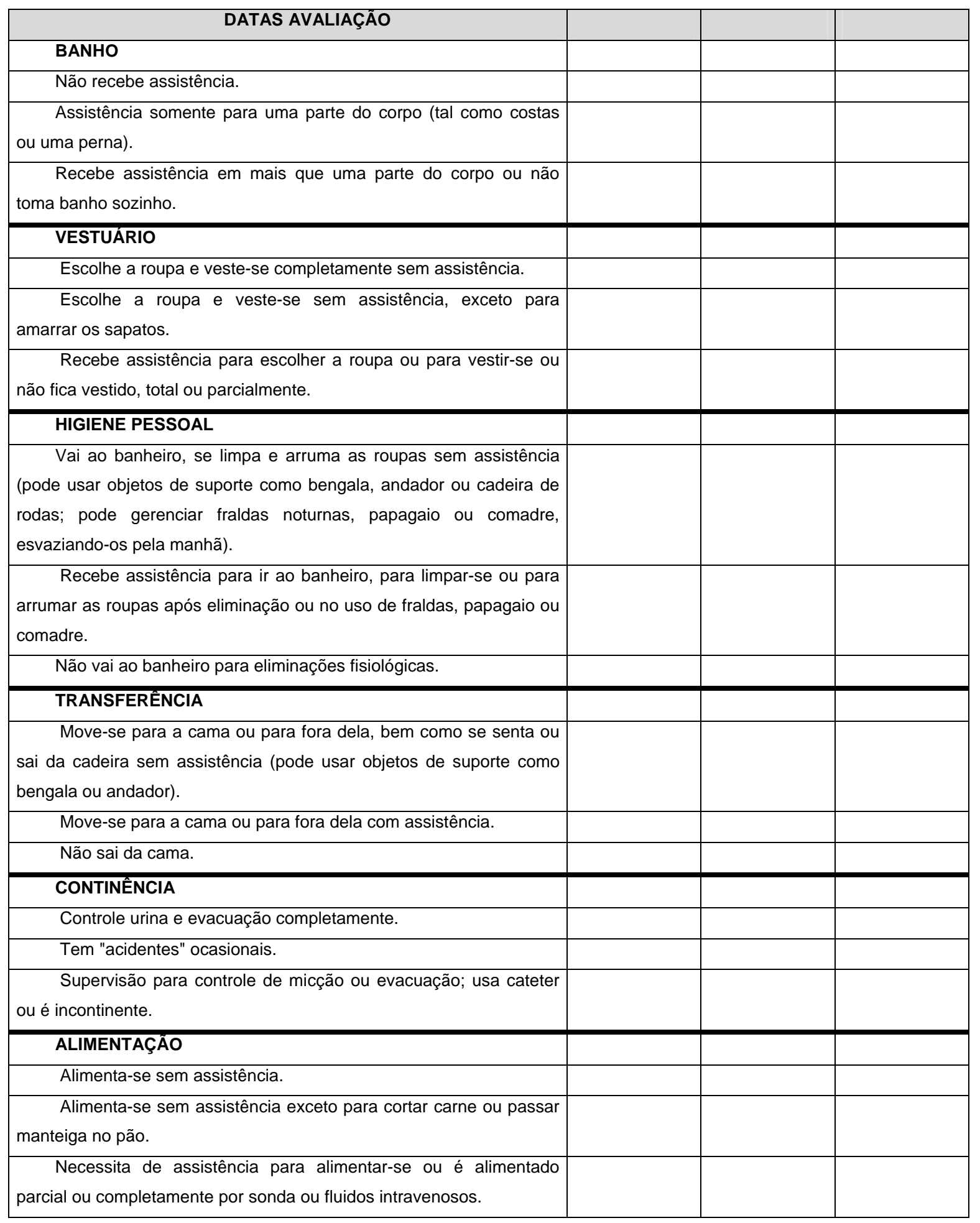


ANEXO C. ESCALA DE BRADEN

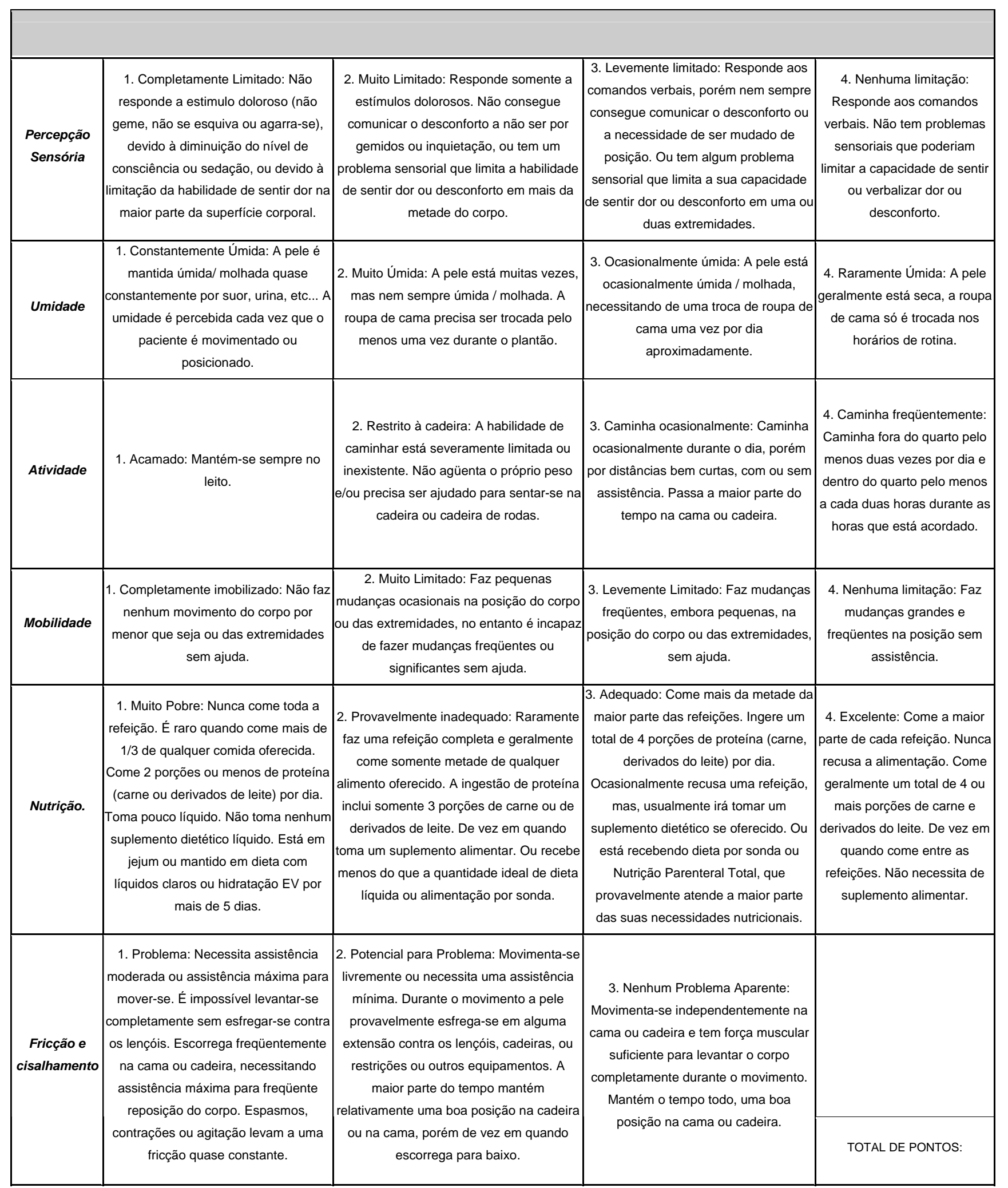

